\title{
What are Faculty Perceptions of Using Emotional Intelligence in Pedagogy and Andragogy?
}

\author{
Eveldora R. Wheeler
}

Follow this and additional works at: https://researchrepository.wvu.edu/etd

\section{Recommended Citation}

Wheeler, Eveldora R., "What are Faculty Perceptions of Using Emotional Intelligence in Pedagogy and Andragogy?" (2015). Graduate Theses, Dissertations, and Problem Reports. 6940.

https://researchrepository.wvu.edu/etd/6940

This Dissertation is protected by copyright and/or related rights. It has been brought to you by the The Research Repository @ WVU with permission from the rights-holder(s). You are free to use this Dissertation in any way that is permitted by the copyright and related rights legislation that applies to your use. For other uses you must obtain permission from the rights-holder(s) directly, unless additional rights are indicated by a Creative Commons license in the record and/ or on the work itself. This Dissertation has been accepted for inclusion in WVU Graduate Theses, Dissertations, and Problem Reports collection by an authorized administrator of The Research Repository @ WVU.

For more information, please contact researchrepository@mail.wvu.edu. 
What are Faculty Perceptions of Using Emotional Intelligence in Pedagogy and Andragogy?

Eveldora R. Wheeler, BS, MSW, MBA, Ed.D.

Dissertation submitted to the

College of Education and Human Services

at West Virginia University

in fulfillment of the requirement for the degree of

Doctor of Education

in

Educational Psychology

Ugur Kale, Ph. D., Dissertation Chairperson

Richard T. Walls, Ph. D., Professor Emeritus

Patricia Chase, Ed. D.

Jaci Webb-Dempsey, Ph.D.

Gerald Blakely, Ph.D. (Jodi Goodman, Ph.D.)

Neal Shambaugh, Ph.D.

Morgantown, West Virginia

2015

Key Words: Emotional Intelligence, Face to Face, On-line, Social Sciences, STEM, cyber keyboard muscles (ckm), and Perceptions of Using Emotional Intelligence PUEI

Copyright 2015 Eveldora Ruth Wheeler 


\begin{abstract}
What are Faculty Perceptions of Using Emotional Intelligence in Pedagogy and Andragogy?
\end{abstract}

Eveldora R. Wheeler, BS, MSW, MBA, Ed.D.

This dissertation study compared the key findings from the first piece of research (pilot study) by allowing further exploration and re-examination of faculties' Perceptions of Using Emotional Intelligence (PUEI) in STEM, Social Sciences, online, and face to face in Pedagogy and Andragogy. This study draws particular attention to the notable rise of emotional issues emerging in differing educational contexts (online and face to face) and the significance of faculty response to their PUEI. Emotional intelligence, a complexity often viewed skeptically is a recurring theme for this study and can greatly benefit higher educational institutions, professional learning environments, and businesses particularly. Faculty perceptions were measured by survey and interviews using Mayer and Salovey (1997) four branch model of emotional intelligence. Participants' reflections strongly supported their PUEI as a catalyst for future consideration and/or implementation in specific disciplines, gender roles, and online and face to face milieus. In some formats, participants' $P U E I$ differed between teaching spaces (online and face to face). Participants reported that the nature of online settings did not offer immediacy of real time responses and correct messages, in comparison to face to face, which often delivered more guaranteed, emotionally reliable, and accurate messages. Although participants found that immediate feedback can assist in building a 
greater sense of support to augment interaction between faculty and students, in online and face to face milieus, teaching online was considered a strong preference. Risks were found to be considered in a narrow perspective. The significance of these findings for practice is discussed. 


\section{Acknowledgements}

"This is my expedition and the destination is still far off."

To begin, I honor God whom makes all things possible, and to whom I give glory for the things He has done, and plans to do in my life.

My emotional intelligence demands that I express sincere gratitude to members of my dissertation committee. Despite their personal lives outside of academe, impressively, they took time to guide my doctoral research and shared a part of their life. To this end, I pause to appreciate their composed scholarly guidance:

Dr. Walls, the co-chair of my dissertation committee, has been a mentor and friend. I want to thank him for providing excellent direction, patience, encouragement, and for working with me until I finished. His editing talents and organization skills are extraordinary, and his book Psychological Foundations of Learning, has been influencial in my life.

I want to thank Dr. Kale for co-chairing my dissertation committee and running across the finish line with me. I am honored to be his first doctoral student to defend a dissertation under his guidance and I look forward to working with you in the future.

Dr. Webb-Dempsey is most appreciated for her advice and countless times we spent at the Blue Moose Café in Morgantown, West Virginia revising my materials. For this, I am grateful. I am indebted to Dr. Chase as a wonderful colleague and friend. An avid runner who competes in half-marathons with her sisters, was a great inspiration. I want to thank her for believing in me. To Dr. Blakely I treasure his continuous support as I transitioned forward. And, for referring Dr. Goodman to fill in while he was in 
Germany. Dr. Goodman's enthusiasm, support, and excellent recommendations were endless. I look forward to collaborating with her in the future.

I would be remised without expressing thanks to Dr. Shambaugh. His kind words reminding me to "Keep going", helped me to stay focused. His commitment to my doctoral achievement will be respected. Lastly, in memory of the late Dr. Hursh who gave selflessly of his time. I recall his words, "You are just in time--keep progressing".

Next, I thank my parents for their unwavering love. They emboldened selfdetermination deep within my spirit. In memory of my father, Mr. Ernest William Wheeler, Sr., who passed away two weeks before I started my doctoral expedition. I appreciate his strength and teachings on leadership. He wisely integrated traditional principles with contemporary thinking, along with challenging me to "Be a leader and stand tall”.

In loving memory of my mother, Mrs. Estella Leevoyn Wheeler who departed this life before I could complete this important, humble work. With a heart of gratitude, I am thankful for her life's work, sacrifice, and encouragement towards my educational endeavors. My incredible mother provided wisdom and direction. She encouraged me to explore my gifts and talents, and taught me the meaning of womanhood. She was my first true friend. Indeed, I am joyful for such a wonderful, dedicated mother. She was a great human being, a gift not had by all. She willingly shared her love, time, words, and stories. I always felt that she held a special place in her heart for me.

Today, because of my mother, I am more than just my own women, I am her legacy who is honored to be her daughter. Her link to many great women, that came before her, is a shining light for generations to follow. My dissertation expedition was 
extended because of my endeavors to support her during her golden years. "People should come before paper."

Many thanks to Ms. Jennifer McIntosh, Chancellors Scholars Program, exhaustive list of mentors, friends, colleagues, and strangers that supported me along the way. Collectively, they were a wealth of motivation and incentives.

My very best friend and husband Donald, soul mate, an angel on earth, deserves much gratitude for always being so caring, solid, and surrounding me with his love. He was my inspiration during the darkest hours of my dissertation's expedition. Especially, when we experienced significant family tragedys of two young bright nephew's. He is my "world's most incredible man". He demonstrates inner resolve and commitment. Despite his own mission, multitude of gifts, and talents to pursue, he made time to share with me. He is an amazing human being, a wonderful man, who reached out to embrace and share each dream with me, while constantly reminding me that rainbows still follow rain. I treasure his love and wisdom. Even more, I adore him. I thank him for discovering and appreciating with me the thousands of things that make our relationship incredible. 
Table of Contents

Abstract.................................................................... ii

Acknowledgements......................................................

Table of Contents......................................................... vii

Chapter 1: Introduction.........................................................

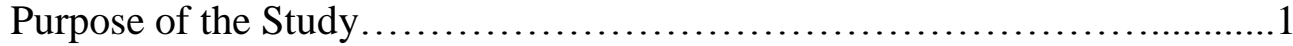

Emotional Intelligence................................................

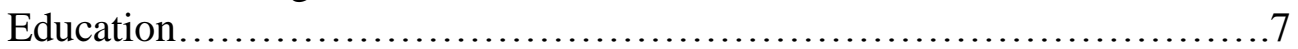

Face to Face and Online

Chapter 2: Literature Review ............................................ 11

Overview of Intelligences......................................... 11

Theorists............................................................. 12

Empirical Domains of Intelligence and Emotions ....................... 16

Emotional Intelligence and Education ............................... 20

Emotional Intelligence in Face to Face and Online......................52

Conclusion............................................................ 81

Chapter 3: Method........................................................ 87

Design......................................................... 87

Participants....................................................... 89

Data Assemblage ................................................. 90

Surveys (Quantitative) ..................................... 90

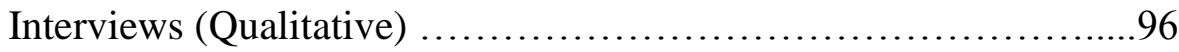

Selection Process ............................................... 102

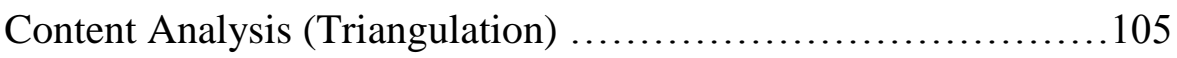

Chapter 4: Results................................................... 111

Survey.................................................................

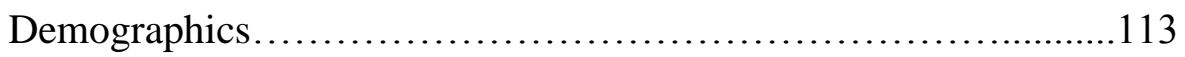

Overall Descriptive Statistics...................................115

Delivery Format ..........................................122

Gender .....................................................123

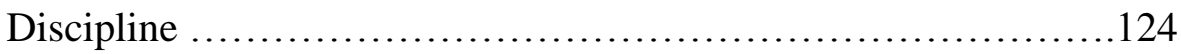

Interview............................................................. 125

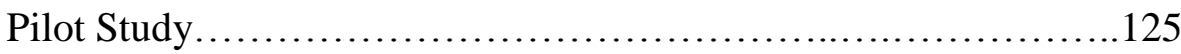

Dissertation Study........................................ 128

Chapter 5: Discussion.................................................. 177

Interview.....................................................181

Emotional Intelligence and Online Challenges........................183

Advantages of On-line Instruction...................................184

Strategies to Managing Emotional Engagement and Language............. 184

Triangulation....................................................... 184

Future Research.................................................... 185

Limitations....................................................... 187

References........................................................... 187

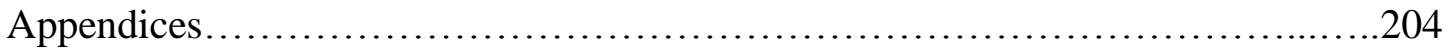




\section{Chapter 1}

\section{Introduction}

\section{Purpose of the Study}

This research investigates a critical topic in academia, the question of " $\mathrm{How}$ instructors, in face to face and online pedagogy, effectively utilize emotional intelligence while teaching and learning in STEM and Social Science professional learning environments?". This exploratory mixed-method (qualitative and quantitative) study investigates some of the issues in relation to face to face and online teaching from exposés of faculty. The study further probes whether the awareness of, usage of, and insight into, emotional intelligence and help contribute to the success of instruction and learning formats in face to face (presence of the physical being) versus online teaching milieus (absence of the physical being). A limited review is conducted on impressions from faculty.

\section{Emotional Intelligence}

While researching “emotional intelligence," I quickly learned that researchers do not agree upon this two-decade-old principle or its definition (Hein, 2003). The emotional intelligence writer must note that a distinction exists between emotional quotients and emotional intelligence (Mayer, 2001). For the purposes of the present dissertation, Mayer and Salovey's (1997) emotional intelligence four basic domains and related skills will be utilized to analyze the connection between online and face to face education of educators as teachers and students as learners in STEM and Social Science disciplines. Emotional intelligence has not been empirically established by the field of theorists. Therefore, for 
the purposes of this study, emotional intelligence will be referenced interchangeably (e.g. theory, concept, model, and construct).

Mayer and Salovey (1997) leading researchers in the field, framed the following definition of emotional intelligence as "the ability to perceive emotions, to access and generate emotions so as to assist thought, to understand emotions and emotional knowledge, and to reflectively regulate emotions so as to promote emotional and intellectual growth" (Mayer \& Salovey, 1997, p. 10).

The Mayer and Salovey (1997) model of emotional intelligence combined discrete emotional abilities when specific emotional situations called for sophisticated problem solving. Mayer and Salovey's (1997, pp. 10-11) related skills are defined and described in Chapter 2 and their four basic domains of emotional intelligence include:

1. The capacity to accurately perceive emotions

2. The capacity to use emotions to facilitate thought

3. The capacity to understand emotional meaning

4. The capacity to manage emotions (pp. 10-11)

The definition of emotional intelligence was never more hotly debated, than by Mayer and Salovey (1997) and Mayer's colleagues in two published articles. Mayer and Salovey (1997) introduced the first formal definitions of emotional intelligence with demonstrations of certain ability and tasks that may help measure the concept (Salovey \& Mayer, 1990). Mayer and Salovey (1993) developed a new set of 12 ability tasks that assess the four-branch model of emotions: perceiving emotion, integration of emotion into thought, understanding emotion, and managing emotion. 
Debates, when introduced, are a part of theory development. Studies of emotional intelligence and emotional quotient have clashed as individual researchers claim success for emotional intelligence's development (e.g., Bar-On, 1997; Goleman, 1998; Mayer \& Salovey, 1997). Emotional intelligence research is part of several newly introduced intelligences that have become popular in the last two decades and have been used to examine emotions in the workplace (Lerner, Small, \& Loewenstein, 2004).

Initially, in 1986, Wayne Payne, a doctoral student from an alternative academic program talked about "emotional intelligence" in his dissertation topic. He stated, "the mass suppression of emotion throughout the world has stifled our growth emotionally" (Payne, 1986, p. 396). The virtual world, Internet, web access, social media, face to face, and online courses would potentially change our emotional world. Technology has altered how we physically and emotionally connect to learning environments. Following Payne's introduction to emotional intelligence, two professors, (Mayer and Salovey) published two academic journal articles "What is emotional intelligence?"(1997) and "The handbook of emotional intelligence: Theory, development, assessment, and application at home, school and in the workplace" (1997).

Beforehand, researchers were exploring the natural habits, talents, and emotions defined as short, intense, organized responses (Salovey \& Mayer, 1990). Since 1990, several tests have been developed attempting to measure emotional intelligence. The following are two examples: (1) MSCEIT (Mayer Salovey Caruso Emotional Intelligence Test) is an ability-based test designed by Mayer, Salovey, and Caruso (2002a) to measure the four branches of the emotional intelligence model. The second example: (2) (EQ-i) (Emotional Quotient Inventory) was originally developed by Bar-On in (1988) as a model 
of emotional-social intelligence. The EQ-i is a self-report measure designed to assess a number of constructs related to emotional intelligence. Although Mayer and Salovey (1993) and Salovey and Mayer (1990) were among the first to conduct empirical research, surprisingly, the person most commonly associated with the term is neither Mayer nor Salovey but a New York writer named Daniel Goleman (1995).

Goleman (1995) wrote a best-seller book titled "Emotional Intelligence” which sold almost 5 million copies worldwide. In another study Mayer, Salovey, and Caruso (2000) were amazed and later dismayed as they accused Goleman of distorting their model in disturbing ways. In essence, they accused Goleman of portraying the emotionally intelligent person as merely a "nice" person, with maturity and character, which Mayer, Salovey, and Caruso (2008) fervently opposed.

The principal claim made by Mayer, Salovey, and Caruso (2008) was that emotional intelligence is deeper than just feelings and emotions. What is more, Mayer, Salovey, and Caruso (2008) argued that "emotional characteristics, or motives, or any single part of personality" (p. 513) should not be viewed as more important than the complete individual. Furthermore, Mayer, Salovey, and Caruso (2008) attested that healthy individuals function best with emotionally interconnected systems and by "viewing emotions as all-important" (p.513) leads to an uneven viewpoint. Thus, Mayer, Salovey, and Caruso (2008) advised investigators of emotional intelligence to reframe from rationales solely based upon emotional characteristics, motives, or any singular part of a personality because

A truly healthy individual has neither thought alone, nor emotion alone, but a functional integration among 
his or her major psychological processes. In this view, mental energy—a combination of motives and emotions - works with adaptive thinking and leads to effective behaviors, all the while being monitored, guided, and controlled, where necessary, by self-consciousness (Mayer, 2007). Being warm is not enough (although it may be pleasant); ditto exhibiting assertiveness. Rather, all its parts must come together for personality to work. (Mayer, Salovey, \& Caruso, 2008, p. 513)

Mayer, Salovey, and Caruso (2008) attempted to counsel the field of scientist against approaches that, from their perspective, were misleading. Instead, Mayer, Salovey, and Caruso, (2008) believed that "theoretical clarity is, at times, more important than incremental validity" (p. 513) meaning that emotional intelligence must be practiced within scientific boundaries. The allegations against Goleman (1995) and other investigators in the field of study have been the excessive disregard of emotional intelligences' intended purpose and conceptual grid system introduced by Mayer, Salovey, and Caruso, (2008).

Scholars Mayer, Salovey, and Caruso (2008) are in agreement with theorists working to bring clarity to emotional intelligence model, even if it means "revising the theory" but not at the expense of ignoring empirical procedures (p. 513). Pleas from Mayer, Salovey, and Caruso (2008) were for "researchers and practitioners alike to refer to the scientific literature on emotions, intelligence, and emotional intelligence to guide their thinking (p. 514). As a final point, the Mayer, Salovey, and Caruso, (2008) team 
developed five recommendations which can best serve the "discipline of psychology and other fields" (p. 514). Mayer, Salovey, and Caruso (2008) stated "simply put, researchers need to cite the research literature rather than journalistic renderings of scientific concepts, which serve a different purpose" (pp. 513-514).

Since the introduction of emotional intelligence, Mayer, Panter, and Caruso (2012) have discovered another theory, Personal Intelligence that they believe is related to emotional intelligence. Mayer (2008) introduced the term Personal Intelligence as a conjecture claiming that it has "the capacity to reason about personality and to use personality and personal information to enhance one's thoughts, plans, and life experience” (p. 209). Mayer (2008) described one of the keys to Personal Intelligence as "our ability to distinguish our own perception of another person from who the person really is" (Mayer, 2014, Know Thy Self, para. 5). He further claimed that personal intelligence is "an evolving, adaptive system that puts together the many pieces of ourselves into a functioning, surviving person" (Mayer, 2013, Personality Described, para. 8). A recent study reported evidence "that the mental ability is related to psychological mindedness, to emotional intelligence, to 'reading the mind' through a person's eyes, and that, behaviorally, people higher in PI are likely to be less domineering and more sensitive to others' needs" (Mayer, Panter, \& Caruso, 2012, p. 137).

According to Mayer, Panter, and Caruso (2012) this study represented the debut of assessing personal intelligence, "and understanding what it might and might not predict" (p. 137). Similar to emotional intelligence and the field of newly discovered intelligences, the road ahead to achieving peer consensus may be just as challenging. But 
Mayer, Panter, and Caruso (2012) are optimistic that the new philosophy is on the right path. This may be helpful information in assessing whether we can accurately apply emotional intelligence domains in online and face to face environments. Personal intelligence theory supports/embodies emotional intelligence ideology that more accurate facial recognition and meaning can occur when individuals are physically present (Mayer, Panter, \& Caruso 2012). As previously stated, Mayer and Salovey’s (1997) four basic domains of emotional intelligence and related skills will be utilized to analyze the connection between face to face and online education of educators as teachers and students as learners in STEM and Social Science disciplines.

\section{Education}

Face to face is no longer the governing culture for learning. Higher education has transitioned to online learning venues which have dramatically changed the personality of learning in academic's face to face classrooms and online. Educators are trained to focus on teaching in professional learning environments. The surge of complaints from faculty may not be entirely directed at the advancement of technology as much as the involuntary path paved by institutional demands for innovative instruction and learning. The emergence of the digital age has revolutionized communication as individuals of all ages interact through new methods (e.g., iPad, Facebook, email, twitter, text, and instant messaging). What is more, higher education institutions have reformed how teaching and learning are delivered. Social Sciences and STEM disciplines have joined the cause as the primary professional learning objectives have been uprooted from a stable educational foundation. The past mandated traditional classroom setting includes the invasion of 
online delivery. For some educators, face to face and online instruction may be viewed as equally effective. Other educators favor either face to face or online academic platforms.

It is essential for Social Science and STEM educators to understand the benefits and risks. Different skills are necessary to adapt and remain competitive in face to face versus online. Such skills are unwelcomed or welcomed by some faculty and/or educational institutions. The present investigation explored information, competencies, and tools that are needed for technology use in Social Science and STEM professional education programs. The participants' reflections, perceptions, and individual experiences will provide a deeper insight into this scientific study comparing face to face and online teaching and education.

\section{Face to Face and Online}

Within academia unique communications and relationships are built in face to face professional learning environments between instructor and student; arguably these explicit interactions are irreplaceable. Yet, online pedagogy is trading places with face to face instruction, despite the exclamation that online environments limit interaction and connections. Academia places importance on evaluating instructor-student interaction in the face to face settings. Technology, however, has changed our concept of formal and informal education involving instructor and student. The U. S. Department of Education reports that online education is one solution to meeting the popular demand for our fast paced, transient, global, non-traditional, and traditional students.

Interactions can be misinterpreted whether in face to face or online. For example, when an instructor's rhetoric is taken out of context or poorly communicated, it has the potential to be deleterious. In either face to face or online context, damaging words can 
injure by creating a hostile environment with the potential of souring the advancement of professional and personal relationships. Face to face statements can be less of a challenge because they offer more imminent opportunities to self-correct misunderstood communications. More often, remote online instruction suffers from unfortunate emotional comments. Thus, communication in face to face and online communication plays a vital role in formal and informal instructor and student relationships.

Mayer, Caruso, and Salovey (1999) argued that emotional intelligence is an important communication augmenter (e.g., for both digital and traditional instruction). One of the questions this study investigated was whether online professional learning environment generated a loss of clarity of emotional responsiveness through the limits of non-verbal messages, intonation, vocal sound, inflection, body posture, and the like. The manner in which faculty adapt to constricted meaning is a significant part of this study. Emotional intelligence may offer support in online or face to face instruction by using emotional intelligence skills to improve connections between instructor and students.

Therefore, the purpose of the current study is to examine the usage of emotional intelligence in academia. Emotional intelligence was examined at several points throughout the teaching and learning process in face to face and online professional environments. Emotional intelligence was further examined for its impact on constructing identity (in and out of the classroom) and the general effect emotional intelligence has on instructors' perceptions.

The rationale for conducting this investigation is to explore faculty Perceptions of Using Emotional Intelligence PUEI online and in face to face learning environments. Faculty voices are critical in assisting higher education institutions to successfully 
transition to online pedagogy. The use of instructional technology tools may require both faculty and student to successfully manage emotional issues online and in face to face learning environments. 


\section{Chapter 2}

\section{Literature Review}

\section{Overview of Intelligences}

Emotional intelligence theory is survived by numerous groundbreaking researchers (Bar-On \& Parker, 2000; Goleman, 1995; Salovey \& Mayer, 1990; Mayer, DiPaolo \& Salovey 1990). Although emotional intelligence theory lacks consensus in the empirical domain, there is a progressive and active scholarly movement to situate emotional intelligence within its place. Meanwhile, theorists are debating whether emotional intelligence should be defined as behavioral, cognitive, or constructivist. The behaviorist view investigates observable behavior of organisms (Skinner, 1978). Cognitive theories believe that knowledge is viewed as symbolic, intellectual constructions in the minds of individuals. In cognitive theory, learning becomes the process to commit these figurative representations to memory where they may be processed (Bandura, 1977). Finally, constructivism sees knowledge as relativistic (Vygotsky, 1987).

The above three psychological theories have competed for ultimate dominance, within the respective disciplines over the past decades. Social-constructivist Bruner (1973) (as cited in Driscoll, 2001) stated that "intelligence is to a great extent the internalization of 'tools' provided by a given culture" and that wide-ranging theoretical views exist as they relate to the impact of intelligence (p. 236).

Cole and Bruner (1971) believed that if intelligences are to be compared between two groups, evaluators must consider the relevant cultures from which each individual 
developed the different manifestations of their ability. Further emphasis was placed on understanding how skills are influenced by culture (Skinner, 1978). Once the applications of these individual skills are appropriately identified, skills may become transferable and useful. Ultimately, such competencies have a greater impact on instructors' performance as well as students' learning capability. This dissertation study will concentrate on the past and current emotional intelligence theorists and their proposed domains. Next, this study will present a brief overview of current leaders in the field of emotional intelligence and theoretical peers of emotional intelligence.

\section{Theorists}

Research indicates that the first mention of the term emotions was addressed in a remedial way by Darwin as cited in Mayer (2001a) "argued for the heritability and evolution of emotional responses, but during this time, emotion was often viewed as culturally determined, largely a product of pathology, and idiosyncratic..." (Darwin as cited in Mayer, 2001a, p.5). Gardner (1983), a more recent theorist, introduced the idea of emotional intelligence as part of his Multiple Intelligence Theory in Frames of Mind. In Gardner (1993), the view involved having an effective working model of oneself, and the ability to use pertinent information to regulate one's life. The main impetus for emotional intelligence movement was likely due to Gardner's (1993) original work. The Gardner (1993) study is considered a paradigm shifter (Smith \& Smith, 1994). Gardner (1993) hypothesized that intelligence is a single entity resulting from a single factor, and that it can be measured simply via intelligence quotient (IQ) tests. If the above is correct, it is fair to assume that all adults progressed through their childhood without blemishing their intelligence systems. To the contrary, Gardner and Hatch (1989) reported that 
intelligence can easily be destroyed and is very difficult to develop. In 1993, Gardner republished Frames of Mind: The Theory of Multiple Intelligences and stated:

"In the heyday of the psychometric and behaviorist eras, it was generally believed that intelligence was a single entity that was inherited; and that human beings - initially a blank slate - could be trained to learn anything, provided that it was presented in an appropriate way" (Gardner, 1993, p. xxiii) According to Gardner's $(1983 ; 1993 ; 2011)$ multiple intelligence theory: "it's not how smart you are its how you are smart" (Gardner, 1983, p. 9). Gardner's (1993) previous study substantiated eight relatively distinct intelligences, which he believed everyone possesses to various degrees. In comparing multiple intelligences theory to emotional intelligence, educational institutions can use appropriate models to improve human work and product delivery. Gardner (1991) postulated that knowledge is not the same as morality. The Gardner (1993) study used eight criteria or 'signs' of intelligence:

(1) Linguistic Intelligence

(2) Logical-mathematical Intelligence

(3) Spatial Intelligence

(4) Naturalist Intelligence/ Integrative Intelligence

(5) Musical Intelligence

(6) Bodily-kinesthetic Intelligence

(7) Interpersonal Intelligence

(8) Intrapersonal Intelligence

(1) Linguistic Intelligence involves the individual's sensitivity to spoken and written language, the ability to learn languages, and the capacity to use language to accomplish certain goals (Gardner, 1993). Gardner's (1993) intelligences include the ability to effectively use language to express oneself rhetorically or poetically. Language also is a means to remember information. Writers, poets, lawyers, and speakers are 
among those that Gardner sees as having high linguistic intelligence (Gardner, 1999, pp. 41- 43).

(2) "Logical-mathematical Intelligence consists of the capacity to analyze problems logically, carry out mathematical operations, and investigate issues scientifically. Gardner (1993) arguments entail the ability to detect patterns, reason deductively and think logically. This intelligence is most often associated with scientific and mathematical thinking” (Gardner, 1999, pp. 41- 43).

(3) "Spatial Intelligence is the ability to visualize, create, and transform objects, concepts, and designs in one's mind. It also involves a superior ability to understand and utilize dimensional space, seeing, for example, that the proverbial square peg will not fit in the round hole" (Gardner, 1999, pp. 41-43).

(4) "Naturalist Intelligence/ Integrative Intelligence involves the ability to break a "whole" into its collective "parts" or the opposite, to assemble a "whole" from its dispersed "parts. A person with this ability can see, or create, the "big picture" along with its "parts" and can excel in numerous diverse careers such as farmer, military commander, top corporate executive, and research scientist, to name a few" (Gardner, 1999, pp. 41- 43).

(5) "Musical Intelligence involves skill in the performance, composition, and appreciation of musical patterns. It encompasses the capacity to recognize and compose musical pitches, tones, and rhythms. According to Howard Gardner musical intelligence runs in an almost structural parallel to linguistic intelligence" (Gardner, 1999, pp. 4143). 
(6) "Bodily-kinesthetic Intelligence entails the potential of using one's whole body or parts of the body to solve problems. It is the ability to use mental abilities to coordinate bodily movements. Howard Gardner sees mental and physical activity as related" (Gardner, 1999, pp. 41-43).

(7) "Interpersonal Intelligence is concerned with the capacity to understand the intentions, motivations and desires of other people. It allows people to work effectively with others. Educators, salespeople, religious and political leaders and counselors all need a well-developed interpersonal intelligence" (Gardner, 1999, pp. 41- 43).

(8) "Intrapersonal Intelligence an intrapersonal leader will place more emphasis on an organization's infrastructure, logistics, and goals, rather than on individual personalities. It includes the capacity to understand and appreciate one's feelings, fears and motivations" (Gardner, 1999, pp. 41- 43).

Issues and problems are customary among scholars, and Gardner's (1993) work is not excluded from some disapproving researchers. One fundamental criticism of Gardner's (1993) multiple intelligence theory is whether the eight multiple intelligences criteria employed are, in fact, adequate. The second major concern with the theory is whether Gardner's (1993) conceptualization of intelligence is sound. As critics go, many believe his work was burdened with judgmental labeling; thus, the question is posed whether all human interaction should be labeled.

Another concern in consideration of multiple intelligences is determining whether there is sufficient empirical evidence to support Gardner's (1983) conceptualization. A common criticism made of Gardner's (1993) work is that his theories derive more strongly from his own intuitions and reasoning than from a comprehensive and full 
grounding in empirical research. For the moment, there is not a properly worked-through set of tests to identify and measure multiple intelligences. An issue with most testing, including Gardner's (1993) test, may lead to labeling and stigmatization. Gardner's (1983) theory involves an effective working model of one's self and the ability to use such information to regulate our lives.

Bar-On (1997) investigated the processes of measuring emotional intelligence. The Emotional Quotient Inventory (a self-report instrument) was designed and developed by Bar-On to measure a number of constructs related to emotional intelligence (Bar-On, Tranel, Denburg, \& Bechara, 2003). Although the Bar-On (2003) theory has been criticized for lack of empirical support, many others have built on his work (Ciarrochi \& Blackledge, 2006; Davies, Stankov, \& Roberts, 1998; Mayer \& Caruso, 1999; Mayer, Salovey, \& Caruso, 2000). Davies, Stankov, and Roberts (1998) examined current measurements used to study emotional intelligence and found "that the status of the emotional intelligence construct is limited by measurement properties of its tests" (p. 989).

\section{Empirical Domains of Intelligence and Emotions (Mayer \& Salovey, 1997)}

The Mayer and Salovey (1997) mental abilities requires two elements, "intelligence and emotion" (p.4). The element emotion was described as “... a feeling state (including physiological responses and cognitions) that conveys information about relationships” (Mayer, Caruso, \& Salovey, 1999, p. 267). Fear, for example, “...is a feeling state that corresponds to a relationship -- the urge to flee others" (p. 267). Mayer \& Salovey (1997) agreed that the term emotion is not easily defined. Their research 
designated emotion as separate from "cognition (thinking) and volition (will, or motivation)" (p. 4).

Mayer and Salovey (1997) suggested that emotional intelligence principles are identified as the "human ability to recognize and manage ones' own emotions" (Mayer \& Salovey, 1997, pp. 10-11). In view of that, Mayer and Salovey (1997) suggested that emotional intelligence concepts are excellent objectives for an egalitarian society (p. 16) because constructs of emotional intelligence focus on molten interface between emotions and intelligence.

As such, Mayer and Salovey (1997) debunked the idea that intelligences are conventional qualities or virtues. Instead, intelligences are defined as "aptitudes, plastic abilities that can be used for good or evil" (Mayer \& Salovey, 1997, p. 16). For example, Mayer and Salovey (1997) used the analogy of an enigmatic cult leader having emotioncorrelated skills, while deficient in good character (p.16).

Emotional intelligence $1^{\text {st }}$ domain: Identifying and perceiving emotions. The first concept of identifying or perceiving emotions is considered the most basic of these four domains. Mayer and Salovey (1997) explained this domain as reading the situation correctly. Mayer, Salovey, Caruso, and Sitarenios (2001) believed that one must be conscious of one's own feelings and emotions, and that having accurate facts about others' feelings and emotions will help to construct solid meaningful relationships with those individuals. Faculty members must help students benefit from valued interpersonal relationships (student-to-teacher and student-to-student) whether teaching on-line or faceto-face. 
Mayer (2001b) suggested that emotional intelligence may support

communication. In the case of instruction, emotional intelligence may support faculty effectiveness in both on-line and face to face instruction (Mayer, Salovey, \& Caruso, 2000, p. 401). Mayer noted that an individual's emotional sensitivity can form the tone of an email. For example, during an on-line or face to face course, emotional intelligence can assist a teacher or student in the regulation, monitoring, and expression of a thought.

Emotional intelligence 2nd domain: Using emotions. Using emotions to facilitate thought is the second concept of the Mayer and Salovey (1997) emotional intelligence model. Mayer pointed out that emotions place human thoughts in hierarchical ranking. In other words, pressing emotions command our attention when "the person matures, emotions begin to shape and improve thinking by directing a person's attention to important changes" (Salovey \& Sluyter, 1997, p. 12). This concept of being able to use emotions to facilitate thought was explained by Mayer (2001a) as giving one the ability to ignite one's feelings and support the cognitive system (thinking). Instructors can use this knowledge as they are constantly required to facilitate thought and adapt to changes within the academic environment. Ultimately, this may help aid in the effective problemsolving and rational reasoning process.

Emotional intelligence 3rd domain: Ability to understand emotions. The third domain of Mayer and Salovey's model (1997) is the ability to understand emotions. We learned from their study that information provides knowledge and hopefully propels individuals forward. Is it true then, that the more knowledge we have, the more successful we are? In this instance, success is best described by one's ability to navigate complex situations and feelings, and somehow move forward. 
According to Salovey and Sluyter (1997) individuals have a greater chance of understanding a situation when they are able to produce "emotions on demand" (p. 12). They further proposed that this allows in the moment "inspection of the feeling and its characteristics" (p. 12). The individual's ability to connect emotional information, maneuver, guide, and steer this information to augment thoughts (Mayer, Salovey, Caruso, \& Sitarenios, 2001) is one measure of emotional intelligence.

Mayer, Salovey, Caruso, and Sitarenios (2001) asserted that this (understanding emotions) relationship involves intelligence and personality, and "the first hallmark of intelligence is abstract reasoning" (p.233). But emotions require calibration and thought adjustment so "that cognitive tasks make use of emotional information" (p. 235).

Emotional intelligence $4^{\text {th }}$ domain: Managing emotions. The fourth domain, managing emotions, means among other things, that one must juggle several emotions at once. Emotions need supervising, distinguishing, and tagging. Mayer, Salovey, and Caruso (2004) stated that our emotions provide us with useful information, but if useful information is discounted, we may end up making poor choices. Managing emotions is learned at an early age, and "by early adulthood, the means of emotional selfmanagement have grown, including abilities to avoid feelings or to reframe appraisals to reassure oneself or achieve equanimity" (Mayer, Salovey, \& Caruso, 2004, pp. 199-200).

Mayer and Salovey (1997) further described the fourth domain as "conscious regulations of emotions" (p. 14) as accepting and "welcoming" (p.14) emotional responses regardless of "how pleasant" or disagreeable they are (p. 14). So, reflective thinking "encourages a process of personal investigation" (p.16)...related to a "person's own politics, ethnicity, and other characteristics" (p.16). 
While the majority of writers substitute the terms emotional quotient and emotional intelligence some theorists distinguished between emotional quotient and emotional intelligence. As such, Hein's (2005) defined emotional intelligence as an individual's innate potential (e.g., babies are born with potential for emotional sensitivity, emotional memory, emotional processing, and emotional learning ability). A Mayer, Salovey, and Caruso (2004) belief is that the above four components are the core of one's emotional intelligence and that innate intelligence may well be developed or damaged with life experiences. More specifically, Salovey and Mayer (1990) initially defined “emotional quotient" (e.g., emotional intelligence) as the relative measure of an individual's healthy or unhealthy development of their innate emotional intelligence. Furthermore, Mayer, Salovey, and Caruso (2004) believed that it is easier to destroy high emotional intelligence than to develop emotional quotient (p. 199).

This following section will deliberate the usage of emotional intelligences' place within educational systems. Boyatzis and McKee (2006) noted that higher educational institutions and businesses desire emotional intelligence concepts for many obvious motives. One such understandable ambition is to use emotional intelligence powerful potential to predict emotional excellence (Boyatzis \& McKee, 2006, p. 53). For example, the provision of this simple, yet powerful emotional tool (emotional intelligence) may enhance faculty communication as well as performance, in face to face and online professional environments (Mayer, Salovey, \& Caruso, 2004).

\section{Emotional Intelligence and Education}

There is a dearth of literature in the combined areas of emotional intelligence and education. Emotional intelligence definitions have been erratic and have endured a 
spirited history, yet the field lacks a pragmatic concept agreement (Humphrey, Curran, Morris, Farrell, \& Woods, 2007, p. 235). Should it matter to schools, businesses, and researchers what it means to be smart? Both popular and scientific researchers agreed that emotional intelligence, once it is confirmed, may very well expand our understanding of what it means to be smart (Bar-On, 2000; Goleman, 1999; Mayer \& Salovey, 1999). Mayer and Geher (1996) believed that serious information processing is taking place, among individuals labeled "romantics," "highly sensitive," or "bleeding hearts" (p. 90). This type of identification of emotional processing remains new and powerful. Emotional intelligence psychological agenda should not be advanced with stretched definitions or sensational claims, but with validity. Mayer, Salovey, and Caruso, (2000) challenged researchers to differentiate between popular and scientific approaches, while supporting the research in this undeveloped field of emotional intelligence (Mayer \& Gehr, 1996).

The Han and Johnson (2012) study initiated a conversation regarding the use of emotions in academia, agreeing that the "area of emotion has remained under-explored in understanding students' interaction in online learning" (p. 86). The Han and Johnson (2012) study contended that more attention is needed to address development of "relationships between emotional intelligence [and] social bond[ing]..." (p. 86) in the educational field. When focusing on emotional intelligence and education, Radford's (2003) study corroborated with other theorists in the field, complaining of the scarcity of literature in this area of emotional intelligence and education (p. 267). Also, Radford (2003) mentioned that emotional intelligence needed more scholars in the field and "are matters for educational debate in schools" (p. 267). 
Moreover, a central theme of the Radford (2003) study revealed similar concerns as it explored the background of emotional intelligence from two aspects: (a) dualist "seeing the emotions as internal events subject to introspection" and (b) "see[ing] the emotions as sourced of energy or tension that can be relieved in the process of articulation" (p. 255). In 2003, Radford's study presented two hypotheses to construct an emotional education paradigm (p.255). It is the above author's opinion that emotional education is not a new arrival, that "emotional culture" (p. 255) has been a part of quality education practice. The example that is given from the Radford (2003) study demonstrates that school systems are "made up of the emotional dispositions of teachers...implicit in the attitudes and values" (p. 256) of the institution.

The addition of the Radford (2003) study adds more weight to the already burdened scale of copious emotional intelligence concepts. Currently, philosophers of emotional intelligence domains have only provided fragmented responses to this elusive theory. Additionally, Radford (2003) questioned "[w]hat sort of emotional environment we should be aiming at in our schools, what constitutes a 'good' emotional culture, is something, upon which we may need to reflect" (p. 256).

Emotional intelligence seductive lure. Thus, seeking to inspire students may mean that emotions, personality, and getting to know the individual on a private and/or personal platform should be a decisive decision (Radford 2003, p. 256). Theorists, (Radford, 2003; Zeidner, Roberts, \& Matthews, 2002; Zeidner, Matthews, \& Roberts, 2004) appeared to join voices in denouncing those individuals or institutions that would misuse emotional intelligence theory. Finally, Radford (2003) envisioned emotions as essential to the "quality of our lives" (p.256) but cautioned that emotional intelligence 
constructs should be used carefully and responsibly. Seemingly, one view that all theorists at least agree with is that individuals using emotional intelligence theory should make the effort to conduct ethical research and protect vulnerable people. Radford (2003) assumes that "as teachers we are continuously aware of the emotional environment of the classroom..." and that part of instruction should include teaching students "about the appropriateness of feeling in particular contexts" (p. 266). The contexts referred to should promote a sense of stability that allows students to thrive and encourages a well-adapted emotional life (p. 266). Moreover, Radford (2003) believes that this can be achieved if "contemporary trends" of dualist are implemented from two angles of "individual emotional identity" (pp. 266-267) and through the well-defined emotional "culture and climate" of institutions.

A further note regarding the topic of emotional intelligence is that it is approximately 21 years old. Unquestionably, established theories are subjected to meticulous scrutiny from scholars in the field before being decreed champion or victor (e.g., Bar-On 2004; Gardner, 1993; Goleman, 1999; Mayer \& Salovey, 1997). In this instance, emotional intelligence concept is no different. Scholars around the globe are competing and pursuing the opportunity to eventually establish their authority and cogency for the enviable crown of emotional intelligences' leaders. This debate was mentioned earlier in this dissertation study. Newly arrived theorists to the field of emotional intelligence study continue to describe how they believe emotional intelligence should be branded.

At the same time, concerned theorists (e.g., Jorgenson, 2003) have appealed for educators to discontinue the use of emotional intelligence completely, until there is sound 
empirical support for emotional intelligence. As noted previously, Jorgensen (2003) contended that the misuse of emotional intelligence constitutes "educational malpractice" (p. 368).

Nonetheless, for the purposes of the present investigation, the four emotional intelligence domains of (Mayor \& Salovey, 1997) will be used. The present study is focused on aspects of empirical research regarding emotional intelligence impacts on faculty interaction in specific courses and programs in Social Science and STEM. As a result, the outcomes will hopefully gauge emotional intelligences' justification or necessity in face to face and online, Social Science, and STEM specific programs. It is noted that in recent years higher educational institutions made a critical shift in pedagogy from (a) face to face to (b) online, and the impact is yet to be determined. Therefore, the effort of this study focused on understanding the diverse perspectives from faculty, their distinction between the aforementioned disciplines, and more importantly, distinctions between face to face and online education interaction.

Ultimately, crucial questions regarding emotional intelligence usage were perceived from respondents in this study. First, the study focused on the history of emotional intelligence and its current status in the field. Second, the study reviewed how emotional intelligence can contribute to educational ideologies. Third, the study focused on faculty use of emotional intelligence in face to face and online professional learning environments. Fourth, the study reviewed emotional intelligence relationships in both Social Science and STEM (Science, Technology, Engineering, and Mathematics) in face to face and online milieus. 
Along with the dearth of literature, previous field analyses have omitted to mention the impact of emotional intelligence on specific programs and courses (e.g., Social Sciences and STEM). Meanwhile, there are limited works that address, identify, agree, and disagree with the application or misapplication of emotional intelligence in face to face and online professional educational settings, involving faculty.

Emotional intelligence critics. The present investigation noted that there are many emotional intelligence skeptics in the field, and we will review some of the anxieties among researchers. The critics' examinations of emotional intelligence have initiated reasonable and warranted attention. Critical analysts of emotional intelligence (e.g., Barchard, 2003; Humphrey, Curran, Morris, Farrell, \& Woods, 2007; Zeidner, Roberts, \& Matthews, 2002) disagree with the current field of scholars' characterization of emotional intelligence constructs. In the realm of presenting a balanced overview of emotional intelligence history, this study included hypotheses by challenging opponents.

Since the popular emergence of emotional intelligences, it is noted that Roberts, Zeidner, \& Matthews (2001) are not alone in sharing their trepidation regarding emotional intelligence constructs (e.g., Zeidner, Matthews, \& Roberts, 2001). Other researchers (e.g., Zeidner, Roberts, \& Matthews, 2002) have expressed their disturbance over emotional intelligence's "lack of consensus" (p. 215). Therefore, Zeidner, Roberts, and Matthews (2002) continued to concentrate their "efforts toward resolving conceptual and measurement issues" (p. 215). Additional scientists have continued to combine their energies in an effort to initiate, regulate, and shape the evolving trajectory of emotional intelligence and its related theories (e.g., Denham, 1998; Saarni, 2000). Ultimately the 
question is to determine the extent to which emotional intelligence will contribute to education (e.g., Salovey \& Sluyter, 1997).

Barchard (2003) was not convinced of the wide-ranging media assertion of Goleman's (1995) introduction of emotional intelligence prominence as “...more important than IQ in terms of success in a variety of areas" (Barchard, 2003, p. 855). Barchard (2003) initiated a study to demonstrate that:

If a large number of emotional intelligence measures are used without preselection, these measures cannot predict academic success. The cognitive ability domain and the personality domain do a far better job at predicting academic success. When considering just one measure at a time, some measures of emotional intelligence (particularly measures of emotional understanding) can be used to predict academic success. However, these measures do not improve our prediction of academic success if relevant cognitive abilities and personality characteristics have already been taken into account (Barchard, 2003, p.856).

For example, Barchard (2003) posited that, although there is a related connection between emotional intelligence and academic success, but he refuted that emotional intelligence has a greater magnitude and is more superior to "verbal ability" (p. 856). Also, the Barchard study speculated that earlier explorations of emotional intelligence "overlooked the question of incremental predictive validity...the most important question of all" (p.856). Barchard (2003) postulated that "it is not enough to know that emotional 
intelligence predicts success; we also need to know if it improves our predictions so that it is worthwhile to add emotional intelligence measures to existing test batteries" (p.856).

In the opinion of Humphrey, Curran, Morris, Farrell, and Woods (2007), overall success in life and prosperity in adulthood are not necessarily "contingent upon learning... social and emotional learning skills to negotiate life's many challenges productively...” (p. 235). Instead, Humphrey, Curran, Morris, Farrell, and Woods (2007) argued that emotional intelligence philosophies contradicted "...more traditional view[s] that the purpose of education is to teach core curriculum subjects and that this knowledge alone will equip students to meet the challenges they will face as adults" (p. 236).

The Humphrey, Curran, Morris, Farrell, and Woods (2007) study also postulates that the use of emotional intelligence in schools, has proven to be as controversial as the lack of agreement among emotional intelligence theorists in the social science area. Moreover, the Humphrey, et al. (2007) study explored how to employ emotional intelligence in relationships, but claimed that the "promotion of emotional intelligence in schools has proven a controversial pursuit, challenging as it does traditional "rationalist" views of education" (p. 235). Humphrey, et al. (2007) in a remedial way have begun to offer critical discourse of emotional intelligence placement in educational context. Humphrey, et al. (2007) are encouraging dialogue and conversation for faculty to learn to make adequate linkages in professional learning environments "in both the academic success of students and their emotional adjustment in school” (p. 235).

Two consecutive studies (Zeidner, Roberts, \& Matthews, 2002; Zeidner, Matthews, \& Roberts, 2004) criticized Mayer and Salovey’s (1997) emotional intelligence concepts. The findings of the initial Zeidner, Roberts, and Matthews, (2002) 
study revealed that mediation programs constructed on the premise of emotional intelligence domains in education and school contexts, "were not specifically designed to change emotional intelligence, and very few systematic interventions meet the canons of internal and external validity" (p. 215). Zeidner, Roberts, and Matthews (2002) went as far as to state, that the study discovered limited and unbiased substantiations of emotional intelligences' usage in educational areas (p. 215). Zeidner, Roberts, and Matthews' (2002) opinion advanced numerous decisive enquiries (p. 215). Again, in another investigation, Roberts, Zeidner, and Matthews (2001) listed the following concerns:

(1) Emotional intelligence tests contain culture and gender bias

(2) Emotional intelligence constructs have theoretical problems, including ambiguity

(3) Emotional intelligence does not exist as a well-defined psychometric and theoretical construct

(4) Emotional intelligence failure to converge creates fundamental signals representing a flaw of the field (Roberts, Zeidner, and Matthews, 2001, p. 219).

Zeidner, Roberts, and Matthews (2002) suggested that emotional intelligence programs should endeavor to include "appreciation of diversity and respect for the demands of growing up in a pluralistic society" (p. 227) and be the leader of prototypical programs. Furthermore, as emotional intelligence programs develop, goals should provide "sensitive, relevant, and responsive with regard to the ethnic, gender, and socioeconomic composition of students" (p. 226). At the same time, higher education institutions should remember to address the heavy strains placed on those providing the 
education and supportive services (Elias, Zins, Weissberg, Frey, Greenberg, Haynes, Kessler, Schwab-Stone, \& Shriver, 1997).

Zeidner, Roberts, and Matthews (2002) recommended that emotional intelligence could not be advanced nor executed until (emotional intelligence) concepts of empirical challenges are unmistakably defined. On the other hand, Zeidner, Roberts, and Matthews (2002) are of the opinion that specific social skills are significant (e.g., "ability, personality, and motivation constructs that are already employed in educational psychology)" (p. 216). Meanwhile, Zeidner, Roberts, and Matthews (2002) disagree with Mayer and Salovey's (1997) well-preserved belief that "emotions have been taught in the schools before the concept of emotional intelligence was developed" (Mayer \& Salovey, 1997, p. 20). Clearly, Zeidner, Roberts, and Matthews (2002) oppose Mayer and Salovey's (1997) argument that educational programs are "arguably one of the most important contexts for learning emotional skills and competencies" (Zeidner, Roberts, \& Matthews, 2002, p. 221).

Emotional intelligence critics proclaim caveat emptor. In part, Zeidner, Roberts, and Matthews (2002) arguments may have further complicated emotional intelligence's ambiguous field, with introduction of their own emotional intelligence definition and claims that other theorists' terminologies and findings are not sufficient (p. 217). Zeidner, Matthews, and Roberts (2004) stated "there is presently an urgent need for sound taxonomic research that focuses on determining the emotional intelligence constructs that are crucial for performance in particular jobs and for identifying the relevant emotional intelligence measures that best assess these affective constructs" (p. 394). The Zeidner, Matthews, and Roberts (2004) study reiterated and advanced new 
concerns. For example, Zeidner, Matthews, and Roberts (2004) corroborated and attempted to substantiate claims that refuted emotional intelligence's original claims. Zeidner, et at. (2004) reminded the field to treat emotional intelligence's existing philosophies as "caveat emptor" (p. 393). Optimally, Zeidner, Roberts, and Matthews (2002) urged the scientific community to pursue robust examination for emotional intelligence measures (p. 227).

Two important areas of agreement that should be noted concerning theorists (Barchard, 2003; Zeidner et al., 2004) are the following two critical analyses: (1) Emotional intelligence has stimulated disagreement both in the empirical community and in the general media, and (2) Most theorists in the field agree that emotional intelligence is still in an innovative and developing stage. What is more, the above critics (e.g., Barchard, 2003; Zeidner et al, 2004) have opposed the primary excitement claims of emotional intelligence constructs advanced by many theorists, including Mayer and Salovey (1997).

Likewise, many other select researchers have rejected the proposition that emotional intelligence is the cure-all solution. Additionally, emotional intelligence theory has many other critics (e.g., Allix, 2000; Cherniss, Extein, Goleman, \& Weissberg, 2006; Landy, 2005; Locke, 2005; Salovey \& Grewal, 2005; Waterhouse, 2006a). Despite the lack of agreement and assertions among theorists, emotional intelligence theory still thrives (e.g., Gardner, 1983; Salovey \& Mayer, 1990; Waterhouse, 2006a). In fact, Waterhouse (2006a) verified that "web sites representing these theories have increased at 10 times the rate of increase of professional journal articles on these theories" (p. 207). 
At first glance, emotional intelligence and education can easily appear to be unrelated. In the disciplinary world of modern knowledge, emotional intelligence is seeking a place in a hallway or main room of online and face to face pedagogy. The opinion of combining higher education intellectual schematics with emotional intelligences' social modules may be regarded by some as unnecessary (Blake, 2000).

According to Blake (2000), forming a relationship or connection between teacher and student ultimately depends on the context (p.186). Rosa and Lerman (2011) believed that online and face to face use different interactions to augment knowledge linking teachers and students (p. 74). Blake (2000) suggested that social needs are not of great concern because "higher education settings are more formal" (p.187). According to Blake (2000) intellectual formality should stand alone without the interruption of ceremonial interactions or socialization skills, as in Sigmund Freud's Civilization and Its Discontents, and a handful of other works (Blake, 2000, p. 193). Blake (2000) questioned whether there should be emotional connections between instructor and students in higher education. Blake (2000) agreed that suppressing personal expressions that reveal too much about our true identity, or who we really are may be acceptable (p.188). Furthermore, Blake (2000) argued that the rigor of critical thinking in higher education has been generally absent of emotions alluding that the two world's emotional intelligence and education should not intertwine (p.187). Moreover, Blake (2000) believed that bland, lack of emotional expression, and keeping one's inner identity undisclosed is more suited for academic setting (p.188).

Carving emotional intelligence at the joint. Another scholar envisioned emotional intelligence and education as two spheres: (a) meeting and (b) reshaping future 
possibilities of teaching. King's (1947) instructional philosophy supports emotional intelligence and education's potential relationship match. However, King (1947) advocated for educational programs to consider an alternative landscape contrary to educators' conventional wisdom in the following:

We must remember that intelligence is not enough. Intelligence plus character--that is the goal of true education. The complete education gives one not only power of concentration, but worthy objectives upon which to concentrate. (King, 1947, “The Purpose of Education,” para. 6). King's (1947) broader perspective questioned what trend, vision, and type of educational forces were needed to shape the global future.

According to Rosa and Lerman (2011) education may not be able to get along without emotions. Rosa and Lerman (2011) further stated that online responsibilities extend well beyond merely instructing courses online. They should include respect and consideration for virtual characters (e.g., instructor and student) (p. 75). Rosa and Lerman (2011) emphasized that faculty have other responsibilities including awareness of situations and awareness of emotions (p. 73).

This study has introduced various emotional intelligence scientific contributors and critical reviews from contrasting opinions. Some theorists believe that intricate discussions between faculty and students, and emotional intelligence usage in academia's face to face and online courses matter greatly (Mayer, 2014). Mayer (2014) quoted Aristotle urging "philosophers (and by extension, today's scientist)" to "carve nature at the joint” (p. 1). The Figure 1 illustration depicts a time table of famous teachers BC 
(before Christ) listed in chronological order from left to right beginning with (a)

Confucius, (b) Socrates, (c) Xenophon of Athens, (d) Birth of Plato, (e) Birth of Aristotle chronology of teaching(Anonymous, 2015).

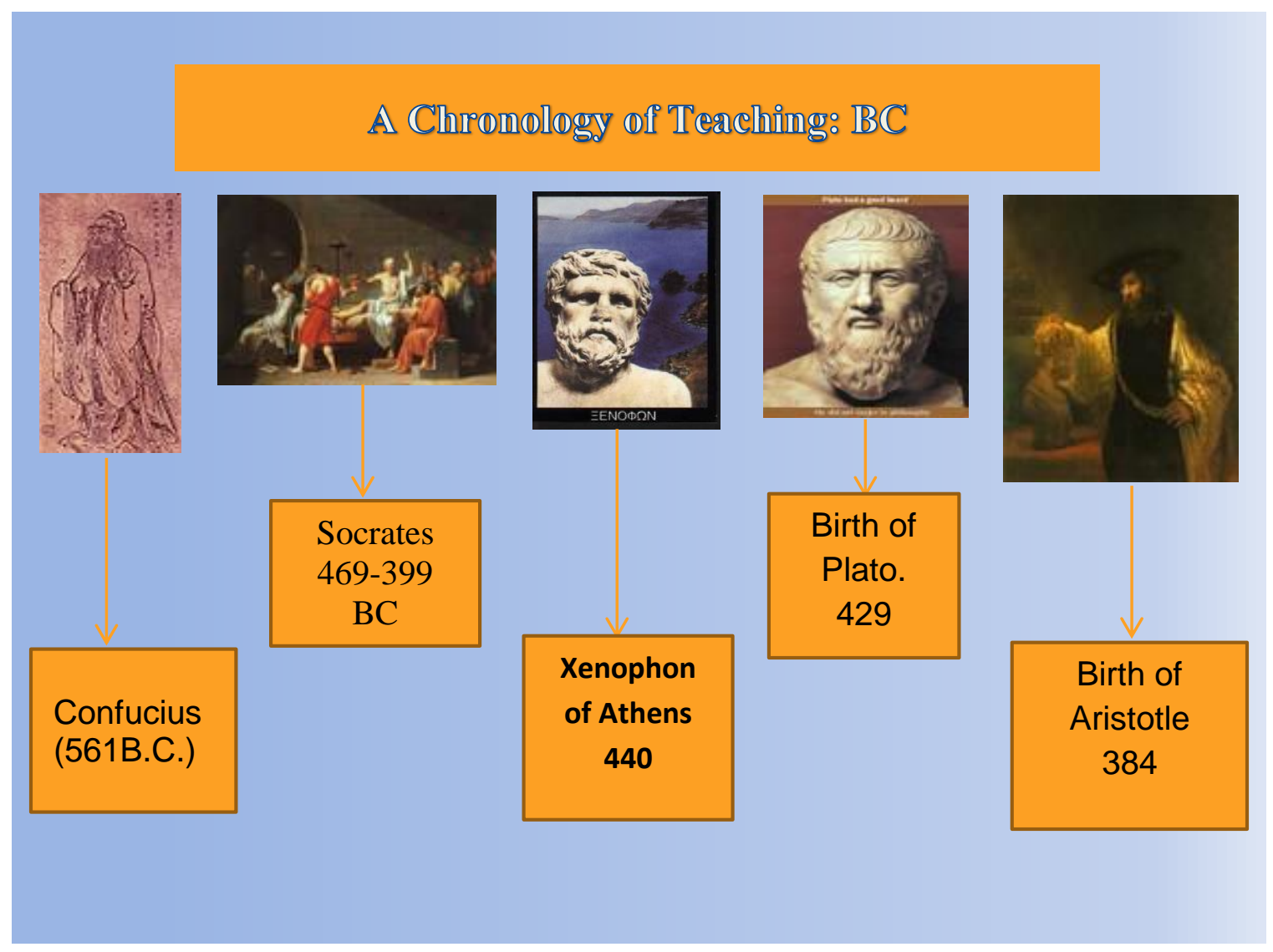

Figure 1. This figure illustration gives a picture of a time table of famous teachers BC (before Christ) listed in chronological order from left to right beginning with (a) Confucius, (b) Socrates, (c) Xenophon of Athens, (d) Birth of Plato, and (e) Birth of Aristotle.

Scientists in the field and public users are drawn to emotional intelligence's experimental topic. The rationales may be: (a) perhaps, the term emotional intelligence suggests emotional enhancement, or (b) emotional intelligence provides answers to 
questions related to emotional content. Irrespective of the lack of literature agreement, emotional intelligence competencies are boldly used in academic classrooms (instructors, students), medical environments (mental health professionals), corporate entities (employees), government (military personnel), conflict resolution programs (mediators), religious facets (spiritual leaders), and family dynamics (parents, children, siblings).

In this dissertation study, emotional intelligence is necessary to address the growing awareness and development of "social and emotional skills...for the foundation of academic knowledge in the classroom" (Kremenitzer, 2005, p. 3). Again, Kremenitzer (2005) speculated that emotional growth is obligatory. She believed that "it is important, therefore to challenge early childhood teachers, particularly veteran teachers, to take a closer look at their own social and emotional skills and to systematically reassess these skills through an emotionally intelligent "lens" (p. 3). The example Kremenitzer (2005) used was of flight attendants requesting "... adult passengers on a commercial airline" to first place the oxygen mask on oneself prior to assisting another individual (Kremenitzer, 2005, p. 4). The Kremenitzer (2005) piece encouraged instructors to "assess and enhance" their emotional abilities in order to "impact the abilities of the young children they teach" (p. 3).

The Kremenitzer (2005) study crafted the following questions from the Mayer, Salovey, and Caruso (2000) emotional intelligence four domains. Kremenitzer (2005) study queried faculty to complete a self-assessment for each Mayer, Salovey, and Caruso (2000) emotional intelligence constructs. Subsequently, the faculty participants in the Kremenitzer (2005) study identified how they proposed to improve their capabilities. The 
Figure 2. illustration is from the Kremenitzer (2005) study, and the emotional intelligence questions drew a parallel to Mayer, Salovey, and Caruso (2000) emotional intelligence branches (faculty completed a self-assessment).

Emotional intelligence ills. Emotional intelligence has a dark side, and sometimes troubled organizational cult leaders and executives have misused its power. In a point made earlier, King (1947) emphasized that emotional intelligence cannot prosper if individuals lacked good character. Mayer, Caruso, and Salovey (1999) maintained that the cottage industry should not have the power to force engagement in trust-building activities, especially when social ills exist (e.g., racism, sexism, or poverty may complicate training). Accordingly, Mayer, Caruso, and Salovey (1999) cautioned organizations to protect individuals from exploitation when using emotional intelligence concepts (e.g., during team bonding activities). At the same time, Goleman (1999) stated that managers and workers can use emotional intelligence domains to advocate against racial prejudice "with the finesse of an effective criticism" (Goleman, 1999, as cited in Murphy, 1999). To this, Mayer, Caruso, and Salovey (1999) rebutted that social ills and lack of awareness may create challenges. Therefore, Mayer, Caruso, and Salovey (1999) believed that a prerequisite to implementing emotional intelligence competencies should include one having good character.

Hein (2012) presented a more somber and critical view of Mayer, Salovey, and Caruso (2000) branches. Hein's (2012) disagreements included the lack of attention that theorists Mayer, Salovey, and Caruso (2000) have given to the darker side of emotional intelligence. Hein (2012) asserted that emotional intelligence theorists must appreciate the darker side of this theory for the reason that "early emotional, physical, and sexual 
abuse along with lack of emotional support will have significant effects on a person's behavior and emotional management later in life (para. 15)."

Hein (2012) has partial respect for the work of Mayer, Salovey, and Caruso (2000). Hein (2012) remarked that Mayer, Salovey, and Caruso (2000) studies have offered very little information and discounted the long term impact of someone who has been sexually, physically, and emotionally abused. Further, Hein (2012) indicated that abused individuals from long term unsupported abusive situations may exhibit the following symptoms: (a) low self-esteem, (b) behavioral effects, (c) and poor emotional management in their beliefs about themselves and others (para. 16). Therefore, emotional intelligence theorists' ought to investigate not only the good side of emotional intelligence theory, but the emotional intelligence phenomenon of abused individuals with darker life experiences.

Unfortunately, past and current decades have yielded many tragic events witnessed by global society's college campuses, elementary schools, high schools, and corporate enterprises. To reinforce this point, the Mayer and Salovey's (1997) study recounted the following true story of an emotional outburst between teacher and student that potentially went too far:

A FOURTH-GRADE BOY was shivering on a school playground when a teacher asked him if he owned a warmer coat. He replied he did not (and his friend agreed). That afternoon, the teacher and the school nurse called the boy's home and offered to buy him a new coat. The boy's mother was delighted, and so the next morning, they outfitted 
the boy. Two boys noticed the child's new coat at recess and accused him of stealing it. When the boy denied it, the accusers launched such a venomous attack that none of the other children dared to defend the boy. Teachers and staff arrived and began to break up the confrontation. One the accusers yelled "suck eggs" at the school nurse. "You suck eggs?" she replied.

The teacher who brought the coat was disturbed that her gift had caused such pain. The school nurse wondered how she could have said "suck eggs" to a child. The teacher whose class contained the troublemakers wondered how her boys could have acted that way. The staff members discussed what had happened and tried to determine what to do next (Mayer and Salovey, 1997, p. 3) According to Conlin (2004) emotions and anger are a part of the work scene. Comparatively, education organizations are not exempt from these incidents. Emotional outburst episodes, face to face, and online pedagogy are not immune. Regrettably, history has recorded numerous volatile occurrences in academia settings. The Mayer and Salovey (1997) study demonstrated that "the definition of an ability is that it is a capacity rather than a topic to be taught...like exercising a person's sports ability. One exercises muscles to build strength; similarly, one teaches emotional skills to build emotional intelligence" (p. 20,31). Arguably, the result of many unstable interactions may underscore the necessity and practice of building emotional intelligence skills for both teachers and students. 
Mayer and Salovey (1997) announced "we are at the beginning of the learning curve about emotional intelligence; the coming years should bring exciting research that contributes to our understanding of the concept" (p. 22). Subsequently, after Mayer and Salovey (1997), Mayer, Caruso, and Salovey (1999), Mayer, Salovey, and Caruso (2004) revealed the advent of emotional intelligence constructs, Hein (2006) and Hein (2012) began compelling Mayer and Salovey (1997) to feature the dark side of emotional intelligence. Hein (2012) identified that current emotional intelligence interpretations had omitted recognition of marginalized populations (e.g., impact on abused individuals). Therefore, he believed this avoidance could amount to misinterpretation of future emotional intelligence analyses (Hein, 2012). Perhaps, a more relevant question that Hein's (2012) might consider is whether Mayer and Salovey (1997) delved enough into the "dark" side of emotional intelligence. Mayer and Salovey (1997) had already conveyed concerns regarding such issues related to emotional intelligence publically when they:

(a) Examined a few educational programs stating their uncomfortableness where the material was not prudently worked out, and the personnel were not well trained

(b) Expressed their discontent with educational programs "that seemed to adopt an 'emotions are good' philosophy untempered by the fact that emotions exist in the context of other personal characteristics and interpersonal relationships are troubling to us" 
(c) Identified that respect was not given to individuals from diverse subcultures that "approach emotions differently" (e.g., Western ideologies of "let it all hang out," but others may take a more stoic view)

(d) Stated "we are not sure such severely damaged children profit from, say being required to share their emotions in a class discussion, or whether they will be overwhelmed by it, or feel coerced" (p. 20-21).

It seemed that Mayer and Salovey (1997) had already alluded to the ominous side of emotional intelligence (e.g., alerting educational programs that communication in some households were emotionally imbalanced, therefore necessitating the need for urgent emotional education) (p. 21). Mayer and Salovey (1997) hypothesized that "emotions have been taught in the schools before the concept of emotional intelligence was developed" (p. 20). Arguably, the Mayer and Salovey (1997) study assessed that culture and fine arts "literature is probably the first home of the [sic] emotional intelligences" as they described the human mind as an "emotional theater" (p. 20). The above examples suggest that theatre and music, etc. may support the formation of learning to using emotions. Ultimately, the "definition combines the ideas that emotion makes thinking more intelligent and that one thinks intelligently about emotion" (p. 5). Thus, in their estimation, intelligence and emotions can link together. But then again "not everything that connects cognition to emotion...is emotional intelligence" (p. 4). Again, Mayer and Salovey (1997) cautioned users to recognize that perception takes emotions into consideration (p. 4). Some situations often require higher end "sophisticated problem solving” (p. 3) as recommended in the following section. 


\section{Emotional intelligence: Neuroscience and behavioral tics in work milieus.}

Prior to researchers' discovery of emotional quotient or emotional intelligence, the scientific world believed that cognitive learning involved fitting new data and insights into existing frameworks of association, understanding, extending, and enriching the corresponding neural circuitry (Mayer, Caruso, \& Salovey, 2000; Rubin, 1999). Since then, theorists have determined that emotional learning involves cognitive learning and stirring the neural circuitry (Mayer, Caruso \& Salovey, 2000). Scientists verified that emotions require that we also engage the neural circuitry where our social and emotional habit repertoire is stored (Rubin, 1999).

Jorgenson (2003) contended that educators have exhibited "carelessness in misinterpreting and decontextualizing the finding of brain research" (p. 368) which is the extent of "educational malpractice" (p. 368). Waterhouse (2006a) concurred with Jorgenson (2003) and argued that scientific theories (e.g., multiple intelligence, emotional intelligence, and mozart effect) must abide by the rules of evidence (Waterhouse, 2006a, p. 221). Waterhouse (2006a) is in agreement with Jorgenson (2003) that previous IQ standardized testing may need rectifying "for the unjust effects of IQ test scores" (Waterhouse, 2006a, p. 220). Even so, Waterhouse (2006a) contended that educational programs' eagerness to embrace the above theories proved hasty and harmful because of the "lack of evidence for these theories" (p. 220) in three essential ways:

(a) Teaching these theories may harm educators

(b) These theories harm students

(c) The acceptance and promulgation of these theories does harm to the field of education (Waterhouse, 2006a, p. 221). 
Thus, Waterhouse (2006b) advised that brain research places reasonable scientific limits on psychological theories of reasoning and knowledge. As well, Stern (2005) pleaded that neuroscience "alone" does not have the means to produce influential education milieus (p.745). Therefore, Stern (2005) presented the notion that "neuroscience findings" contribution and responsibility is to assess "insights into the abilities and constraints of the learning brain" (p. 745). For the foregoing reasons, Waterhouse (2006a) protested that theories must be "supported by a preponderance of sound evidence" (p. 221).

Both Jorgenson, 2003 and Hosie, Forster, and Sevastos, 2004 agreed with Mayer, Caruso, and Salovey (1999) that emotional learning and cognitive learning engage the brain's neural circuitry system, but they challenge how educators interpret and practice the theories. Hosie, Forster, and Sevastos (2004) added that this type of engagement requires mastering one's emotions and the emotions of other individuals. Goleman 1998; Mayer and Salovey 1993; Salovey and Mayer 1990 suggested that the above competencies can be achieved by enhanced self-awareness, self-management, social awareness, and social skills, otherwise known as emotional intelligence. Apparently, “changing habits such as learning to approach people positively instead of avoiding them, to listen better, or to give feedback skillfully, can be a more challenging task than simply adding new information to old" (Hosie, Forster \& Sevastos, 2004, p. 140).

Neuroscience discipline reported two discoveries according to Mayer and Gaschke (1988): (1) That humans can develop new neural tissue as adults, but stress may inhibit the process through secretion cortisol. (2) In 2000, another discovery was made that the left prefrontal cortex light shines when thoughts of hope and possibilities are 
imagined. Comparatively, the right prefrontal cortex light shines when thoughts of defensiveness and depression are experienced or when we are stressed. In fact, stressful situations cause the brain to stop the positive production of neural tissue, by immediately shutting down any process that is not essential for survival (Mayer \& Gaschke, 1988).

Reports have shown that one stressful episode will negatively affect the brain and how one thinks for approximately 36 hours. Human thoughts originate in the limbic system which is the feeling or emotional part of the brain and then travel through the brain. Lane (1994) believed that developing leadership without emotional intelligence is like dancing without tempo. In the present study emotions may affect executive administrators, leaders, instructors, or students, in face to face, and/or online professional environments.

To this point, Conlin's (2004) article titled I'm a Bad Boss? Blame My Dad debated how professional learning and working cultures are influenced by "family dynamics" (p. 61) (e.g., when emotional pandemonium behaviors interrupt professional productivity). The Conlin (2004) piece revealed two sensitive incidents. Apparently, in both episodes, introspection assisted two executives as they self-examined their public display of emotional experiences.

The first executive portrayed was Peter Tilton, Microsoft Corporation Director Level Executive who "within seconds, he was banging his fist on the whiteboard and 'yelling his face off'" at corporate headquarters. According to Tilton, havoc began “when an 'incompetent' colleague began needling him about his own progress on a project" (p. 60). After "the emotional outburst, Tilton now recognizes, was eerily similar 
to one he had back in seventh grade, when his parents- 'chronic misunderstanders'forbade him to wear his jeans with the holey knees to school" (Conlin, 2004, p. 60).

The second executive depicted was Bert Whitehead, CEO of Cambridge Connection who, "after announcing he would be away on a business trip, he noticed a stealthy rejoicing rippling through his offices" (Conlin, 2004, p. 60). Whitehead stated that his expectations were such that "nobody was ever quite good enough" (Conlin, 2004, p. 60). In reflection, Whitehead referred to himself as a temperamental pressure-initiator averring, "I had a mother I could not get approval from and I had unknowingly really adopted that into my management style" (Conlin, 2004, p. 60).

Author Conlin (2004) illustrated epiphany's from the two above high level corporate executives that had allowed their "trip wires to go off" (p. 60) in professional environments. The above events are matters that can occur between (e.g., employees, faculty to faculty, faculty to student, and student to student). Meanwhile, Conlin (2004) suggested that companies and institutions should be aware "that these highly rational, utterly left brained executives are delving into their pasts illustrates a new strain of organizational therapy coursing through the inner sanctums of corporate power" (p. 60).

Conlin (2004) posited that education and business environments are seeking marriages with productive and emotionally efficient employees, as part of the job (pp. 6061). Desroches (1995) author of Your Boss is Not Your Mother assessed that unresolved re-enactments of family dramas at work can waste $20 \%$ or more of personnel time. Conlin (2004) wasn't alone in comparing family systems therapy to business organization (p. 60). For example, Conlin's (2004) point was buttressed by Desroches (2006), Lafair (2009), and Mandel (2006) who concurred that business entities and professional learning 
environments that are seeking leading edges are paying closer attention to emotional intelligence competences, as part of the job (e.g., "personalities, emotions, behavioral tics") (Conlin, 2004, p. 61).

Conlin (2004) used satire to illustrate the basic concept of "office politics [and] family dynamics" in professional environments as:

corporate strivers behaving like thumb-suckers

in knee pants, yearning for pats on the back from

the boss 'daddies and mommies'.

(Conlin, 2004, p. 60).

Conlin (2004) also contended that office politics can resemble modern day road rage as colleagues off one another (p. 60). To this end, Conlin (2004) suggested that corporate enterprises, institutions, and many theorists have begun the discussion on how to observe family histories to recognize the origin of [individual emotions] anger, in an effort to "improve dysfunctional work relationships" (p. 61) in the workplace (Conlin, 2004, p. 61). Thus professional learning environments and corporate cultures are pairing “corporate cultures with employees' personal cultures, in an effort to reduce 'scandals' " (p.61).

As such, Conlin (2004) advised that individual success may be predicated on one's ability to recognize these delicate "emotional subtexts" (p. 60) which are usually the driving force behind many encounters. At the same time, these shadowy decomposing behaviors may be "subconsciously self-sabotaging" (p. 61) (e.g., "shying from authority figures, or engaging in hypercritical judgments of subordinates”) (p. 60). Thus, Mandel (2006) identified that "childhood bruises can create workplace chaos" (p. 3) coming from 
“...many sources and do not have to be severe to have lasting effects" (p. 50). Conlin (2004) contended "when it's hysterical, it's historical" (p. 61).

Brain research studies have revealed that individuals need to feel connected, capable, and appreciated during stressful situations (Conlin, 2004, p. 61). According to Mandel (2006) unwanted emotional discomforts are often shoved into the subconscious by way of (e.g., rejecting, disregarding, or delaying) (p. 4) such injuries. Mandel (2006) and Conlin (2004) reasoned that emotional "thriving" (Mandel, 2006, p. 3) (e.g., taking charge of situations) is equally significant to professional "analytical savvy" (Conlin, 2004, p. 61). Emotional fulfillment, Mandel (2006) claimed, is elusive when "ineffective coping strategies and rigid defenses" (p. 4) are practiced. Conlin (2004) analogized effective teamwork performances to a well-functioning "showcase Six Sigma plant" (p. 61). Whereby, group dynamic researchers have emphasized that the first emotional organization an individual belongs to or is placed in, is usually considered family "with parents the first bosses and siblings the first colleagues" (Conlin, 2004, p. 60).

\section{Emotional intelligence: Professional programs and business solutions.}

Researchers at Carnegie Mellon University, Department of Social and Decision Sciences believe they have established the first link between incidental emotions and economic behavior (Lerner, Small, \& Lowenstein, 2004). The outcome of Carnegie's study showed that economics of emotions and negative moods might prove to be bad for business and learning systems (Lerner, Small, \& Loewenstein, 2004). For example, Lerner, Small, \& Loewenstein (2004), determined that sadness and disgust drives down the prices sellers are willing to accept for their product (Lerner, Small, \& Loewenstein, 2004, p. 337). Likewise, poor attitudes can affect the reputation of instructor, students, and overall 
higher educational institution. The Carnegie study discussed a financial broker squabbling with his spouse in the morning, and how conflict may impact the trades he made later that day. Understanding the relationship between emotional combination states and perceptions of value could influence negotiating strategies, marketing efforts, and tools economists use to anticipate the behavior of financial markets (Lerner, Small, \& Loewenstein, 2004, p. 337). Likewise, education has real-world consequences. With the potential of real world implications, this dissertation study may possibly be a close analogy to emotional intelligence. If the promotion of emotional intelligence within business and educational environments is to be taken seriously and to be sustained, rather than becoming a passing management fad, instructors should attempt to follow guidelines based on best available research. Only when emotional intelligence training is based on sound, empirically based methods, will it realize prominence.

Today's businesses expect workers to be a part of business intelligence solutions as competency models have developed. Goleman (1995) made no guarantee that what a manager values bears any exact relationship to what makes an employee a success. Mayer, Caruso, and Salovey (1999) noted that accurate measurement of emotional intelligence still uses self-report measures, similar to personality tests. Meanwhile, Mayer, Caruso, and Salovey (1999) developed two ability based emotional intelligence tests (a) The MSCEIT tests: The Mayer-Salovey-Caruso Emotional Intelligence Test (e.g., for adults) and (b) The MSCEIT-YV-R: The Mayer-Salovey-Caruso Emotional Intelligence Test-Youth Version Research Edition (e.g., suitable for 12 to 18-year olds) criterion evaluates participants' correct responses. 
Mayer, Caruso, and Salovey (1999) cautioned the empirical and public culture that Goleman's (1995) book, Emotional Intelligence, although widely accepted, should not be considered the answer to the world on emotional intelligence. Goleman (1999) declared that emotional intelligence offered hope through learnable skills. Mayer, Caruso, and Salovey (1999) reaffirmed that meaningful research investigations are occurring with emotional intelligence, in a series of articles written in the early 1990s (e.g., Mayer, DiPaolo, \& Salovey, 1990; Mayer \& Salovey, 1993; Salovey \& Mayer, 1990) (Mayer, Caruso, and Salovey, 1999, p. 268).

It is also noted that Mayer, Caruso, and Salovey (1999) distinguished their emotional intelligence theory from Goleman's (1995) emotional intelligence theory. For instance, one such difference suggested that individuals capable of displaying rational and healthy emotions and intelligence should be viewed more favorably (Mayer, Caruso, \& Salovey, 1999). Contrary to Goleman's theory, Mayer, Caruso, and Salovey (1999) believed that their emotional intelligence theory may enrich thought.

Murphy (1999) credited the academic community as the originator of emotional intelligence theory. Although Goleman (1995) stated that part of his intent in writing the book, Emotional Intelligence, was to challenge intelligence quotient (IQ) dominance. Instead, Goleman's (1995) book reinforced intelligence quotient's (IQ) superiority. Moreover, Murphy (1999) stated that Goleman (1995) (1) did not abide by assiduous or scientific protocol and (2) instead of situating emotional intelligence as a rival to IQ's superiority, IQ was reinforced as the standard by which intelligence is still defined. In the end, Murphy (1999) believed that Goleman (1995) may have missed the chance to present the most essential question to the intelligence community "Why must we call 
something an intelligence in order to value it?" (Murphy, 1999, Promotional Intelligence, para. 32). Therefore, intelligence quotient (IQ) priority remains as the standard by which the scientific community defines intelligence (Murphy, 1999).

Prior to Goleman's (1995) Emotional Intelligence publication, Herrnstein and Murray (1994) published The Bell Curve. As such, their concept of intelligence was even more divisive than emotional intelligence theory (e.g., The Bell Curve asserted that (a) a correlation existed between intelligence quotient (IQ) and one's social class and (b) intelligence quotient (IQ) was fundamentally irreversible). What's more, Herrnstein and Murray (1994) described The Bell Curve book as "blithely" (p.1). Herrnstein and Murray (1994) invited readers to explore their "apparently heterodox" beliefs (p. 1). The Bell Curve promoted a gloomy forecast and disheartening framework regarding one's intelligence quotient (IQ) (Goleman, 1995).

For many, Goleman's (1995) book, Emotional Intelligence, was welcomed as a redeemer to The Bell Curve. Perhaps, the larger community was desperate to embrace an inspirational and supportive solution after receiving The Bell Curve message. In part, Goleman (1995) promoted Emotional Intelligence in reply to Herrnstein and Murray’s (1994) assertions and stated that Herrnstein and Murray’s (1994) analyses were discouraging. Goleman (1995) believed that emotional intelligence offered an adaptable skill. Despite Goleman’s (1995) claims Mayer, Caruso, and Salovey (1999) opposed Goleman's (1995) publication stating that the book lacked empirical rigor.

Emotional intelligence has sparked schools and workplaces that are struggling to accommodate increasingly diverse populations by offering training that promised to deliver results (Mayer et al., 1999). Those results would "enhance” emotional 
intelligence. Success in life has been considered by some researchers to be dependent on intelligence.

Emotional intelligence: Technology and software design. The Goldsworthy (2002) investigation is one of the limited literature pieces supporting the advancement of emotional intelligence through technology. As such, the Goldsworthy (2002) analysis was "used to elucidate potential uses of computer technology to support the development of emotional intelligence” (p.119). Basically, Goldsworthy (2002) systematic approach "encouraged educationalists and technology designers" (p.119) to take part in emotional intelligence's research confirmation process and to use technology "to support socioemotional development" (p. 121). In a previous study introduced by Goldsworthy (1999), he "consider[ed] technologies relationship to learning" (Goldsworthy, 2002, p. 123) and in a follow up study Goldsworthy (2002) underscored the “... areas in which computer technology has been used to support emotional intelligence" (Goldsworthy, 2002, p. 123).

Goldsworthy (2002) questioned "what is emotional intelligence" and "what are its components" (p. 120). For the purposes of determining whether "emotional intelligence is teachable or, at the very least, learnable" (Goldsworthy, 2002, p. 120), Goldsworthy's (1999) study had already begun to explore results. Therefore, Goldsworthy (1999) proposed that software developers should divide "computer-supported socioemotional development" (Goldsworthy, 2002, p. 124) into four distinct measurements "(a) from technology, (b) around technology, and (c) through technology. Learning may also be assisted through (d) technology-supported assessment" (Goldsworthy, 2002, p. 124). For example, inserting QuickTime movies or interactive videos which "promise[s] to hold 
attention better and therefore increase the effectiveness of models for emotionally intelligent behavior" (Goldsworthy, 2002, p. 125).

Nearly two decades earlier, Dickson (1985) had begun urging information technology designers to consciously create software that encouraged emotional learning. Goldsworthy (2002) also urged "software developers to deliberately design applications to juxtapose different symbolic representations in such a way as to encourage the learners themselves, perhaps supported by the software, to perform the translations between the differing systems of representation" (p. 129). Dickson (1985) also suggested that other essential and probable benefits of the symbolic presentations allowed computer users to translate meanings between different emotional emblematic schemes (p. 30). For example, Goldsworthy (2002) explained, if users of software games and online programs were to include emotional content "...to perform the translations between the differing systems of representation" (p. 129), perhaps the software could gratify users in (a) enjoyment and excitement, and (b) enhancement of social skills.

Dickson (1985) emphasized this point by "arguing that software designed for this purpose would be more successful in that it deliberately creates social encounters among learners" (p. 30). With the purpose of improving social interaction in users of software games and programs, Dickson (1985) deliberately challenged the technology industry to create software games and programs that would enrich learners emotionally:

Using software to encourage learners to translate back and forth between symbol systems is based partly on the belief that such active translation may to some extent increase the generalization of skills across media, stimulate 
metacognitive awareness of the existence of these relatively

independent skills-in-media, and evoke a broader

understanding of the content to which these symbol

systems are applied (p. 31).

Further, Goldsworthy (2002) recommended that technology products should be used as an asset for diverse and inclusive populations to "support the performance and development of emotional intelligence in people of all ages" (Goldsworthy, 2002, p. 144). Besides, Goldsworthy's (2002) experimentation with emotional software tools led him to forecast that software programs can "help people become more socially competent" (p. 144) when using emotional intelligence context.

Goldsworthy (2002) remarked that "outside of special needs populations" (p. 144) limited or no exploration on didactic tools (p.144) existed to enhance learners' real-world “emotional recognition capabilities" (144). Therefore, Goldsworthy (2002) appealed to interested researchers to invent electronic technology tools which can stimulate “emotion-generating capabilities" (p. 144). Synergizing emotional intelligence and technology together is one approach to support and produce an emotionally competent effective end-user (e.g., instructor or employee) (Goldsworthy, 2002).

Ultimately, Goldsworthy believed that "software games can educate and assist with social development and "social problem intervention" (Goldsworthy, 2002, p. 145). Therefore, Goldsworthy envisioned interested researchers inventing emotionally intelligent software "for an ill-defined domain, one epitomizing the complexity and potential of human development" (Goldsworthy, 2002, p. 145). Then, what company 
would agree to sponsor the first emotionally intelligent war game with a potential title of Emotionally Intelligence and War of the Worlds.

\section{Emotional Intelligence in Face to Face and Online}

In the spirit of this research investigation, a critical review was conducted to ascertain more about face to face and online program methodology. This study will add to the limited amount of existing research in emotional intelligence, in face to face, and in online instruction. Besides, it will hopefully inform us what we do not know about the use of emotional intelligence in higher education, among faculty, in social science, and in STEM programs. The present study attempted to explore and develop our understanding of issues pertinent to teaching in the above specialized programs that interface with face to face and online programs. Also, this study reports finding from (a) faculty and (b) intervention methods needed for interacting in face to face and online programs.

The role of faculty teaching in virtual venues may be very important (Zheng \& Smaldino, 2006), but all instructors have not eagerly embraced on-line technology for various reasons. Some instructors' on-line indifference may stem from fiscal reports and threats that "technology could push them out of their jobs" (Quillen, 2012, p. 21). Other instructors prefer "[t]raditional classes...generally defined as teacher-centered environments" (Appleton, 1997 as cited in Tatli \& Ayas, 2012, p. 193). Online pedagogical methods confront teachers with new tasks that challenge their individual and collective comfort levels (Zheng \& Smaldino, 2006).

\section{Emotional intelligence effect and usage in education and learning. Faculty} perceptions of their effectiveness within online and face to face courses rank high on the list of achieving a professional environment in both venues. Within the context of those 
valued interpersonal relationships (teacher-to-student and student-to-student), the virtual "instructor's role has become more of a facilitator than a traditional lecturer" (Yang, Cornelious, \& Association for Educational Communications, and Technology, 2004, p. 849). The second primary responsibility of the instructor's role was to "select and filter information for student consideration, to provide thought-provoking questions, and to facilitate well-considered discussion" (Kettner-Polley, 2000) as cited in Yang et al., 2004, p. 849).

Effective and healthy teaching environments, whether online or face to face depend, in part, on implementing structures and activities which are appropriate to the way faculty view learning (Powell \& Ross, 2003). One specific definition suggested that we keep in mind:

Members of a school's faculty constitute a group; they are a collection of individuals sharing certain common circumstances.

Like all groups, faculty will progress through a set of developmental stages—-forming, norming, storming, and performing. Schools that pay attention to these stages and establish rituals and other healthy practices on an ongoing basis reap the benefits of high teacher morale, cooperative and collegial professionals with a shared passion for teaching and learning, and a climate that supports risk-taking and "reflective" conversation (Powell \& Ross, 2003, p. 93).

Baran (2011) recommended that instructors participating in professional online environments may require additional support from their institutions (e.g., valuing their 
opinions and supporting their transition to new teaching formats) as instructors construct new online identities. All in all, the inclusion of faculty members rather than exclusion may encourage and improve the transitional process. Clearly the available literature offers conflicting positions regarding the advantages and disadvantages of online instruction and teaching (Baran, 2011). Those opposed to on-line instruction believe that interactive technology is notorious for creating and fueling misinterpreted online messages. Consequently, Baran (2011) suggested new ways for technology to positively impact pedagogical practice.

There are numerous questions to consider. Are higher educational institutions taking pedagogy processes for granted? Can materials transition between both face to face and online formats? What are some of the challenges that will remain as the status quo in teaching venues? Are the master class and new online format in an old but familiar metaphorically shoot-out likened to the western historical times? Instead, face to face and online professional learning venues need special attention to address the emotions that come with the new technology. Fleming (2004) wrote:

at this juncture in leadership thought and practice, we need uncommon lenses to view a domain that has grown too predictable. The fundamental woe of mechanical leaders is their lack of humanity. We “technique" leadership when we don't have the time for the messiness of human encounter and interaction. When our humanity is an interruption in an otherwise happy existence, we've missed the point 
of life, not to mention the point of leadership. It is our humanity that makes leadership a pain and a privilege (p. 15).

The Han and Johnson (2012) study suggested that the use of emotional intelligence in pedagogical settings may help to narrow "transactional" online distance between teachers, students, and peers. The above study also warned about the variances in emotional intelligence styles. For example, face to face and online professional learning environment interactions may not always be duplicated between settings. A second example of this variance is the inconsistency between synchronous and asynchronous online venues. Thus, the argument has been made that classroom results in face to face settings should not or "cannot be applied to online environments without evidence of empirical studies in online" (p. 86). Fabio and Palazzeschi (2008) used the Bar-On (2004) design to posit that "emotional intelligence and self-efficacy have a positive relationship in traditional school settings" (p. 86). This is an indication from the theoretical debaters in the field, that varying emotional intelligence constructs "may give different results in understanding the relationship between emotional intelligence... and learning environments" (p. 87). The outcome of the Han and Johnson (2012) study verified that fostering "an emotional-oriented perspective" may tend to improve online interaction between instructors and students. Two final indicators from the Han and Johnson (2012) examination reported that the lack of environmental clues may have a direct impact on whether or not teachers and students can communicate gracefully (p. 87).

Pedagogy environments trading places. Institutions and faculty begin each semester with an instructional message or a goal in mind. Whether teaching online or 
face to face, unique messages are initiated by faculty and delivered to the student population. Instructors attempt to convey teaching messages within these two (online and face to face) contrasting contact situations. The question may become whether the intended academic and expressed messages were conveyed successfully. Faculty roles and responsibilities have increased with the unique demands generated by technology gateways. Seok, DaCosta, Kinsell, and Tung (2010) proposed that the facilitation of an effective online class "may depend upon increased technology skills" from instructors (p. 34). Yang, Cornelious, and Association for Educational Communications, and Technology (2004) asserted that the roles of faculty in online are numerous for both synchronous and asynchronous environments.

The methods of communication for faculty in online and face to face classrooms are technology driven: email, web, twitter, and face book (Hurt, 2008). Office visits, telephone correspondences, and face to face meetings are no longer the standard or typical interaction mode. Electronic messages, the new norm for teacher-student communication, lack the context of earlier interaction modes, therefore increasing possibilities for misunderstandings.

Instructors in face to face courses derive information differently than in online courses. Emotional information, in a face to face course (e.g. traditional), is communicated utilizing physical interactions, whereas online courses (e.g., virtual setting) utilize nuances of written text. Using contextual material effectively in face to face and online settings might be considered a measure of emotional intelligence. Accessing emotional information and "detect[ing emotional] changes" (Kettner-Polley, 
2000, p.93) in the virtual classroom is equally important, but absent the physical presence the emotional environment can be challenging.

Depending on the course and whether professional learning environments are synchronous or asynchronous, theorists Rosa and Lerman (2011) claim that online can help instructors engage in more concrete exercises and assignments (e.g., math) through the use of natural logical arguments and a reasonable exchange of ideas (p. 81). For example, concrete exercises and assignments can create the ability to discuss and argue in an effort to arrive at the truth (Rosa \& Lerman, 2011, p. 82). Rosa and Lerman (2011) contended that emotions are used and needed in online interaction (e.g., perception, consideration) (p. 75). Blake (2000) questioned whether instructor should remain detached and distant, or whether there should there be a connection emotionally (p. 188). Overall, Blake (2000) debated that higher education symbolizes more of a sterile stiff atmosphere and has done very little to embolden personal expression and emotions between faculty and students (p. 188).

Teaching and learning with emotional intelligence "may be foundational to developing competencies that lead to increase[d] teachers' efficacy in the classroom..." (Vesely, Saklofske, \& Leschied, 2013, p. 71). Instructors' primary concerns include their own ability to deliver the curriculum and content to students. According to Seok, DaCosta, Kinsell, and Tung (2010) increasing one's competency level and technology skills “... may contribute to instructors' perceptions of delivering more effectively designed online courses" (p. 34).

Communication. Instructional formats can often demand further comprehension, explanation, reframing, and modifications, to avoid failed communication between sender 
and receiver. Educational value will likely be achieved from studying the impact of emotional intelligence and interactive technology. The good of emotional intelligence for online delivery may be its context. The art of emotional intelligence competencies are heralded for their ability to harness, make connections, and reinforce human emotions for communication in face to face settings. In virtual classroom settings emotional intelligence can be used to strengthen and act as an emotional compass in the absence of physical human presence.

The question may be whether online technology has become a liability or an asset for instructor and students alike. Some instructors argue that education has become more cumbersome in virtual environments. One protest from students accentuates the irony of instant information and the burden of login access to multiple web accounts, including both professional and personal access. Instructors may disapprove of the constant digital communication and time consumption required to respond. Absence from the traditional style master class (face to face) may require extra time online. Perception of educators is that they are working harder to meet educational requirements and demands of online learning styles of students (e.g., Comas-Quinn, 2011; McKenna, 2013; Quillen, 2012). Additionally, online communication has invited unwelcomed interactions that may distract, and even increase rudeness which may distract from the educational process.

McKenna (2013) contends that virtual education is equal and comparable to face to face instruction with one missing inconsequential component, human touch (p. 22). McKenna (2013) argued that " $[\mathrm{t}] \mathrm{o}$ think of learning as the relationship between a learner and some given subject matter is profoundly distorting. Learning is first and foremost a relationship between two people" (p. 26). McKenna (2013) presented ten compelling 
arguments in opposition of what he phrased as "the predatory pedagogy" (p. 21). The ten oppositions to online:

(1) Trojan Horse of Capital (shine the light on the shadows...)

(2) Deskilling Professors

(3) The Surveillance State

(4) Less Touch, Less Trust

(5) Informal Communication on the Backburner

(6) Waning of Cooperation

(7) Erosion of the Eros Effect (and Dancing in the Streets)

(8) Collapse of the Commons

9) “Techno-utopia" arrives just in time as state falters

10) Attack on Critical Pedagogy

McKenna (2013) posits that real excitements of learning are predicated on experiences rich in physical human contact (pp. 24-26).

Embracing new technology. Teaching faculty in higher education institutions are not always eager to embrace new instructional technology tools (Singh \& Pan, 2004).

One rationalization for this position is that influencing and stimulating a student's mental aptitude is far more impactful when the learner is physically present. A second overarching theme related to online instruction is that it does not suit everyone. Research findings suggested that perception of online course effectiveness may vary based upon one's technology skills (Yang, Cornelious, \& Association for Educational Communications, and Technology, 2004). 
Neither does on-line education suit every instructor (Comas-Quinn, 2011). One of the reservations that instructors have identified for online education is the evolving uncertainties of their roles and responsibilities (Zheng \& Smaldino, 2003). As interactive technology improves and “...[w]eb-based pedagogy brings new opportunities, it also brings new challenges to both instructors and students" (Seok, DaCosta, Kinsell, \& Tung, 2010, pp. 25-26).

Human trusts versus technology. McKenna (2013) strongly argued that human interaction is a powerful tool for building trust:

Trust is fundamental for education. Trust is a byproduct of working through struggles with others. Education is itself a struggle, a struggle over meaning. You learn to trust others through small reciprocities over time. You share knowledge and intimacies and form a bond. In struggle you absorb the breadth of another's character, their force of being. Most of this is done non-verbally, informally, and unconsciously. It is tactile and sensual. It takes place in the presence of another... (p. 25).

McKenna (2013) went so far as to plead to humanity to maintain the closeness in professional learning environments. McKenna (2013) not only emphasized the need for education to maintain a certain level of intimacy, he also alluded to what he believed to be a necessity. Similarly to Maslow Hierarchy of basic needs, McKenna (2013) speculated that for humans to thrive, physical contact and interaction are needed; without human connection emotional development would be diminished on a deeper emotional 
level. Consequently, McKenna (2013) did not believe true learning or intimate connections can develop in a healthy manner in the absence or lack of another human presence. Furthermore, he postulated "...think of learning as the relationship" (p. 26). In this instance, the writer is advocating for personal relationships in learning.

How can trust be established in virtual settings when the physical tangible presence is absent? Over the centuries education has once again been advanced by innovative technology. The introduction of emotional intelligence may represent another enormous addition to education's support of human experiences during online and face to face interaction. The techniques associated with emotional intelligence body of work are revered both for challenges and organized responses. Emotional intelligence challenges us to think about social responsibility and the social framework of technology.

Instructor and student willingness and participation. Thus, the opinion of the anti-technologist seemed to be that face to face instruction is more trustworthy. Essentially, face to face instruction automatically endorses students as "eye witnesses" to more accurate communication than do on-line courses. In other words, the antitechnologists argued that instructors who present in face to face venues deliver more guaranteed emotionally reliable messages. Also, there may be some perception that greater teaching liabilities and pressures are attached to developing into an excellent online instructor. Faculty may believe that they must work harder on on-line courses to emotionally connect to students and to ensure that the syllabi and content, including the instructions, are accurate, well understood, and carefully crafted. Arguably, this justification becomes the dissenters' very reason to refrain from the online instruction. An earlier researcher agreed to the following: 
Disadvantages cited by the instructors included the increased preparation time required to teach effectively on-line, isolation caused by a lack of face to face contact, technical problems, a drain on enrollment in seated classes, issues related to dial-up Internet access, and under-prepared students in on-line courses (Hurt, 2008, p. 10).

All of the above can impact the emotional environment of virtual classrooms. Because of the historical relationship between the physical and practical nature of teaching, virtual instruction remains confusing for some (Hallström \& Gyberg, 2011). Also, face to face classroom communication is not easily replicated in online formats. For example, "live" instructional moments are not easily transposed from traditional face to face settings to online settings. Thus, "technology teachers, teacher educators, curriculum developers and researchers can be provided with good analytical tools for this purpose" (Hallström \& Gyberg, 2011, p. 3). Those opposed to online instruction believe that interactive online technology contributions are negligible. Therefore the dissenters ask, why tussle to teach with such an awkward and impersonal approach? But according to Hurt (2008), "no one stands to benefit more from the on-line option than the ... college student who lives some distance from the college and who has family obligations and rotating work schedules" (p. 11).

Anti-technologists prefer face to face. In our electronic world, emotional perception of words, content, messages, tones, humor, and written expressions can easily become misunderstood. One premise of the technology debate is that the adjustment and transfer of instructional methodologies are quite challenging. To this end, the anti- 
technologists argued that online instruction places a greater burden on faculty to prepare and deliver pedagogical content. For example, in a face to face class, one's physical presence and body language function to complement and clarify the professor's words, often allowing faculty to immediately explain misunderstood messages. The combination of physical expressions and spoken words, generally, informs the audience of both the emotional and "intended" meanings of the speaker. Other strategic scholars are in agreement with anti-technologists. Rosa and Lerman (2011) asserted that due to the nature of the virtual world, emotions and expressions are often hidden (p. 88). Their contention relates to the inability to view facial emotions. Perry (2012) also believed that facial expressions allow direct mentoring and monitoring of true emotions (p. 57).

Response to dissenters: Online here to stay? The master face to face classroom from previous centuries has likely come to an end. The Quillen (2012) response to dissenters is that “...developers of even the most sophisticated learning technologies insist their goal is to help make teaching a more efficient and effective profession, not a less relevant one" (p. 20). Online courses are likely to remain, and the technology will continue to advance. Researchers at the Language Technologies Institute at Carnegie Mellon University in Pittsburgh, are discovering the kinds of technologies that they "believe could aid even those more sophisticated tasks through natural-language processing, the science of how computers can interact with human language" (Quillen, 2012, p. 20).

Perceptions of instruction. The Zheng and Smaldino (2006) study explicitly focused on faculty perceptions and encouraged instructors to develop in the areas of "delivery technology" (p. 35). In another study, Zheng and Smaldino (2003) affirmed that 
faculty support for distance learners should "provid[e] frequent and adequate feedback" and understand "[s]tudent needs and limitations" (p. 158). According to Yang et al. (2004), one of the foremost apprehensions of teaching with technology is "How will effective communication and interaction be established with students in the absence of face to face instruction" (p. 847)? Zheng and Smaldino (2006) suggested that faculty should seek individualized, yet meaningful teaching stratagems to instruct academic materials online, although individual faculty pedagogy, style, delivery, and format may vary.

Beginning of virtual learning in 1728: Face to face and online. Amazingly, the 21 st century was not the first to introduce virtual learning environments. Teaching within a traditional face to face environment was a single-minded thought for centuries, until 1728. Conceivably, the first virtual learning experience was introduced by Caleb Phillipps, a Short Hand instructor. He is believed to be one of the first to offer lessons to students in a non-traditional milieu, dating back to March 20, 1728. He posted an advertisement in the Boston Gazette stating, "Teacher of the New Method of Short Hand," advising that any "Persons in the Country desirous to Learn this Art, may by having the several Lessons sent weekly to them, be as "perfectly instructed as those that live in Boston" (Bower \& Hardy, 2004, para. 6).

Now the 21 st century has developed advanced instructional technology tools that were unavailable, even unimaginable 30 years ago (Bower \& Hardy, 2004). Now faculty routinely utilize electronic tools including white boards, LED projectors, tablets, clickers, touch screen computers, streaming video, twitter, text, collaborate, and wireless telephone connections. 
According to Bower and Hardy (2004), a time machine might easily depict the classic scene of a college classroom, from centuries ago. For example, a familiar depiction is a professor behind or near the lectern, a neat row of desks, paper for notes, blackboard, chalk, and limited interaction between students and professor (Bower, et al. 2004). However, in today's learning environment, technology tools inundate the classroom. A continuous array of new technology products are used by students and faculty on campuses (e.g., laptops and iPads). One additional compelling didactic reason to promote online teaching is that online motivates shyer students to participate in dialogue, where the student is not being directly observed, unlike the classroom.

Facing the future. Online instruction has shifted face to face education away from institutions' traditional format and lecture hall connections, to global experiences in a matter of seconds. Since the emergence of the Internet, the definition of attending school has changed. Learning has become a stream flowing seamlessly throughout instructors and students daily lives, with the use of portable technology devices. Instructors may choose home, work, or play while continuously engaging in the pursuit of their educational objective.

Institute for the Future (IFTF) (2014) is a think tank which began as an academic discipline organized to essentially help organizations plan and promote future studies. One of IFTF's (2014) goals was to attempt to recognize patterns of things that are deriving and transforming. To this point, IFTF (2014) believes technology and learning future are "plural not singular" filled with variables and possibilities (p. 1). IFTF (2014) agrees that online education availability will help redesign higher education (p. 1). Also, IFTF (2014) agreed that the changing of the proverbial academic regiment will be the 
way of the future (p. 1). IFTF (2014) envisioned that one day online pedagogy may increase in momentum and force face to face education to "pass the baton and trade places' (e.g., online becomes the preferred choice over face to face educational programs). The question remains whether virtual access to online learning can save the world from the poverty of literacy. Arguments mount in favor of both platforms (face to face and online). Allegedly, face to face learning and attendance requirements can profoundly interrupt one's lifestyle. Differentiated from face to face pedagogy, online pedagogy can be viewed as less intrusive to family, recreational activities, and life events. Despite the above, McKenna (2013) argued that online education is a "predator to education" (p. 22). McKenna (2013) further argued that "the craft of teaching face to face is increasingly cornered, forced to justify its relevance in the face of its high tech replacement" (p. 22).

Furthermore, this dissertation study investigated a key concern among faculty and academic programs regarding their perception and usage of emotional intelligence in face to face and online interactions. Equally, this study focused on faculty from postsecondary institutions that are concerned with the future of digital learning. A goal of IFTF (2014) is to investigate "opportunities and resources for learners" in online and face to face environments. Recently, IFTF (2014) conducted an intricate survey of online educational environments. Similarly, the present investigation, examined the relationship between learners in face to face and online programs.

\section{Learning spaces and relationships improve learning and instruction.}

According to Brooks (2011), the "subject of learning spaces" (p. 719) should not be limited to structural or systematic spaces. Brooks (2011) suggested that dialogues must 
reach beyond conversations of mere physical places but must include the identification of "relationship between formal learning and student learning outcomes" (p. 719). Brooks (2011) argued that dialogues, conversations, and relationships will improve online “pedagogical approaches” (p. 720).

The present investigation explored the challenges and issues associated with face to face and online communication, as well as the interesting and often awkward manner in which faculty and students adapt to face to face and online constricted emotional meaning. Kremenitzer (2005) cautioned that emotional intelligence domains should be developed by "using a focused hyper-awareness strategy [sic] to reflect upon and ponder" (p. 4). Kremenitzer, (2005) study also produced the following private questions for teachers to consider for each emotional intelligence branch. Similar to the present study, Kremenitzer (2005) challenged individuals to "try and increase one's sensitivity" (p. 4) in and out of the learning milieu. Kremenitzer (2005) indicated that this type of "sensitivity can be considered being 'hyper-aware' of important details as one increases in skill”' (p. 4).

Often online and face to face non-verbal communications are loaded with opportunities to use emotional intelligence and emotional meaning. Kremenitzer (2005) endorsed instructors to learn to emotionally go to "a neutral place in order to keep on teaching in an effective manner" in order to get through negative moments in the professional environments (p. 8). But remaining in neutral, should not be a constant state. Instead, '[a] teacher with strong awareness of being able to 'go into neutral' can choose to use this as a 'teachable moment' by informing the class 'how he/she is choosing to respond at any given moment" " (Kremenitzer, 2005, p. 8). Senior, Howard, Reddy, 
Clark, and Lim (2012) stated that empirical evidence recommends that not only should faculty develop self-assessment skills but "that students should develop critical thinking skills" (p. 957) in professional learning environments. Yet, Senior, et al. (2012), similar to many theorists, struggled to respond to the question "of how best to measure naturalistic social behaviours performed by students" (p. 968) as the area of emotional intelligence remains under-explored.

Identity construction. Hanson (2009) argued that cyber learning environments can naturally deplete one's tangible "presence" (p. 553) and displace the knowledgeable “expert” (p. 553) when changing from face to face or online. Hanson (2009) suggested that cyber pedagogy will also change the nature of how faculties establish their identity in online or face to face professional learning environments (p. 553). Accordingly, the same process of establishing a professional identity in an online venue applies to students. Hanson (2009) warned that professional online users (e.g., instructors) may "experience a jolt to their "trajectory of self" " (p. 553) meaning that how one is viewed in a face to face milieu may be observed differently from an online setting. This occurrence is best explained by comparing instructor teaching and/or student learning experiences while engaged in online as an instructor or student.

The impact on academic identity is less understood than the impact of e-learning with instructor and students (e.g., teaching and learning experiences) (Hanson, 2009, p. 553). Virtual users, (e.g., instructors) must carve out new identities-when joining the newest entity of academic teaching and learning processes. Historically, knowledge and education were viewed as one of the most powerful tools for human advancement. 
For example, teaching for numerous years in a traditional face to face professional learning environment, may imply an established professional reputation also referred to as “one's identity." In contrast to the classroom, online instruction may require faculty to create new professional identities (e.g., presenting one's physical, emotional, and professional self to the cyber world of work). In view of that, faculty must adjust, modify, and rethink their online presence (e.g., (a) instructors - must introduce and present themselves as proficient instructors) and (b).students - must introduce and present themselves as dedicated students.

Online technology intrinsically demands that faculty consider different "analytical and pedagogical models" (p. 4) of teaching, apart from the usual instructional mode (Hallström \& Gyberg, 2011). The Comas-Quinn (2011) study suggested that "a new professional identity might not come easily to all” (p. 219). As such, the voice of faculty is not often recorded or as evident as the voice of students (Ellis, Goodyear, O'Hara, \& Prosser, 2007).

Online instruction may require faculty to transform ones teaching style. A second requirement and larger question becomes how instructor change, exchange, reform, recreate, and develop a new "self-identity" (Hanson, 2009, p. 554) apart from the traditional classroom. Hanson (2009) defined self-identity as "an individual's achievement built-up over a period of time, expressed as the 'trajectory of the self' that the individual gives voice through a coherent narrative about themselves" (p. 554). Giddens (1991) concurred with Hanson (2009) and further defined "self-identity" as a historical chronicle that is built over time through a progression of instinctive activities that constantly change the description in response to altered events and circumstances. 
Giddens (1991) and Hanson (2009) focused these reflexive underpinning and concurred that the foundation of "self-identity" are (1) ontological security (e.g., provides a sense of continuity and order in events) and (2) protective cocoon (e.g., "acts as barrier to perceived threats and which stands guard over the self in its dealings with everyday reality") (Hanson, 2009, p. 554).

Another theorist defined identity in three measures (a) discipline, (b) institution, and (c) professionally (Henkel, 2000). Several theorists, Becher and Trowler (2001); Hanson (2009); Harris (2005); Kinman, Jones, and Kinman (2006); Nixon (1996) agree with Henkel (2000) and they characterized the three parts of identity as (1) "disciplines" provide opportunities (e.g., social connections) for faculty to meet as a community (Becher \& Trowler, 2001; Hanson, 2009), (2) "institutional" pressures and demands (e.g., presentation and responsibility) for faculty to build company identities and to devote oneself to the organizational brand (Harris, 2005), and (3) "professional" cultural identities have declined according to Kinman, Jones, Kinman (2006), and faculty expressed a sense of isolation (e.g., from colleagues and organization) (Nixon, 1996). Nonetheless, faculty felt rewarded for being a part of the educational profession and witnessing students' progress.

Instructors transitioning from face to face instruction to cyber environments are required to modify their "skills and conceptions of learning and teaching" (Hanson, 2009, p. 556). The online paradigm shift in pedagogical formats includes a learning curve and new skills in (a) technology, (b) teaching dogmas (e.g., instructor-focused to students as "discoverers and constructors of knowledge" (p. 556), and (c) re-establishing an online identity. 
As the current culture continues to change from face to face to online, faculty experiences include (1) a decline in connectedness in academic culture, (2) a sense of remoteness from colleagues, and (3) a disconnect from the academic institution (Nixon, 1996). Hanson (2009) argued that emotionally, faculty are experiencing online tension and feelings of emotional challenges (p. 555) due to the mandatory "new approaches to higher education, which $\mathrm{r}[\mathrm{u}] \mathrm{n}$ counter to the myths and models that they valued" (Henkel, 2000, p. 217). Then again, a more progressive interpretation offered by Delanty (2008) denoted that faculty still have governance over their work, and that new protocols have increased identities of females and underrepresented groups (Clegg, 2008) in teaching and learning.

Now, cyber learning is growing into one of the most powerful learning products in the world. Gardner and Davis (2013) have linked the current generation of youth as deeply or completely involved with digital media. Gardner and Davis (2013) tagged today's youth as "The App Generation," meaning they are "app-dependent" versus "appenabled" (p. 10), and these authors depicted how life for the App Generation differed from life before the digital period. Gardner and Davis (2013) spoke of three vital concerns with adolescent life. Those three (each beginning with letter I) are referred to as: (a) identity, (b) intimacy, and (c) imagination (pp. 3, 5, 14). Similar to the concerns of this dissertation and the issues impacting face to face and online professional learning environments, Gardner and Davis (2013) uncovered the disadvantages of "digital learning" (p. 33). It is Gardner and Davis's (2013) opinion, that the three "I-s" have two sides (a) optimistic and (b) cynical. For the cynical, the first (identity) may exclude the development of identity, the second (intimacy) encourages shallow relationships with 
others, and the third (imagination) deflects from inspired imagination. In contrast, the optimistic benefits of the digital age can promote a strong sense of identity, allow deep relationships, and stimulate creativity. Gardner and Davis (2013) suggest that App end users must think and develop creatively. Ultimately, Gardner and Davis (2013) recommended how to best use digital tools to support development and creativity.

In this instance, identity is defined as an individual's personal view, in cyber space (Gardner \& Davis, 2013, p. 161), and for the purposes of this dissertation, it will also include one's individual view, portrait, or silhouette of oneself in face to face professional environments. Additionally, Gardner and Davis (2013) expressed concerns that digital Apps have emotional power and that worldviews have influenced, shaped, and placed limits:

with respect to identity, there is pressure to present oneself as an impressive, desirable kind of person and to make sure that all signs (and postings) confirm that perhaps precociously crystallized sense of identity. Similarly, with respect to intimacy, the capacity to announce-indeed, to define---one's connections to other persons may preclude fuller exploration, with its heightened vulnerability but also with greater potential for deep and continually evolving relations with truly significant others. Finally, and on a more positive note, with respect to imagination and creativity, digital technologies afford enormous potential for individual or group 
breakthroughs---provided that the existing apps are treated as

approaches to be built upon (allowing us to be app-enabled),

rather than ones that constrict or constrain one's means

and one's goals (causing us to become app-dependent)

(Gardner \& Davis, 2013, p. 161).

The purge and surge of STEM and Social Science IFTF (2014) made an audacious statement "the illiterate of the $21^{\text {st }}$ century will not be those who cannot read and write, but those who cannot learn, unlearn, and relearn" (Toffler, 2014, as cited in IFTF, 2014, Educational institutions to learning flows p. 1). The use of technology is considered an important aspect in Social Science and STEM education. The present dissertation objectives are to effectively explore, in a beginning way, some of the limited issues, trends, and patterns related to emotional intelligence and pedagogy in Social Science and STEM. Although many universities are taking the lead on how and when to integrate face to face and online courses in Social Science and STEM professional learning programs, the decision remains challenging. Some faculties in professional programs have argued that all courses are not suited for online delivery. The determination must be made (1) which course(s) are adaptable to online and (2) which courses can enhance or harm learning experiences. According to Institute for the Future (IFTF, 2014), the answers to these questions point to transformation.

Changing from traditional "educational institutions to learning flows is profound and disruptive, and no existing institution will have the luxury of remaining unchanged" predicted Institute for the Future (IFTF) (2014) (p.1). Such transformation require faculty and institutions "to rethink all of the assumptions, structures, and principles" (IFTF, 
2014, p. 1) normality and familiarities of the past. To this, McKenna (2013) replied, "unfortunately, many professors across the country are being pressured or required to do e-teaching” (p. 24). Driscoll (2001) believed that technology should be used for its power to "facilitate, even transform teaching and learning..." (p. 335). As far as this logic is concerned, Driscoll (2001) stated "only by using technology in a transformative way will student[s] themselves come to realize the potential of technology and begin to develop ever more powerful uses and applications" (p. 335).

Social science and technology: Possibilities and hope. Cyber spaces (e.g., online and hybrid programs) emerged as a promise to support higher education institutions' goals to seek new ways of maintaining, increasing, and attracting talent. Perhaps, professional learning programs can benefit from using business prototypes (e.g., product, place, price, and promotion) to thrive in the economic market changes. Recently, the Chronicle of Higher Education published an article titled, "Why Professors at San Jose State Won't use a Harvard Professor's MOOC” Kolowich (2013). The Social Science philosophy faculty at San Jose State wrote a letter of dissent, refusing to instruct from the Eduventures (edX), Massive Open Online Course (MOOC) (e.g., online course format). In this instance, MOOC represented (e.g., a taped lecture widely distributed for large lecture hall use by a Harvard University professor). The resistance was emotional and passionate as the letter detailed their rationale to encourage public dialogue.

San Jose State administration affirmed that faculty would have options and that the college "would never impose or mandate these teaching methods on faculty members" (Kolowich, 2013, “Why Professors at San Jose State Won't use a Harvard Professor's MOOC, ” para.12). Nonetheless, San Jose State's Philosophy Department 
faculties are concerned about "the future" and are not convinced technology will not replace "faculty with cheap online education" (Kolowich, 2013, "Why Professors at San Jose State Won't use a Harvard Professor's MOOC, ” para. 13). Yet, administration at San Jose State indicated that, “...collaboration with edX does indeed locate the responsibility for the course solely with our faculty members, who will determine how much, or how little, of the edX course materials they will incorporate into their blended courses” (Kolowich, 2013, “Why Professors at San Jose State Won't use a Harvard Professor's MOOC, " para. 12).

Super stars not wanted. According to McKenna (2013), the future of face to face instruction may resemble a forced venture (p. 22). Some instructors are reluctant as they watch the future unfold in face to face (e.g., teaching and learning) and as the future materializes in online formats. Online instructional transformation is here for Social Sciences and STEM professional programs, but "some faculties are not taking this lying down” (McKenna, 2013, p. 22). For example, faculty at San Jose State Philosophy Department wrote a letter with the intent to "spark a public conversation about the consequences that can result when superstar professors work with edX and other MOOC providers" said Hadreas chair of the Philosophy Department at San Jose State.

Eventually, McKenna (2013) believed that the permanent arrangement of "a Massive Open Online Course (MOOC) platform cooperating with the best instructors, universities and knowledge-based companies to democratize education" (p. 22) is bound to transpire. Regardless of the future of education, both face to face and online will be met with opposition and challenges. 
MOOC resistance pointless? McKenna (2013) did not believe that faculty or students, for that matter, will have a choice, and he has little regard or trust in the future and direction of face to face and online education. Therefore, McKenna (2013) pressed that opposition or "resistance is futile" (p. 22). He further questioned, whether democracy exists (p. 22). Similar to McKenna (2013), others believe that online and face to face exchange is a movement that is senseless to fight against, because the surge will occur in education (e.g., against online and face to face interactive and connected services).

Quality. In the end, San Jose faculty were allowed to decline teaching the philosophy course developed by edX, (e.g., edX's JusticeX is a sequence of video recorded lectures that included responses and commentaries from Harvard students). Clearly, San Jose faculties were "saying they do not want to enable what they see as a push to 'replace professors, dismantle departments, and provide a diminished education for students in public universities" (Kolowich 2013, "Why Professors at San Jose State Won't use a Harvard Professor's MOOC, ” para. 1). Although, San Jose State administrators reiterated that the institution's intentions were to allow faculty members to maintain autonomy of their courses regardless of experimentation with edX materials, San Jose State Philosophy Department faculty adamantly stated, "we believe that having a scholar teach and engage with his or her own students is far superior to having those students watch a video of another scholar engaging his or her students" (Kolowich, 2013, “Why Professors at San Jose State Won't use a Harvard Professor's MOOC, ” para. 4). Another concern with MOOC is the potential influence to further extend the educational division between wealthy universities, and less affluent ones. Finally, San Jose State is not the only educational program to oppose outside provider technical intervention 
(Kolowich, 2013, “Why Professors at San Jose State Won't use a Harvard Professor's $M O O C$ ”). For now, San Jose State Philosophy Department faculty announced that they are not opposed to revisiting the issue of distance education (Kolowich, 2013, “Why Professors at San Jose State Won't use a Harvard Professor's MOOC”). However, faculty passionately pleaded and "feared that maintaining high quality might not be a top priority” (Kolowich, 2013, “Why Professors at San Jose State Won't use a Harvard Professor's MOOC, " para. 9) as university and system administrators navigate budget constraints.

STEM and technology: A perfect combination? There are many reasons some colleges, instructors, and students are against MOOC (Massive Open Online Course) deals. For now, the idea of integrating technology into science, technology, engineering, and math programs may seem like a natural fit. The Kolowich (2013) article discussed, “Why Some Colleges Are Saying No to MOOC Deals, at Least for Now”.

The partnership between STEM and technology, is a perfect fit for some. Talbert's (2014) article “Blending and Flipping Modern Architecture” discussed the method of teaching STEM courses in various technology platforms (a) blended, (b) hybrid, (c) online, or (d) face-to-face. Talbert's (2014) flipped model represented delivering substantial lectures via short videos and classroom. Although grand challenges may await mathematics, the impact appears to be powerful, "extremely difficult but doable” (Talbert, 2014, “Grand Challenges for Mathematics Education,” para. 1). A major parameter that Talbert (2014) added is a similar argument that earlier researchers presented. Mathematics should be "grounded in sound pedagogical research" (Talbert, 2014, “Grand Challenges for Mathematics Education,” para. 3). 
Along with advocating for the use of Mathematics in a flipped model, Talbert (2014) identified several "grand challenges for mathematic education" (Talbert, 2014, "Grand Challenges for Mathematics Education," para. 1) (a) materials and research should be free (e.g., open to the public) whereby (b) learners should not be required to obtain membership (e.g., higher education programs or journal). Talbert (2014) challenged educational learning environments to make a revolutionary change to become an open accessible discipline. In sum, Talbert (2014) put forward four opinions: “(1) Create a complete open-source curriculum for high school and early college mathematics, (2) Create a complete set of statistically-validated concept inventories for all K-12 mathematics subject areas, (3) Using the concept inventories developed in the number two, replicate the study by Richard Hake at all levels of K-12 mathematics and in university courses at the calculus level and below, and (4) Create an online repository for preprints in mathematics education" (Talbert, 2014, “Grand Challenges for Mathematics Education," para. 3). Additionally, Talbert (2014) reported that flipped classrooms may have future implications in engineering and calculus education programs.

In the above article titled Why Some Colleges Are Saying No to MOOC Deals, at Least for Now, an article in The Chronicle discussed faculties' disapproval of integrating MOOC technology into STEM programs (Kolowich, 2013). Similarly, Amherst College argued against implementing MOOC Eduventures (edX) courses on campus in an article in The Chronicle titled Why Professors At San Jose State Will Not Use a Harvard Professor's MOOC (Kolowich, 2013). Ultimately, Amherst College did not join. To the surprise of MOOC founders, the unprecedented line-up of colleges expediently vying to participate with the "high-profile" (Kolowich, 2013, "Why Some Colleges Are Saying No 
to MOOC Deals, ” para. 2) conglomerates run by Eduventures (edX), a nonprofit founded by Harvard University, appeared unprecedented (Kolowich, 2013).

MOOC founders mocked that higher education institutions are not known for making expedient executive decisions, but academia is “...notorious for its tortoise like reflexes” (Kolowich, 2013, “Why Some Colleges Are Saying No to MOOC Deals,” para.

2). To this point, Eduventures (edX) observed a rapid increase of higher education institutions joining Eduventures (edX) but noted "often with little input from faculty members" (Kolowich, 2013, “Why Some Colleges Are Saying No to MOOC Deals," para. 2). However, Amherst College faculties' dissent represented one of the few educational learning environments, invited to participate in MOOC, to include their faculty in the decision making process. Amherst College's resistance to impose an executive decision upon its faculty represented a shift from other professional learning cultures. Thus, Amherst College leadership (a) included faculty and (b) permitted the crucial decision to be "decided by a faculty vote" " (Kolowich, 2013, "Why Some Colleges Are Saying No to MOOC Deals," para. 3).

Inverted classrooms in humanities or social sciences. Statistically, MOOC reported "massive online courses have grown from side projects of a few techie professors into companies fueled by tens of millions in venture capital funds and the imagination of the entire education industry" (Kolowich, 2013, “Why Some Colleges Are Saying No to MOOC Deals, " para. 4). Universities (e.g., instructors) can develop their own courses, but it was noted that (a) instructors spent 100 hours or more in development, (b) eight to 10 hours weekly, and (c) the additional time is draining on normal campus responsibilities (Kolowich, 2013). MOOC membership is not free, and 
universities must pay to play (Goldstein, 2013). Some higher education institutions are concerned with MOOC Eduventures (edX):

(1) base membership rate is $\$ 250,000$

(2) distracting from teaching and service

(3) breeding and unknown and newfangled competitor

(4) jeopardizing smaller colleges

(5) selling large student data to external industries

(6) placing unwarranted emphasis on credentialing (Kolowich, 2013, “Why Some Colleges Are Saying No to MOOC Deals, ” paras. 8, 11, 13, and 14).

Largely, Amherst College contentions were not based on fiscal concerns, demonstrated by their "\$1.64-billion endowment," nevertheless the focus was on its own institution's “philosophical qualms” (Kolowich, 2013, “Why Some Colleges Are Saying No to MOOC Deals," para. 12), which included Amherst's obligation to "learning through close colloquy" with students (Kolowich, 2013, "Why Some Colleges Are Saying No to MOOC Deals, ” para. 12). Amherst faculty committee worries addressed MOOC's presence far beyond their personal borders, but as gatekeepers for the greater academe community. For example, the Amherst faculty feared that MOOC may (a) " "enable the centralization of American higher education' and (b) 'create the conditions for the obsolescence of the B.A. degree' " (Kolowich, 2013, “Why Some Colleges Are Saying No to MOOC Deals, ” para. 13).

A geology professor from Amherst College portended that the "risk to remaining on the sidelines is higher than the risks of joining up" (Kolowich, 2013, "Why Some Colleges Are Saying No to MOOC Deals, " para. 16) explicating that being on the inside 
would grant greater access to steering change of education's new ways of instruction (e.g., "flipped classrooms and online videos - that is within reach") (Kolowich, 2013, “Why Some Colleges Are Saying No to MOOC Deals," para. 18). Yet, another STEM professor from biology and neuroscience disciplines motion was against joining MOOC groups. The outcome vote for Amherst College was 70 opposed to 36 in favor to edX membership, with five abstentions (Kolowich, 2013). In the end, Amherst College exemplified "a healthy change in the way a leading institution might approach the question of how to incorporate online education into its curriculum" (Kolowich, 2013, “Why Some Colleges Are Saying No to MOOC Deals,” para. 19). To Amherst College credit, a deeper thinking occurred "in a way that they wouldn't have a few years ago" (Kolowich, 2013, “Why Some Colleges Are Saying No to MOOC Deals,” para. 20).

The Association of Public and Land-Grant Universities expressed concerns for public universities facing economic challenges, (a) Whether public universities can afford to invest with MOOC organization? (b) Will public universities recoup from such costly investments? and (c) Whether public universities can remain sustainable in the presence of MOOC (Kolowich, 2013)? Nonetheless, the future of online and face to face will be tested by the unraveling of unknown questions and transformations, in Social Science, STEM, face to face, and online courses. Professional learning organizations may ponder one applicable question, Which Social Science or STEM disciplines are more suited to face to face or online courses?

\section{Conclusion}

Digital learning is still a developing phenomenon which makes this study unique in two categories. The first approach attempted to explore and merge innovative concepts 
of emotional intelligence and virtual professional learning in two well established longstanding concepts (Social Sciences and STEM programs). The next approach linked teacher and student, with these two respected disciplines noted above (Social Sciences, and STEM programs). The information and evidence collected from this present study contributed to emotional intelligence's developing field. A main impetus of this study is to help faculty improve face to face and online interaction (e.g., Urtel, 2008; Georgouli, Skaldidis, \& Guerreiro, 2008).

In a beginning way, the provisional view and outcome of the present data evaluated several questions:

(1) Does emotional intelligence have educational value?

(2) Is emotional intelligence theory suited to the educational context?

(3) Does emotional intelligence inquiry have coordinated, blended, and integrated value for education?

(4) Does emotional intelligence conceptualization contribute, develop, and clarify faculty interactions in face to face and online instruction?

The present dissertation study encouraged faculty to consider their past and present emotional experiences in professional learning settings. Faculty documented reflections and concerns generated additional controversial issues. Also, faculty PUEI Perceptions of Using Emotional Intelligence in classroom formats and themes emerged from their perceptible responses.

The advent of new technology in professional learning environments is demanding the attention of educational systems to acquire and learn information that improves both face to face and online learning platforms. During the course of this present study, faculty Perceptions of Using Emotional Intelligence PUEI were examined. 
Although, face to face venues are generally physically oriented, traditional formats often use hybrid and virtual technology tools, to interact in and out of the learning environment. For example, face to face professional learning environments offer faculty the option to: (1) alternate between traditional office hours contrasted to virtual office hours or chat room; (2) teacher may physically interact before, during, and/or after class in lieu of virtual email; (3) teacher are physically present in the classroom: (4) clicker technology tools are used to respond to in-class questions posed by the instructor; and (5) finally a shared apparatus of films on demand which is an advantage in both settings, allowing films to be presented immediately in the physical classroom or virtually anywhere the Internet connection is available.

Theorists continue to explore emotional intelligence in spite of measurement challenges, particularly as emotional intelligence relates to education. "Emotional Intelligence may be foundational to developing competencies that lead to improved psychological health and teaching success and, in turn, positive student outcomes" (Vesely, Saklofske, \& Leschied, 2013, p. 71). Perhaps, the present study complicated and challenged the world of academia, by presenting responses documented from instructor experiences over multiple years of teaching and studying. Specifically, this study assessed online and face to face issues that concerned instructors during the course of the semester.

This dissertation explored empirical questions for "digital natives" and "digital immigrants" (Prenksy, 2001, p. 1). A "digital native" is an individual that grew up with Internet access. A "digital immigrant" is an individual that did not grow up with Internet access. A "digital native" is comfortable with constructing online relationships, 
connections, and virtual identities, compared to a digital immigrant needing to make technology adjustments. Gardner and Davis (2013) described the new App Generation as passionately involved with digital media in their new publication The App Generation: How Today's Youth Navigate Identity, Intimacy, and Imagination in a Digital World.

What challenges do instructors face, and how do they deal with these challenges?

What are the hopes and desires that are not reflected in face to face and online learning venues? What is the long-term role of emotional intelligence in teaching and learning experiences of pedagogy?

The results of this dissertation study may remain inconclusive as it relates to measurement of emotional intelligence. However, information gathered from this mixed method study (quantitative and qualitative) may suggest the significance of the two professional milieus. Additionally, the feedback from this study may inform investigators of emotional intelligence interactions and reactions. Further implications may provide validation for future studies about emotions and intelligence of face to face and online pedagogy.

Costs, convenience, and chance. Academic institutions have been greatly impacted by the digital world. Most institutions have begun to completely revamp the settings and practices of how instructors teach and students learn, but did they have a choice? The introduction of cybernetic (e.g., online) methodology is a dramatic deviation from face to face instruction. Largely, the flexibility to meet beyond the classroom walls has reduced the physical and economic requirements of traveling to a physical space. Nonetheless, classes are still meeting face to face, in rooms with desks and a live 
professor. Even in such a classroom environment, some high end technology tools are likely to exist.

The digital world has revamped how instructors teach and how students learn. The flexibility to meet beyond the classroom walls reduces the physical and economic requirements of traveling. In this respect, online learning is especially useful for students who, for reasons of work, family, or social commitments, require a different way of accessing learning (Díaz \& Entonado, 2009; Jeffcoat \& Golek, 2004). Additionally, strong considerations are the research information and learning opportunities available online from library databases (e.g., articles, journals, and books).

The emotional intelligence leaders have provided a haven for emotional quotient, but on-going exploration, development, and accountability should be scrutinized. Based on the opinion of most theorists, emotional intelligence will continue to develop as longitudinal studies are conducted. Scientists are eager to discover the true definition of emotional intelligence.

Teaching faculty who are committed to promoting virtual instruction are often convinced that online courses indeed offer perks, and believe that online tools and venues offer the greatest opportunity for students to learn. As previously mentioned in the Blake (2000) and McKenna (2013) studies, there exists a population of teachers who prefer face to face as opposed to online. Similarly, students and faculty may prefer to teach or complete their professional studies in an online format.

Online is viewed by some as a competitor to face to face instruction and has been referenced by many names (e.g., progressive or unconventional). Bejus (2013) promulgated that the move to online is not due to its vast superiority. Online offers fiscal 
advantages in educational programs. Accordingly, online courses may be viewed as a resourceful alternative to face to face (a) long standing, (b) highly esteemed, or (c) well regarded teaching method. Moreover, Bejus (2013) believed that online instruction may be the final step toward devastation of interpersonal relations (face to face). McKenna (2013) posited that culture and expertise of teaching in face to face environments will soon erode as "more students are logging in [and] more teachers are checking out" due to "predatory pedagogy" (p. 22). 


\section{Chapter 3}

\section{Method}

This study aims to examine the use of emotional intelligence by higher education instructors in face to face and online pedagogy, in Social Sciences and STEM professional learning environments. The purpose of this basic research is "to contribute to the fundamental knowledge and theory" of emotional intelligence (Patton, 2002, p. 213) or another way of stating the purpose "is knowledge for the sake of knowledge" (Patton, 2002, p. 215). As such, doctoral students are usually expected to make hypothetical contributions (p. 215) and accordingly, "theories encapsulate the knowledge of a discipline" (p.215).

The study evaluated faculty professional experiences while engaged in online and face to face instruction in professional learning environments. Faculty critiqued and described their individual experiences in online and face to face instructional venues. The research question is What are Faculty Perceptions of Using Emotional Intelligence in Pedagogy or Andragogy? Ultimately, the survey and interview were used to inquire and learn about essential context within online and face to face unique to faculty. Therefore, this investigation attempted to understand faculty perceptions of using emotional intelligence in STEM, Social Sciences, online, and face to face settings.

\section{Design}

A mixed-method plan involved quantitative and qualitative procedures. The quantitative measures included the participants' evaluative ratings of emotional intelligence concepts as used in online and face to face settings. The qualitative measures included the participants' evaluative ratings of experiences and issues of emotional 
intelligence concepts as experienced in online and face to face settings. Together, the quantitative and qualitative instruments facilitate understanding of the four branch hierarchy of (a) Perceiving Emotions, (b) Facilitating Thought, (c) Understanding Emotions, and (d) Managing Emotions.

The measurement modes included (a) interviews with faculty, (b) surveys rated by faculty, and (c) a collection of artifacts in the form of syllabi from both online and face to face environments (Appendix J). Interview questions consisted of emotional intelligence constructs, how emotional intelligence was reported in face to face courses, how emotional intelligence was reported in online courses, the role of emotional intelligence in STEM, and the role of emotional intelligence in Social Sciences. These all had reference to professional learning milieus, higher education institutions, or general academia. For example, emotional intelligence questions covered topics such as:

(1) Does emotional intelligence have educational value?

(2) Is emotional intelligence theory suited to the educational context?

(3) Does emotional intelligence consider the coordinated, blended, and integrated value of educational systems?

(4) Does emotional intelligence conceptualization contribute, develop, and clarify faculty and student interactions in face to face and online instruction?

(5) Has online technology become a liability or an asset for instructors and students?

(6) Can materials transition between face to face and online formats?

(7) Are higher education institutions taking pedagogy processes for granted?

(8) What are some of the challenges that will remain as status quo in teaching venues?

(9) Are both master class (traditional face to face) and newer online formats (virtual cyber) maintaining value in pedagogical settings? 
(10) What remains to be ascertained between/about face to face and online program methodology in relation to emotional intelligence?

This study adds to the limited amount of existing research regarding faculty perceptions in face to face, and in online instruction. Additionally, it informs us about what we do not know about the use of emotional intelligence in higher education, among faculty and students, in Social Sciences, and in STEM programs. The present investigation attempted to explore and develop our understanding of issues pertinent to teaching in specialized programs (Social Sciences and STEM) that interface with face to face and online methodology. Also, this study reports findings from (a) faculty and (b) their innovative methods in teaching and learning in both milieus. The survey questionnaire contained 38 statistical items and the interview contained 17 semi-structured questions.

\section{Participants}

The study examined "What are Faculty Perceptions of Using Emotional Intelligence in their Instruction, Face to Face and Online, Pedagogy and Andragogy in Professional Learning Environments?" Twenty higher education instructors, with online and face to face teaching experience, were recruited to participate in a forty-five minute to one-hour interview session with the investigator. Participants were contacted via email, telephone, and/or face to face communication. The principle investigator invited them to participate in this research. Recruitment for the study began in January 2015 and ended in March 2015.

Prior to the study, West Virginia University's Internal Review Board (IRB) process and procedures were followed and approval obtained. The information for study participants was distributed and confidential releases were obtained from each participant 
(Appendices B, C, D, and E). They were informed of the voluntary nature of this quantitative and qualitative (mix-method) study. The 20 study participants (20 faculty) had at least one year experience teaching online and face to face (instruction and learning) at post-secondary institutions within the United States.

Faculty were recruited from East $(\mathrm{N}=6)$, West $(\mathrm{N}=1)$, South $(\mathrm{N}=10)$, North $(\mathrm{N}=1)$, and Mid-West $(\mathrm{N}=2)$ regions of the country and invited to participate in this investigation. The study represented fourteen universities and colleges across the United States (e.g. Central Michigan University, California State University, College of Idaho, Community College of Beaver County, Embry-Riddle Aeronautical University, Indiana Wesleyan University, University of Charleston, Utah Valley University, and West Virginia University).

The instructors recruited were female and male university or college instructional personnel, (instructors, assistant professors, associate professors, or professors) who taught courses in both venues (face to face and online). Participants were identified by their experience and employment at higher education settings. Individual participants were identified by referral and contacted via telephone, email, office visit. Next, the investigator determined participants' goodness of fit by their agreement to complete the survey, interview, and provide syllabi. Once an agreement was established, dates and times to complete the protocol were partially elected by the participant at their convenience.

\section{Data Assemblage}

Surveys (quantitative). As noted, this study investigated a limited sample of $(N=20)$ higher education faculty with experience instructing and/or learning in both face 
to face and online mediums. The survey consisted of a 38-item questionnaire. Individual faculty perceptions examined the role of emotional intelligence in interactive technology instruction as compared to traditional face to face teaching.

The Kremenitzer (2009) sixteen instrument scale was selected for its correlation to Mayer and Salovey (1997) four branch Emotional Intelligence model (See Table 1). 


\section{Table 1}

Kremenitzer (2005) Faculty Self-assessment

\section{Branch One: Perception, Appraisal, and Expression of Emotion}

Questions to ponder:

- Am I good at identifying how I am feeling?

- Am I good at identifying how my students are feeling?

-Would most people I know consider me to be perceptive regarding my emotional state and theirs?

- Am I able to notice when my students are angry, sad, bored, etc.?

-What can I begin to do to increase my perception of emotions?

\section{Branch Two: Emotional Facilitation of Thinking}

Questions to ponder:

- Am I good at identifying emotional swings in myself and in others?

- Am I able to counsel myself in delaying important decisions if I am in a negative state?

- Do I try to do creative and interesting projects when I am in a highly positive and motivated state?

- Can I also identify optimal times for my students to work on certain projects?

Write down your current appraisal of yourself regarding the abilities found in "branch two" and what you think you might do to increase your abilities here.

\section{Branch Three: Understanding and Analyzing Emotions}

Questions to ponder:

- Am I good at finding the right word(s) to use to express my feelings?

- Can I help my students to use words appropriately to express themselves both at positive and negative times?

- Am I good at understanding what causes children to feel and behave in a certain way?

- Am I good at reminding myself about the different developmental stages and that sometimes students act in a more "mature" or "immature" manner and to see the "whole child" in perspective and not just an isolated event?

\section{Branch Four: Reflective Regulation of Emotions}

Questions to ponder:

- Am I good when I am "caught off-guard" and good at responding to an unexpected event?

- Am I able to self-regulate my behavior even under very difficult circumstances?

- Can I model good self-regulation for my students and use this as a "teachable moment" for how they could similarly regulate in the future? 
As such, Kremenitzer (2009) provided written permission for the use of the Kremenitzer four branch emotional intelligence itemized scale and instrument originating from Mayer and Salovey (1997) four branch emotional intelligence concepts. The Kremenitzer four branch constructs were modified for the purposes of this study investigation (Table 1).

Typical quantitative rating scales range from 1 to 5 . For this study, the semi-structured interviews will inform the survey to explore this study's question of "What are Faculty Perceptions of Using Emotional Intelligence in Pedagogy and Andragogy?" Descriptive statistics used in this investigation reported the basic findings and data collected from this study's exploration of faculty perceptions of using emotional intelligence online and in face to face venues. The basic "nominal level data" and findings from Mayer and Salovey (1997) four branch model of emotional intelligence theory: (a) Perceiving Emotions, (b) Facilitating Thought, (c) Understanding Emotions and, (d) Managing Emotions proved appropriate for reporting online and face to face frequencies and percentages from this present examination (Morgan, et al., p. 23). For example, the descriptive measure allowed this examination to assess the differences between faculty perceptions online and face to face, in STEM and Social Science courses. The means and variance reported the "estimate relationships" among the variables (e.g. among participant data and questionnaire items). The semi-structured interviews informed the surveys related to participant proportion, complexity, and the ultimate results. Overall, the present study reported some frequencies, percentages, mean, and standard deviation in chapter four (e.g. tables). 
The survey items were created from the Qualtrics survey platform and software tool. The survey questions related to Mayer and Salovey (1997) emotional intelligence theory's four branch constructs (see Appendix I). Using a five point Likert scale (e.g. Strongly Disagree, Disagree, Neither Agree nor Disagree, Agree, and Strongly Agree) the higher the number, the higher the emotional capacity to perceive, facilitate, understand, and manage emotions. Analyses can assist in understanding the significance of emotional intelligence by following the empirical direction of emotional intelligence and its impact in learning. Respondents were expected to think about their emotional intelligence acumen in teaching, interaction, and problem solving abilities. As Gardner (1993) and Mayer and Salovey (1997) suggested, one might consider the ability approach, which is focused on emotional problem solving. The study identified how the above factors are related among the four branches and the perceptions and influences of emotional intelligence online and in face to face courses.

A descriptive statistical survey and analysis provided the means and standard deviations. For this study, descriptive information from participants was used with supplementary tables, since the conditions to report were too numerous to report efficiently in the upcoming results section in chapter four. The descriptive statistics mainly reported and measured this study's central tendency (e.g. means) and variance (e.g. standard deviation). The central tendency information (e.g. means) provided an easy way to identify the values being linked between Mayer and Salovey (1997) emotional intelligence four branch model. Basic information and results from this survey investigation helps efficiently display tables (e.g. comparing proportions and type to 
individual responses) and means (e.g. individual faculty perceptions being assessed and compared).

Morgan, Reichert, and Harrison (2002) suggest when using Descriptive statistics and tables, "that it is important to report the data in sufficient detail to both justify the conclusions and allow inspection of the data" (p. 20). Descriptive information is reported in this study in the nature of text, tables, and nominal proportion of graphs. The integration of descriptive statistics in this study (e.g. tables and minimal graphs) provided supplemental details on the findings and conclusion of this investigation, "What are Faculty Perceptions of Using Emotional Intelligence in Pedagogy and Andragogy?" Additionally, the supplemental descriptive data allowed this investigator to graphically communicate, clarify, and proliferate information. The Mayer and Salovey (1997) four branch model (e.g., capacity to perceive, facilitate, understand, and manage emotions) was used to explore faculty perceptions in online and face to face professional environments. Data were collected from semi-structured online questionnaires and surveys. The descriptive statistics (means and standard deviation) survey component provided relevant data based upon the question in this survey, "What are Faculty Perceptions of Using Emotional Intelligence in Pedagogy and Andragogy?" The descriptive statistics assisted in sorting out and "piecing together" significant information and data reported by participants in their experiences online and in face to face (p. 21). According to Morgan et al. (2002) the size and sophistication of a study matters, when figuring whether descriptive information can be provided. This study's population size was limited to 20 participants. Participating faculty were more than generous with their time and information sharing and one hundred per cent participation in both 
semi-structured interviews and survey.

Once faculty confirmed their participation they were provided with consent forms, electronic survey link via email. Instructors completed the survey before proceeding to the final protocol steps of syllabi collection and interviewing. As such, 20 participants (faculty) completed the survey and interviews, resulting in $100 \%$ response rate. Due to a scale discrepancy and technical error, the researcher recontacted the original 20 participants and requested them to re-submit the 38 item survey responses. In the end, within a span of less than three days, 19 of the original participants responded and completed a second survey. The final participant responded and completed their survey a few days later after returning from abroad. The investigator credits the participants' professionalism and consideration of the research process for their $100 \%$ participant completion.

Interview (qualitative). Twenty cases are presented which reflect similar and different examples of how faculty responded to, utilized, their approaches or emotions, particularly "phenomenon small or large" (Merriam, 2009, p. 177) or their sense of emotional intelligence during online and face to face pedagogy or andragogy. Therefore, it is recognized that, because of the limited size of the sample, these results may not be representative of broader practice and beliefs. The participants' examples were carefully selected, as they represent the most collective responses discovered among the small sample. They are also presented as examples of the many different ways by which emotional intelligence is perceived and used in academia.

The qualitative data for this study were collected from semi-structured in-depth, open ended interviews, survey, and documents. Patton (2002) defined interviews as 
“open-ended questions and probes yield in-depth responses about people's experiences, perceptions, opinions, feelings, and knowledge. Data consist of verbatim quotations with sufficient context to be interpretable" (p. 4). In this dissertation, semi-structured interviews were used to yield direct quotations from faculty about their "experiences, opinions, feelings, and knowledge" (Patton, 2002, p. 4). Additionally, "document analysis" was collected from 20 participants, and the investigator studied the quotations and open-ended written responses to questionnaires and surveys (Patton, 2002, p. 4).

Patton (2002) described documents as "written materials and other documents from organizational, clinical, or programs records; memoranda and correspondence; official publications and reports; personal diaries, letters, artistic works, photographs, and memorabilia; and written responses to open-ended surveys. Data consist of excerpts from documents captured in a way that records and preserves context" (Patton, 2002, p. 4). For this study, qualitative findings will be presented in combination with quantitative data. According to Patton (2002) "a questionnaire or interview that asks both fixed-choice (closed) questions and open-ended questions is an example of how quantitative measurement and qualitative inquiry are often combined" (Patton, 2002, p. 5).

"The quality of qualitative data depends to a great extent on the methodological skill, sensitivity, and integrity of the researcher" (Patton, 2002, p. 5). Therefore, skillful interviewing involved much more than the researcher asking questions. The interviewing process involved establishing a genuine rapport with participants. The investigator had several conversations with various participants prior to the interview. Perhaps, Patton (2002) would view this as a way to establish trustworthiness, since the single most important component in qualitative research is the investigator (p. 167). The investigator 
viewed information and materials obtained from participants as proprietary, and made efforts to be professionally resourceful, responsive, and supportive to participant inquiries and special requests (e.g. letter of research participation, etc.).

The interviews were conducted using a 17-item semi-structured interview schedule. The semi-structured interview schedule was developed by the researcher from the pilot study emerging themes and the 17 -item semi-structured questions were mainly categorized in Mayer and Salovey (1997) emotional intelligence four branch model. The semi-structured questions addressed why and how the participants felt about using emotional intelligence in andragogy or pedagogy, their perceptions of online and in face to face, and their experiences and reflections of emotional intelligence use in their classes or higher educational institutions. The following represent two questions from the 17- item semi-structured interview: (1) Whether Emotional Intelligence has educational value in institutions of higher education? (2) What challenges do academicians face that would validate the use or support of emotional intelligence when communicating and interacting in academe?

Using Merriam (2009) "purposeful sampling method" a total of 20 participants were invited to participate in the survey and interview process. This study aimed to explore, realize, and gain insight into the cyber world of pedagogy by "select[ing] a sample from which the most can be learned" (Merriam, 2009, p. 77). Of the 20 participants, their reported years of instruction ranged substantially from $(N=35)$ to seasoned $(N=5)$ teaching online and in face to face environments. According to Patton (2002), purposeful sampling offers "information -rich[ness] and are "those from which one can learn a great deal about issues of central importance to the purpose of the 
inquiry" (Patton, 2002, p. 230). Therefore, semi-structured interviews indicated the faculty specific levels of their unique awareness, competence, and capability in their pedagogy.

Patton (2002) warned researchers that "perfectionism breeds imperfections" (p. 437). According to Patton (2002) researchers often struggle when attempting to perfectly duplicate methodological thought procedures (p. 433). Also, Patton (2002) believed that "the human factor is the great strength and the fundamental weakness of qualitative inquiry and analysis---a scientific two-edged sword (p. 433). However, this investigator attempted to use good judgment, create useful comments, and utilize creativity. This study collected large amounts of data and analyzed substantial quantities of transcribed data. The researcher reduced the volume of raw information by "sifting trivia from significance" by categorizing noteworthy patterns (Patton, 2002, p. 432). Additionally, this researcher aimed to build a context for connecting the heart of what the data revealed, and looked to tell the participant's story with assiduous detail.

This investigator conducted semi-structured interviews with participants. Individual semi-structured interviews were digitally transcribed, typed, and printed in hard copy format from Microsoft Word and Windows 8 operating system. Early in the data collection process, participants' formal names were reassigned to pseudonyms. Participants' cases illustrated faculty diverse experiences and outcomes during their online and in face to face instruction. Participants told their story as faculty members experiencing online and face to face instruction and day to day issues with students. Respondent's stories provided concentrated, rich explanation for this qualitative analysis and reporting. Through in-depth case study descriptions, participants' expressed their 
understanding of advantages and disadvantages experienced online and/or in face to face course instruction.

According to Patton (2002) "the challenge of qualitative analysis lies in making sense of massive amounts of data" (p. 432). In the present research, this investigator reviewed transcripts in a private, quiet office space. Overall, this investigator combined, analyzed, and categorized participants' responses. Next, in the present research, the researcher tested and observed emerging themes, while writing annotations regarding what was learned. Often this process involved adding a new question based upon participants' shared experiences, which outlined their online and/or face to face experiences with students.

In an attempt to tell the participants' story and make sense of hundreds of pages of data, this investigator began by reading one transcript at a time, followed by another until all were reviewed. The researcher next began the iterative steps to determine how, what, and where to start decoding the discoveries of data from this examination. One example of coding began with the researcher constructing 17 categories based on matching questions and responses. Respondents' replies from question one were combined from 20 participants, reviewed, re-read, and combined, searching for emerging themes. Respondents' replies from question two were combined from 20 participants, reviewed, re-read, and combined, searching for emerging themes. Ultimately, the remaining questions were correlated, coded by association, and this iterative process was repeated. To reiterate, several rounds of coding the semi-structured interview questions occurred. In general, all semi-structured interview questions one to seventeen were combined by question number. 
Patton (2002) suggested creating a system that identifies "paradigm motifs" (p.432). For this study, themes emerged and were created and developed by this researcher. A theme identifying process was developed and informed via the researcher's separate memorandums, comments written in margins, and summarized data. The first set of semi-structured interview data consisted of memos which helped the investigator capture thoughts, initiate themes, and concepts. From these potential notable occurrences derived the second round of semi-structured interviews, which were compared to the first set of semi-structured interviews. The third round of data collected were compared to the second, the fourth round of data collected were compared to the third, and ongoing. Merriam (2009) argued that continued comparisons tend to "inform the next round of data collection" (p. 170). But, special attention was paid to this iterative process, impact, and effectiveness of questions in the subsequent rounds. The qualitative findings from the study assessed faculty reactions and also attempted to demonstrate the significance of this facet of review, ground the discussion, and consecutively address the problem.

Previously developed analytic semi-structured interview questions helped to focus this study's purpose and summarize each participant's data. After careful review of the data sets, the investigator chose five major questions which interconnected the three data sets (e.g. survey, semi-structured interview, and content analysis). The investigator continuously looked for emerging themes among the three sets of data. The analysis process was iterative, redundant, as well as time consuming. This study included several iterative rounds of comparing the data from two disciplines (e.g. STEM and Social Science). Overall, the semi-structured interview analysis included: 
(1) Data collection

(2) Data analysis

(3) Decoding data

(4) Managed Data

The above four steps represent: (1) data collection required collecting and integrating from three areas (e.g. survey, semi-structured interview, and content analysis); (2) data analysis involved reviewing the purpose of the study to combine, analyze, and categorized participants' responses; (3) decoding data process involved reading and rereading collected data in order to identify themes and report findings; and (4) managed data were kept in three secure locations for protection, security, and loss prevention.

Overall, this researcher endeavored to adequately "represent the data and communicate what the data reveal[ed] given the purpose of the study" (Patton, 2002, p. 433). Moreover, Patton (2002) posited that missing information and unanswered questions should equally be considered significant to the study's responses and/or used for future exploration.

Selection process. To begin this study participants were selected from Science, Technology, Engineering, and Mathematic (STEM) and Social Sciences disciplines to participate in the survey and interview process. Participants were required to meet the following requirements: (a) 18 years of age or older, (b) have past or current experience teaching online and face to face at a higher educational institution, (c) willing to sign a consent form, (d) complete a survey, and (e) respond to interview questions.

The participants determined the physical location and setting for their interviews (e.g. whether the semi-structure interviews were face to face or another electronic 
option). Individual semi-structured interviews were private, began with an ice breaker, introduction of the research purpose, and a brief informational exchange. Interviews were digitally recorded, transcribed, analyzed, and rated. The interviewee's responses and comments were recorded verbatim, and the researcher made every possible attempt to maintain the integrity of this investigation and the confidentiality of each participant. Comments were not edited or paraphrased to make the findings more satisfactory. Participants' private information shared during the interview and on the survey will be protected and deleted after the expiration of IRB protocol. The semi-structured interviews were categorized by Mayer and Salovey (1997) four branches of Emotional Intelligence, from the perception of respondent's (faculty) instruction in their online and face to face teaching (see Appendix A).

Participants' received a pre-solicitation letter, formal solicitation letter, and a written consent form, prior to the interview. The consent form and relevant documents requested permission to electronically record the interview, for the purposes of this study and potential publications. Additionally, all interview transcripts were manually transferred to personal external hard drives. This process reaffirmed that participants identity will remain protected and confidential.

Therefore, 40 percent of the semi-structured interviews $(N=8)$ were conducted over the telephone and 60 percent of the semi-structured interviews $(N=12)$ were conducted in person (interviewer with interviewee). Interviews lasted between thirty to sixty-five minutes.

At the end of the study each participant received a formal letter of participation and a five dollar complimentary gift card from Starbucks Corporation coffee company. 
Two participants declined the letter of participation, but accepted the complimentary gift card and two different respondents declined the complimentary gift card, but accepted the letter of participation. As such, 20 participants (faculty) completed the semi-structured interviews, resulting in $100 \%$ response rate.

The individual interviews were transcribed verbatim. The transcribed data were downloaded to memory cards. The data were analyzed using Ethnograph 6.0 Qualitative Data Analysis Software content analysis (Merriam, 2001, p. 88; Patton, 2002, pp. 248, 452) and involved: (a) open coding where each line of text was read and abbreviated with either one word or expression and (b) interpretation and analysis where the investigator looked for a logical and epitomizing themes. The next step was conducted simultaneously while reviewing the frequency of the context of the interviewee's perception, experience, and knowledge obtained from the recipient.

Trustworthiness and authenticity stratagems (Merriam 2006; Patton 2002) were employed to reinforce the rigor of the data composed and analysis phases which included: (1) rich, concentrated descriptions where themes are supported by participant's verbatim quotes within the context of this studies design, (2) typicality or modal category where faculty were compared with others from similar professional environments, and (3) despite the limited participant proportion a multisite designs was employed (Merriam 2006, p. 198; Patton, 2002, p. 51). Therefore, several higher educational institutions were recruited for breadth and diversity in the phenomenon of interest, which provided a greater range of situations and perceptions for this limited study.

Stake (1994) urged investigators to respect that "Qualitative researchers are guests in the private spaces of the world. Their manners should be good and their code of ethics 
strict" (p. 244). Regardless of the method, risks and benefits are a part of the interviewing process. Merriam (2001) reminded researchers that ethical dilemmas are often present in qualitative researchers that "respondents may feel their privacy has been invaded, they may be embarrassed by certain questions, and they may tell things they had never intended to reveal. In-depth interviewing may have unanticipated long-term effects" (p. 214) while some "interview may improve the condition of respondents" (p. 214).

During data collection, the examiner considered the risks and benefits to participants. The investigator adhered to ethical protocol by reminding participants of the voluntary nature of the study, treated participants with professionalism and prompt communication, respondent's decisions were respected and valued. The investigator made every attempt to cautiously adhere to Patton (2002) argued "that the interviewer's task is first and foremost to gather data, not change people (p. 405). The investigator should not be judgmental or offer therapeutic advice nor behave as "a cold slab of granite - unresponsive to the human issues, including great suffering and pain, that may unfold during an interview" (p. 405). To this point, this investigator made every effort to be sensitive to critical information revealed during a participant's interview.

Content analysis triangulation. Patton (2002) stated that "the term triangulation also works metaphorically to call to mind the world's strongest geometric shape-the triangle (e.g., the form used to construct geodesic domes a` la Buckminster Fuller)” (Patton, 2002, p. 247). According to Patton (2002) the expression triangulation is inspired from land surveying terminology. This study was strengthened through the triangulation method where three separate data sources were used. The final side of the triangle for this study was content analysis of participant syllabi (Appendix J). This content analysis 
included two digital typed syllabi from each participant representative of one online and one face to face course. Syllabi were measured in a limited manner, but served as a significant analytical tool in joining the survey and interview questions together for this investigation. Communication of meaning, as well as observing the emergence of themes from the survey and interview responses, were the focus.

The content analysis (syllabi) in this examination focused more on discovering "themes and recurring patterns of meaning" (Merriam, 2009, p. 205). Some advantages noted regarding content analysis as one unit of measure for this study centered on:

(1) Communication

(2) Frequency

(3) Variety of messages

(4) Number of times a certain phrase or speech pattern used (Merriam, 2009, p. 205).

In contrast, some disadvantages noted regarding content analysis review as one unit of measure for this study included:

(1) Challenging and time consuming

(2) Incomplete information and limited access to additional content

(3) Restricted data on insight into participants thinking

(4) Lost opportunity to gather more reliable and valid data

Patton (2002) suggested "establishing a set of guid[ing] questions" for analyzing and reviewing raw data from each individual source (p. 452). The three sources in this dissertation study included quantitative, qualitative, and content analysis documents (syllabi). The researcher integrated information from three sources producing a triangular 
study exploring how faculty incorporated their $P U E I$ online and in face to face instruction. Moreover, three sources of information were used to cross-validate whether syllabi data matched two areas (quantitative/survey and/or qualitative/interview). This researcher independently reviewed the material in each case attempting to critique and interpret the content and meaning. The syllabi collected were previously used by this study's participants either in prior semesters or in the current semester.

Likewise, this study considered whether content analysis substantiated faculties' PUEI among the three data collection methods. Three substantive questions with subcategories were compared and weighed:

(1) Whether participants' PUEI principles were evident in their syllabi online and face to face course? For example, do the syllabi reveal, show, demonstrate, engagement with students, or offer opportunities for students to connect with instructors?

(2) Whether participants' syllabi are representative of faculty surveys, interviews, and PUEI.

(3) Whether participants' syllabi language, semantic, content, assignments, communication style, were inviting and/or supportive?

The method used to analyze syllabi content for this study began by analyzing individual survey scores, survey text responses (Appendices $\mathrm{G}$ and $\mathrm{H}$ ), as well as interview responses. Then, survey and interview responses were analyzed and matched with the content analysis (e.g. syllabi) in a repeated, yet limited cycle of analysis. A thorough review of the syllabi was conducted to determine course outline, regularity, and appearance of specific elements in the syllabi text, which reflected or resembled survey and interview responses. As such, the iterative process was constantly utilized in order to 
link syllabi, survey, and interview responses. For example, if a participant scored high on specific survey question(s) (four or better), the survey branch question was compared to a closely matched interview question and syllabi content. The objective of each repetition or iteration was to discover whether individual syllabi content matched the participant's survey and interview responses. Moreover, the intention was to determine if the survey, interview, and syllabi content responses were consistent and/or parallel.

Overall, the syllabi analysis was completed after the survey questionnaire report was scored, interview questions were transcribed, and separately reviewed. As such, the syllabi analysis compared questions from the survey and interview responses. The categories were defined and separated by questions/responses, purposes, frameworks, organizations, and results.

The survey inquiries were mainly developed from Mayer and Salovey (1997) four branch model, matching on a five point Likert scale. However, a second way to explain how the syllabi content was analyzed and compared to the survey and interview questionnaires included analyzing the survey results from the Descriptive Statistics measures outcome (e.g. frequency, means, standard deviation, and t-test). The syllabi content analysis were measured specifically from interview and survey questions. Again, the iterative process analyzed four branches by matching survey and interview questions, to determine patterns.

As previously noted above, respondent comments were a result of twenty interviews from this three tier study. The triangulation occurred in this investigation between content analysis (e.g. syllabi), survey responses, and interview questionnaire. By comparing cases and group responses, the iterative process was performed continuously. 
This dissertation study analyzed the syllabi content using quantitative measures of the descriptive frequency scores from the participants $P U E I$ in their online and face to face interaction with students. In order to measure the significance of a respondent's idea or measure the participant's linkage to the survey, interview, or content analysis syllabi, the investigator analyzed the number of times that particular items were used, and the number of contexts in which items appeared in the syllabi. Content analysis was used as a way to study the contents of the syllabi. Also, content analysis was used to determine if these four branches of emotional intelligence skills and systematic framework were practiced in each series of responses from quantitative and/or qualitative study on faculty PUEI.

Therefore, the qualitative study used (a) Semi-structured open ended interviews, (b) Document analysis of course material, and (c) Triangulation across participant perspective. This point is significant because the triangulation allowed the investigator in a limited way to:

(1) Assess participants with similar experiences

(2) Place syllabi in categories

(3) Compare participant data to other participants, etc.

(4) Triangulate course artifacts

To this end, this research intended to discover awareness, intentions, and interests behind PUEI particularly to demonstrate how faculty responses shaped their interaction online and in face to face instruction. This syllabi content analysis investigation aimed to show how faculty $P U E I$ online and in face to face can potentially produce a linear message. The detailed examination of content analysis document by this researcher did 
not include additional instructional materials. Instead, this detailed examination measured participants' PUEI from quantitative, qualitative, and individual syllabi, as documenting record and evidence of respondents' instruction or engagement.

To attempt to reduce bias or unwarranted conclusions, the researcher reviewed and analyzed whether six areas of the syllabi were comprehensive and characterized participants survey and questionnaire responses (e.g. language, semantic, content, assignments, communication style, and invitation to engage). For this study triangulation suggests evidence of potential relationships between survey, interview (e.g. online, face to face) and syllabi components were evident. For this investigation, some suggested connections of triangulations indicated that students met with instructor (e.g., online and in face to face - office visit, chatroom, discussion board, etc.). Therefore, the importance of triangulation can best be demonstrated by various modes of data collection. 


\section{Chapter 4}

\section{Results}

This chapter presents the findings from three data sets (a) survey items, (b) semi-structured interviews, and (c) a limited review of content analysis (e.g., syllabi) collected from participants. The survey will be presented in four sections (a) Descriptive statistics, (b) Delivery format, (c) Gender, and (d) Disciplines. The interview will be presented in four sections (a) Branch I The capacity to accurately perceive emotions (Perception, appraisal, and expression of emotion), (b) Branch II The capacity to use emotions (Emotional facilitation of thinking), (c) Branch III The capacity to understand emotions (Understanding and analyzing emotions), and (d) Branch IV The capacity to manage emotions (Reflective regulation of emotions). The third section of the chapter four reports results from the content analysis collected.

Table 2 results are displayed horizontally representing survey, interviews, and content analysis (e.g., syllabi). Survey used descriptive statistics and $t$-tests to analyze and report branches individually. Semi-structured interviews were coded, analyzed, and digitally transcribed from Microsoft Word and Windows 8 operating system. The branch questions were mainly composed from Mayer and Salovey (1997) and Kremenitzer (2009) emotional intelligence scales. A few questions were developed by the investigator. Content Analysis (e.g., syllabi) were coded for content and Emotional Intelligence Communication (E.I. Communiqué). E.I. Communiqué content represents analysis of PUEI actions, interactions, events, occurrences, trends, and instances of communication that occurred during online and face to face instruction. 
Table 2

Concept Organizer/Data Reduction Coding for survey, interview, and content analysis

\begin{tabular}{lccl}
\hline Branch Type & $\begin{array}{c}\text { Survey } \\
\text { Questions }\end{array}$ & $\begin{array}{c}\text { Interview } \\
\text { Questions }\end{array}$ & $\begin{array}{c}\text { Content Analysis } \\
\text { (Syllabi) }\end{array}$ \\
\hline Branch I & $1-12$ & $1-3$ & E.I. Communiqué \\
Branch II & $13-16$ & $4-7$ & E.I. Communiqué \\
Branch III & $17-24$ & $8-10$ & E.I. Communiqué \\
Branch IV & $25-38$ & $11-17$ & E.I. Communiqué \\
\hline
\end{tabular}

Concept organizer and data reduction coding. Table 2, represents 38 survey questions constructed using a Likert scale (a) Branch I The capacity to accurately perceive emotions (Perception, appraisal, and expression of emotion), contains $N=12$ survey questions, $N=11$ of which were paraphrased from Kremenitzer (2009), and $N=1$ question developed by this investigator, (b) Branch II The capacity to use emotions (Emotional facilitation of thinking), contains $N=4$ survey questions and $N=1$ question developed from the Kremenitzer (2009) study, (c) Branch III The capacity to understand emotions (Understanding and Analyzing Emotions, contains $N=8$ survey questions paraphrased from the Kremenitzer (2009) study, and (d) Branch IV The capacity to manage emotions (Reflective Regulation of Emotions), contains $N=14$ survey questions, $N=6$ of which were paraphrased from the Kremenitzer (2009) study, and $N=8$ questions were developed by this investigator.

Table 2 represents 17 semi-structured interview questions (a) Branch I The capacity to accurately perceive emotions (Perception, appraisal, and expression of emotion) contains $N=3$ semi-structured interview questions, (b) Branch II The capacity to use emotions (Emotional facilitation of thinking) contains $N=4$ semi-structured interview questions, (c) Branch III The capacity to understand emotions (Understanding 
and Analyzing Emotions contains $N=3$ semi-structured interview questions, (d) Branch IV The capacity to manage emotions (Reflective Regulation of Emotions) contains $N=7$ semi-structured interview questions.

Table 2 represents syllabi questions organized by (a) Branch I The capacity to accurately perceive emotions (Perception, appraisal, and expression of emotion), syllabi questions organized by (b) Branch II The capacity to use emotions (Emotional facilitation of thinking), syllabi questions organized by (c) Branch III The capacity to understand emotions (Understanding and Analyzing Emotions, and syllabi questions organized by (d) Branch IV The capacity to manage emotions (Reflective Regulation of Emotions).

Table 2 syllabi column emotional intelligence communication content (E.I. Communiqué Content) represents analysis of PUEI actions, interactions, events, occurrences, trends, and instances of communication that occurred during online and face to face instruction. Syllabi were analyzed to reinforce and verify survey and interview responses. Syllabi represented respondents' online and face to face course interaction. Syllabi coding and analysis were examined to verify participants $P U E I$. Ultimately, survey, interview, and syllabi questions were matched by branches and divided by category.

\section{Survey}

Demographics. Each participant $(\mathrm{N}=20)$ completed both surveys and interviews. Table 3 shows the nine female and eleven male participants from Science, Technology, Engineering, Mathematics and Social Sciences disciplines. Twelve participants were interviewed face-to-face and eight were on the phone. 
Table 3

Descriptive Statistics: Branch I - The Capacity to Accurately Perceive Emotions

\begin{tabular}{lccccc}
\hline & Female & & Male & $\begin{array}{c}\text { Participants by } \\
\text { Discipline }\end{array}$ & $\begin{array}{c}\text { Participant Interviews: } \\
\text { Telephone versus (Live) }\end{array}$ \\
\cline { 2 - 3 } \cline { 5 - 6 } & & & & \\
\hline STEM & $4(20 \%)$ & & $5(25 \%)$ & $9(45 \%)$ & $5(6)$ \\
Social Sciences & $5(25 \%)$ & & $6(30 \%)$ & $11(55 \%)$ & $3(6)$ \\
Totals & 9 & 11 & 20 & 20 \\
\hline
\end{tabular}

The majority of participants (75\%) self-reported their ethnicity as White $(N=15)$, of which $35 \%$ were females $(N=7)$ and $40 \%$ were male $(N=8)$; followed by $05 \%$ Afro Caribbean $(N=1)($ male $(N=1)$; and $15 \%$ reported their ethnicity as African American/Black $(N=3)$ of which $67 \%$ were female $(N=2)$ and $33 \%$ were male $(N=1)$; and finally, of the overall $20, .05 \%$ did not identify $(N=1)$.

Survey responses were analyzed in a statistical program (SPSS). Using Descriptive statistics, participant responses were analyzed categorically by measuring respondent's Perception of Using Emotional Intelligence herein referred to as PUEI in terms of each individual Branch, Branch I, Branch II, Branch III, and Branch IV. Individual branches are described as Branch I the capacity to accurately perceive emotions (Perception, appraisal, and expression of emotion), Branch II The capacity to use emotions (Emotional facilitation of thinking), Branch III The capacity to understand emotions (Understanding and Analyzing Emotions), and Branch IV The capacity to manage emotions (Reflective Regulation of Emotions). Each Branch represents Mayer \& Salovey (1997) Emotional Intelligence model. The following section presents the findings from the survey in terms of overall descriptive statistics for each branch. 
Overall descriptive statistics. Table 3, Table 4, Table 5, and Table 6 report the descriptive statistics for 38 items of the questionnaire, including the mean, standard deviation, range, minimum, and maximum values for each item in each Branch.

The first Branch and category Perceiving Emotions is a rudimentary Emotional Intelligence skill which requires one to have awareness of ones' own and the feelings of others' in order to accurately assess and synthesize the world around you. This item (Table 4) measured faculty's overall perception of their awareness of their own feelings, their students' feelings, and the faculty's ability to correctly evaluate and synthesize online and face to face professional environments. 
Table 4

Descriptive Statistics: Branch I - The Capacity to Accurately Perceive Emotions

\begin{tabular}{|c|c|c|c|c|c|}
\hline Survey Branch I Average Branch I Tabulated & $M$ & $S D$ & Range & Min & Max \\
\hline \multicolumn{6}{|l|}{ (Perception, Appraisal, and Expression of Emotion): } \\
\hline $\begin{array}{l}\text { I am good at identifying how my students are feeling in } \\
\text { online courses? }\end{array}$ & 3.55 & .68 & 2 & 2 & 4 \\
\hline $\begin{array}{l}\text { I am good at identifying how my students are feeling in } \\
\text { face to face courses? }\end{array}$ & 4.40 & .59 & 2 & 3 & 5 \\
\hline $\begin{array}{l}\text { I am good at identifying how I am feeling in online } \\
\text { instruction? }\end{array}$ & 4.30 & .65 & 2 & 3 & 5 \\
\hline $\begin{array}{l}\text { I am good at identifying how I am feeling in face to face } \\
\text { instruction? }\end{array}$ & 4.50 & .51 & 1 & 4 & 5 \\
\hline $\begin{array}{l}\text { Most...consider me good at identifying how I am feeling } \\
\text { during online instruction? }\end{array}$ & 3.75 & .85 & 3 & 2 & 5 \\
\hline $\begin{array}{l}\text {...consider me good at identifying how I am feeling } \\
\text { during face to face instruction? }\end{array}$ & 4.00 & .85 & 3 & 2 & 5 \\
\hline $\begin{array}{l}\text { I am able to make emotional connections with my } \\
\text { students regardless of my instructional venue? }\end{array}$ & 3.90 & .64 & 3 & 2 & 5 \\
\hline $\begin{array}{l}\text { Most people I know consider me to be perceptive } \\
\text { regarding my emotional state and theirs? }\end{array}$ & 4.25 & .63 & 2 & 3 & 5 \\
\hline $\begin{array}{l}\text { I am able to notice when my online students are angry, } \\
\text { sad, bored etc.? }\end{array}$ & 3.50 & .88 & 4 & 1 & 5 \\
\hline $\begin{array}{l}\text { I am able to notice when my face to face students are } \\
\text { angry, sad, bored etc.? }\end{array}$ & 4.45 & .51 & 1 & 4 & 5 \\
\hline $\begin{array}{l}\text { I am interested in increasing my online perception of } \\
\text { emotions? }\end{array}$ & 4.40 & .59 & 2 & 3 & 5 \\
\hline $\begin{array}{l}\text { I am interested in increasing my face to face perception } \\
\text { of emotions? }\end{array}$ & 4.25 & .91 & 3 & 2 & 5 \\
\hline
\end{tabular}

Source: Kremenitzi (2005) Branch I: Statistical Analysis for Survey Questionnaire

The second Branch and category Using Emotions to Facilitate Thought skill is an ability which requires one to think for more effective problem-solving. This item (Table 5) measured faculty's perception of using emotions to facilitate their thinking and the faculty's ability to correctly evaluate and synthesize online and face to face professional environments. Mayer and Salovey (1997) pointed out that emotions place human thoughts in hierarchical ranking. In other words, pressing emotions command our 
attention when "the person matures, emotions begin to shape and improve thinking by directing a person's attention to important changes" (Salovey \& Sluyter, 1997, p. 12).

Table 5

Descriptive Statistics: Branch II - The capacity to use emotions to facilitate thought

\begin{tabular}{|c|c|c|c|c|c|}
\hline \multirow{2}{*}{\multicolumn{6}{|c|}{$\begin{array}{l}\text { Survey Branch II Average Branch II Tabulated } \\
\text { (Emotional Facilitation of Thinking): }\end{array}$}} \\
\hline & & & & & \\
\hline $\begin{array}{l}\text { I am good at identifying emotional swings } \\
\text { in myself and in others? }\end{array}$ & 4.10 & .55 & 2 & 3 & 5 \\
\hline $\begin{array}{l}\text { I am able to counsel myself in delaying } \\
\text { important decisions if I am in a negative } \\
\text { state? }\end{array}$ & 4.05 & .88 & 3 & 2 & 5 \\
\hline $\begin{array}{l}\text { I try to be creative and work on interesting } \\
\text { projects, when I am in a highly positive } \\
\text { and motivated state? }\end{array}$ & 4.35 & .58 & 2 & 3 & 5 \\
\hline $\begin{array}{l}\text { I am able to identify optimal times for my } \\
\text { students to work on certain projects? }\end{array}$ & 3.80 & .61 & 3 & 2 & 5 \\
\hline
\end{tabular}

The third Branch and category Understanding Emotional Meaning require calibration and thought adjustment so "that cognitive tasks make use of emotional information" (Mayer, Salovey, Caruso, \& Sitarenios, 2001, p. 235). According to Salovey and Sluyter (1997) individuals have a greater chance of understanding a situation when they are able to produce "emotions on demand" (p. 12). They further proposed that this allows in the moment "inspection of the feeling and its characteristics" (p. 12). Another item (Table 6) measured individual's ability to connect emotional information, maneuver, guide, and steer information to augment thoughts (Mayer, Salovey, Caruso, \& Sitarenios, 2001). Mayer, Salovey, Caruso, and Sitarenios (2001) also asserted that this (understanding emotions) relationship involves intelligence and personality, and "the first hallmark of intelligence is abstract reasoning" (p.233). 
Table 6

Descriptive Statistics: Branch III - The Capacity to Understand Emotional Meaning

\begin{tabular}{|c|c|c|c|c|c|}
\hline Survey Branch III Average Branch 1 Tabulated & $\mathrm{M}$ & SD & \multicolumn{3}{|r|}{$\mathrm{Ma}$} \\
\hline (Understanding and Analyzing Emotions): & & & & & \\
\hline $\begin{array}{l}\text { I am good at finding the right word(s) to use to express my } \\
\text { feelings in online? }\end{array}$ & 4.05 & .60 & 2 & 3 & 5 \\
\hline $\begin{array}{l}\text { I am good at finding the right word(s) to use to express my } \\
\text { feelings in face to face? }\end{array}$ & 4.20 & .52 & 2 & 3 & 5 \\
\hline $\begin{array}{l}\text { I can help my students to use words appropriately to } \\
\text { express themselves both at positive and negative times } \\
\text { online? }\end{array}$ & 3.80 & .69 & 3 & 2 & 5 \\
\hline $\begin{array}{l}\text { I can help my students to use words appropriately to express } \\
\text { themselves both at positive and negative times face to face? }\end{array}$ & 3.95 & .60 & 2 & 3 & 5 \\
\hline $\begin{array}{l}\text { I am good at understanding what causes students to feel } \\
\text { and behave in a certain way in online? }\end{array}$ & 3.60 & .82 & 3 & 2 & 5 \\
\hline $\begin{array}{l}\text { I am good at understanding what causes students to feel } \\
\text { and behave in a certain way in face to face? }\end{array}$ & 3.95 & .75 & 2 & 3 & 5 \\
\hline $\begin{array}{l}\text { I am good at reminding myself about the different } \\
\text { developmental stages and that sometimes students act in a } \\
\text { more "mature" or "immature" manner at times. I see the } \\
\text { "whole [person]" in perspective and not just an isolated } \\
\text { event online? }\end{array}$ & 3.80 & .76 & 3 & 2 & 5 \\
\hline $\begin{array}{l}\text { I am good at reminding myself about the different } \\
\text { developmental stages and that sometimes students act in a } \\
\text { more "mature" or "immature" manner at times. I see the } \\
\text { "whole [person]" in perspective and not just an isolated } \\
\text { event in face to face? }\end{array}$ & 4.00 & .79 & 3 & 2 & 5 \\
\hline
\end{tabular}

Source: Kremenitzi (2005) Branch III: Statistical Analysis for Survey Questionnaire

The fourth Branch Capacity to Manage Emotions managing emotions means among other things, that one must juggle several emotions at once (Table 7). Emotions need supervising, distinguishing, and tagging. Mayer, Salovey, and Caruso (2004) stated that our emotions provide us with useful information, but if useful information is discounted, we may end up making poor choices. Mayer and Salovey (1997) state that 
reflective thinking "encourages a process of personal investigation" (p.16)...related to a "person's own politics, ethnicity, and other characteristics" (p.16). 
Table 7

Descriptive Statistics: Branch IV - The Capacity to Manage Emotions

\begin{tabular}{|c|c|c|c|c|c|}
\hline Survey Branch IV Average Branch IV Tabulated & $\mathrm{M}$ & SD & Range & $\begin{array}{l}\mathrm{Mi} \\
\mathrm{n}\end{array}$ & Max \\
\hline \multicolumn{6}{|l|}{ (Reflective Regulation of Emotions): } \\
\hline $\begin{array}{l}\text { I am good when I am caught off-guard and } \\
\text { responding to unexpected events online? }\end{array}$ & 3.55 & 1.05 & 3 & 2 & 5 \\
\hline $\begin{array}{l}\text { I am good when I am "caught off-guard" and } \\
\text { responding to unexpected events in face to face? }\end{array}$ & 3.58 & 1.01 & 3 & 2 & 5 \\
\hline $\begin{array}{l}\text { I am able to self-regulate my behavior even under } \\
\text { very difficult circumstances online? }\end{array}$ & 4.25 & .44 & 1 & 4 & 5 \\
\hline $\begin{array}{l}\text { I am able to self-regulate my behavior even under } \\
\text { very difficult circumstances in face to face } \\
\text { courses? }\end{array}$ & 3.95 & .75 & 3 & 2 & 5 \\
\hline $\begin{array}{l}\text { I can model good self-regulation for my students } \\
\text { by using face to face issues as "teachable } \\
\text { moments?" }\end{array}$ & 4.10 & .71 & 3 & 2 & 5 \\
\hline $\begin{array}{l}\text { I can model good self-regulation for my students } \\
\text { by using online issues as "teachable moments?" }\end{array}$ & 3.85 & .81 & 3 & 2 & 5 \\
\hline $\begin{array}{l}\text { It is important for faculty to be aware of } \\
\text { emotional sub-text in their words/tone online? }\end{array}$ & 4.70 & .47 & 1 & 4 & 5 \\
\hline $\begin{array}{l}\text { It is important for faculty to be aware of } \\
\text { emotional sub-text in their words/tone in face to } \\
\text { face? }\end{array}$ & 4.70 & .47 & 1 & 4 & 5 \\
\hline $\begin{array}{l}\text { I am able to maintain emotional equilibrium and } \\
\text { awareness online? }\end{array}$ & 4.30 & .57 & 2 & 3 & 5 \\
\hline $\begin{array}{l}\text { I am able to maintain emotional equilibrium and } \\
\text { awareness in face to face? }\end{array}$ & 4.10 & .71 & 3 & 2 & 5 \\
\hline $\begin{array}{l}\text { It is important for instructors to extend } \\
\text { consideration when students experience personal } \\
\text { difficulties in face to face and online? }\end{array}$ & 4.30 & .65 & 2 & 3 & 5 \\
\hline $\begin{array}{l}\text { It is important for students to extend } \\
\text { consideration when instructors experience } \\
\text { personal difficulties in face to face or online? }\end{array}$ & 4.05 & .94 & 3 & 2 & 5 \\
\hline $\begin{array}{l}\text { I purposely engage with students to develop } \\
\text { emotional and personal connections with } \\
\text { students in face to face? }\end{array}$ & 3.90 & .91 & 3 & 2 & 5 \\
\hline $\begin{array}{l}\text { I purposely engage with students to develop } \\
\text { emotional and personal connections in online? }\end{array}$ & 3.80 & 1.10 & 4 & 1 & 5 \\
\hline
\end{tabular}

Source: Kremenitzi (2005) Branch IV: Statistical Analysis for Survey Questionnaire 
Table 8 represents average tendencies of participant survey responses and perceptions of using emotional intelligence PUEI measuring the means and standard deviation scores. Cronbach's Alpha measure of internal reliability indicated results from measures are acceptable.

Table 8

Descriptive Statistics of Perception of Using Emotional Intelligence PUEI Scores across Branch Types $(N=20)$

\begin{tabular}{llll}
\hline Branch Type & Mean & SD & $\begin{array}{l}\text { Cronbach } \\
\text { Alpha }\end{array}$ \\
\hline Branch I & 4.10 & .442 & .857 \\
Branch II & 4.07 & .459 & .617 \\
Branch III & 3.91 & .420 & .742 \\
Branch IV & 4.10 & .423 & .805 \\
\hline
\end{tabular}

Overall, descriptive statistics allows us to report that participants PUEI scored highest in their ability to accurately perceive emotions and manage emotions. Means 4.10 (.442) for Branch I and 4.10 (.423) Branch IV respectively, indicating that the means were the same but the $S D$ was slightly different. The second highest PUEI measure reported was participant's Branch II capacity to use their emotions means 4.07 (.459) respectively. The final PUEI score was Branch III Capacity to understand emotions reported the lowest PUEI mean scores in their ability to understand emotional meaning $\mathrm{M}=3.91$ (.420) respectively. Overall, Branch I and IV were equal. $\mathrm{M}=4.10(.423)$ respectively.

The following sections present the findings from the survey in terms of the differences across branches related to variables including delivery format, gender, and discipline. 
Delivery format. Table 9 represents average tendencies of participant PUEI

mean and standard deviation scores across Branch I, Branch III, and Branch IV for online and face to face settings.

Table 9

Descriptive Statistics of Emotional Intelligence (EI) Perception Scores across Branch Types (Online/Face to face) $(N=20)$

\begin{tabular}{lcc}
\hline Branch Type & Mean & SD \\
\hline Branch I Online & 3.90 & .55 \\
Branch I Face & 4.32 & .47 \\
Branch II & -- & -- \\
Branch III Online & 3.8 & .45 \\
Branch III Face & 4.02 & .50 \\
Branch IV Online & 4.07 & .49 \\
Branch IV Face & 4.07 & .45 \\
\hline
\end{tabular}

Note. -- Indicates Branch II survey question did not reference the terms online and face to face.

Paired $t$-tests were conducted to see the differences between faculty's perception online and perception in face-face settings (Table 10).

Table 10

Descriptive Statistics and Paired t-test Results for Branch I, Branch III, and Branch IV (online and face to face)

\begin{tabular}{lcccccccc}
\hline & \multicolumn{2}{c}{ Online } & & \multicolumn{2}{c}{ Face-to-Face } & & \multicolumn{2}{c}{ Sig } \\
\cline { 2 - 3 } & $\mathrm{M}$ & $\mathrm{SD}$ & & $\mathrm{M}$ & $\mathrm{SD}$ & $\mathrm{t}$ & $\mathrm{df}$ & (2-tailed) \\
\hline Branch I & 3.90 & .55 & & 4.32 & .47 & $-3.57^{*}$ & 19 & .002 \\
Branch III & 3.81 & .45 & & 4.02 & .51 & -2.06 & 19 & .053 \\
Branch IV & 4.09 & .50 & & 4.07 & .46 & .17 & 18 & .864 \\
\hline$* p<.05$ & & & & & & & &
\end{tabular}

A significant difference was found in terms of Branch 1-capacity to accurately perceive emotions. The mean score of faculty's perception on their capacity to accurately perceive emotions in online settings $(M=3.90, S D=.55)$ was significantly lower than in 
face to face settings $(M=4.32, S D=.47)\left(t=-3.57^{*}, \mathrm{df}=19, N=20, \mathrm{p}<.05\right)$. The mean scores in Branch II online were not indicated.

Gender. Table 11 represents average tendencies of participant PUEI mean and standard deviation, scores across Branches for females and male participants.

Table 11

Descriptive Statistics of Emotional Intelligence (EI) Perception Scores across Branch Types (female/male) $(N=20)$

\begin{tabular}{llccc}
\hline & Gender & $\mathrm{N}$ & Mean & SD \\
\hline Branch I & male & 11 & 3.98 & 0.43 \\
& female & 9 & 4.25 & 0.43 \\
\multirow{3}{*}{ Branch II } & male & 11 & 4.07 & 0.46 \\
& female & 9 & 4.08 & 0.48 \\
Branch III & male & 11 & 3.74 & 0.36 \\
& female & 9 & 4.14 & 0.39 \\
Branch IV & male & 10 & 3.99 & 0.39 \\
& female & 9 & 4.23 & 0.44 \\
\hline
\end{tabular}

Independent t-tests were conducted to see the differences between female and male faculty's perception for each Branch (Table 12). A significant difference was evident in Branch III, females $(M=4.14, S D=.39)$ scored higher than males $(M=3.74$, $S D=.36)\left(t=-2.36^{*}, \mathrm{df}=18, N=20, \mathrm{p}<.05\right)$. This indicates that female faculty had a significantly higher perception than their male counterparts on their ability to understand emotions profoundly in general. 
Table 12

Descriptive Statistics and Paired t-test Results for Branch I, Branch III, and Branch IV (females/males)

\begin{tabular}{lccccccccc}
\hline & \multicolumn{2}{c}{ Female } & & \multicolumn{2}{c}{ Male } & & & Sig \\
\cline { 2 - 3 } & $\mathrm{M}$ & $\mathrm{SD}$ & & $\mathrm{M}$ & $\mathrm{SD}$ & $\mathrm{t}$ & $\mathrm{df}$ & (2-tailed) \\
\hline Branch I & 4.25 & .43 & & 3.99 & .42 & -1.36 & 18 & .19 \\
Branch III & 4.14 & .39 & & 3.74 & .36 & $-2.36^{*}$ & 18 & .03 \\
Branch IV & 4.23 & .44 & & 3.99 & .39 & -1.28 & 17 & .22 \\
\hline
\end{tabular}

$* \mathrm{p}<.05$

Discipline. Table 13 represents average tendencies of PUEI mean and standard deviation, scores across Branches Social Science and STEM participants.

Table 13

Groups by Discipline

\begin{tabular}{llccc}
\hline & Discipline & N & Mean & SD \\
\hline Branch I & STEM & 8 & 4.03 & .54 \\
\multirow{3}{*}{ Branch II } & Social Sciences & 12 & 4.15 & .38 \\
& STEM & 8 & 3.90 & .38 \\
Branch III & Social Sciences & 12 & 4.19 & .49 \\
& STEM & 8 & 3.86 & .51 \\
Branch IV & Social Sciences & 12 & 3.96 & .37 \\
& STEM & 8 & 3.96 & .42 \\
\hline
\end{tabular}

Independent $t$-tests indicated no statistically significant differences between STEM and Social Science groups across branches (Table 14). 
Table 14

Descriptive Statistics and Paired t-test Results for Branch I, Branch II, Branch III, and Branch IV

(Pairing STEM/Social Sciences)

\begin{tabular}{lcccccccc}
\hline & \multicolumn{2}{c}{ STEM } & & \multicolumn{2}{c}{ SS } & & \multicolumn{2}{c}{ Sig } \\
\cline { 2 - 3 } & $\mathrm{M}$ & SD & & $\mathrm{M}$ & $\mathrm{SD}$ & $\mathrm{t}$ & $\mathrm{df}$ & (2-tailed) \\
\hline Branch I & 4.03 & .54 & & 4.15 & .38 & -.59 & 18 & .56 \\
Branch II & 3.90 & .38 & & 4.19 & .49 & -.1 .56 & 18 & .19 \\
Branch III & 3.86 & .51 & & 3.96 & .37 & -.51 & 18 & .62 \\
Branch IV & 3.96 & .42 & & 4.20 & .41 & -1.66 & 17 & .12 \\
\hline $\mathrm{p}<.05$ & & & & & & & &
\end{tabular}

\section{Interview}

Pilot study. A qualitative pilot study titled "The Role of Emotional Intelligence on: Instructors' Perception of Effectiveness with On-line and Face-to-Face Instruction" was conducted in 2013 . The pilot study recruited $(N=5)$ faculty members from $(N=4)$ different higher education programs (Social Work, Sociology, Education, and Technology), interviewed, and reported faculty perceptions of Emotional Intelligence in face to face and on-line courses. Of which, there $(N=3)$ were female and $(N=2)$ were male. In essence, the pilot study was used as an experimental run, with a smaller-scale population of $(N=5)$ in preparation for the larger dissertation project of $(N=20)$. The current study did not include the original pilot study $(N=5)$ participants. This mini description of the larger dissertation study attempted to capture the variety and scope of the importance of faculty in higher educational institutions perceptions of emotional intelligence use Perceptions of Emotional Intelligence use PEIU.

Therefore, the pilot study helped to inform whether the dissertation's topic was probable and identify modifications needed in the design of the larger, subsequent study, 
this dissertation. Next, the aim and second purpose of the pilot study was to investigate a critical topic in academia. The pilot study explored (a) faculty perspectives, (b) related to face to face and online pedagogy, and (c) effective utilization of emotional intelligence while teaching and learning in STEM and Social Science professional learning environments. This exploratory method (qualitative) study investigated some issues related to face to face and online teaching from faculty exposés. Additionally, the study further probed whether awareness, usage, and vision into emotional intelligence can contribute to the success of instruction and learning formats in face to face (presence of the physical being) versus online teaching milieus (absence of the physical being).

From this perspective, the pilot study attempted to explore instructors' views of differences, comfort levels, and effectiveness comparing online and face to face teaching. Faculty participants were employed at three different higher education institutions. The pilot study data indicated that respondents felt competent to teach in either online and face to face but preferred the physical contact with students that face to face offers. Participants felt competent to teach in either online and face to face but preferred the physical contact with students that face to face offers.

Other emic insider perspectives from the study revealed that students tend to be more aggressive online than face to face or in the physical classroom. As a result, this present study investigated phenomena described by pilot study respondents and attempted to explore related issues. Respondents were not opposed to online pedagogy and expressed appreciation for the essential role which alternative education offers instructors (teachers) and learners (students). 
The strengths of online instruction were identified as offering flexibility and engagement opportunities for all students, but in particular introverted students. Pilot study respondents reported more issues and difficulties during online instruction. Additional results of the pilot study revealed that students tended to be more aggressive online than in face to face or the physical classroom. However, respondents reported that the cyber classrooms (online) provided less opportunities to correctly analyze communication tone and body language. Besides offering flexibility, other findings indicated that online can be less intimidating for introverts and its alternative interpersonal engagement opportunities can be conducive for introverted students.

In the same way, the strengths and challenges were observed in face to face venues. Scheduling and time constraints were identified as a challenge for face to face instructors and learners. For example, face to face venues offered faculty members more opportunities to accurately dialogue with students. Response time can be immediate and strategically. An advantage identified in face to face environments were the immediacy to address and resolve emotional issues (e.g., more comfortable and appropriate to resolve intense situations). Overall, participants identified strategies to manage emotional content for on-line and face to face learning. The pilot study data are not combined with this dissertation investigation. According to Leon, Davis, and Kraemer (2011) pilot studies do not offer enough useful information due to the limited and "crude[ness] owing to the small sample sizes” (p. 627). According to van Teijlingen and Hundley (2004), "pilot studies are relatively rare and often only justify the research methods and/or research tool used" (p. 825). 
Dissertation study. This study took a theme constructing perspective (Merriam, 2006) in examining the interview data. The interview data were analyzed to identify emerging themes that may corroborate the content analysis results, and survey results from this research question, as well as themes emerging from Mayer and Salovey (1997) four branch model.

A total of 20 interviews were conducted in this limited study of $(N=20)$, distinguished from the pilot study which investigated a smaller number $(N=5)$. The present investigation consisted of $(N=9)$ females and $(N=11)$ males. The quantitative analysis was informed by the qualitative method. To complement the qualitative data, Statistical Package for Social Sciences (SPSS) was used to report the quantitative data.

This study, employed a multiple methods design combining qualitative findings (e.g. interviews) with quantitative data (e.g. survey questionnaire). Also, the quantitative included "both fixed-choice (closed) questions and open-ended questions" (Patton, 2002, p. 5). Therefore, qualitative and quantitative systems have "differing strengths and weaknesses, they constitute alternative, but not mutually exclusive, strategies for research" (Patton, 2002, p.14).

Generally, the first few interview questions began with this investigator asking participants to briefly describe their room, setting, ambience, and aesthetic of their interview location. After which, participants self-identified their personality types: (1) Introvert $(N=8),(2)$ Extrovert $(N=3)$, (3) Both Ways $(N=8)$, and No report $(N=1)$.

At the start of the interview, some participant's expressed curiosity regarding the research topic. Other participants expressed feelings of apprehension. In order to limit feelings of trepidation in the initiation phase, the investigator requested participants to 
describe their physical surrounding, location, seating position, and their state of mind. Another attempt to reduce trepidation participants were asked to reflect on their individual life pace, how they attempt to maintain balance between family, work, students, social, etc. Once participant felt comfortable they provided permission for the recorded interview to begin.

During the interview, this investigator was attentive to individual anxiety with participants. Merriam (2009) asserted that " $[\mathrm{t}]$ he interaction between interviewer and respondent can be looked at from the perspective of either party or from the interaction itself" (p. 107). The investigator remained aware that "[b]oth parties bring[ing] biases, predispositions, attitudes, and physical characteristics that affect the interaction and the data elicited" (Merriam, 2009, p. 109). Therefore, the investigator attempted to remain cognizant that "the interviewer-respondent interaction is a complex phenomenon" (p. 109).

Branch I: Capacity to accurately perceive emotions (Perception, appraisal, and expression of emotion).

The importance of accurately acknowledging and being aware of the emotional issues/needs of your online and face to face students. As discussed in the literature review, previous research indicated that faculty perceptions of their effectiveness within online and face to face courses rank high on the list of achieving a professional environment in both venues. Within the context of those valued interpersonal relationships (teacher-to-student and student-to-student), the virtual “instructor's role has become more of a facilitator than a traditional lecturer" (Yang, Cornelious, \& Association for Educational Communications, and Technology, 2004, p. 849). The second primary 
responsibility of the instructor's role was to "select and filter information for student consideration, to provide thought-provoking questions, and to facilitate well-considered discussion" (Kettner-Polley, 2000) as cited in Yang et al., 2004, p. 849).

Questions and probes in the interview began by addressing the instructors' Capacity to accurately perceive emotions in STEM, Social Sciences, online, and in face to face instruction. From this perspective, instructors shared by what method and practice they practiced used to engage their PUEI online and in face to face instruction. Particularly participants reflected on their awareness of emotional issues and needs of students in both venues. Participants were passionate about their professional work, which was evident from their collective feelings and reactions regarding the two juxtaposed instructional settings. This limited sample shared a common connection. They represented a group of individuals with a unique expertise that have taught in dual capacities in professional learning environments, STEM, Social Sciences, online, and face to face courses. As such, their experiences and direct knowledge distinguishes them from colleagues teaching traditional "only" classrooms. Participants' discussions point out how they think about emotional issues and needs of students, as well as how they go about accomplishing this task. As previously mentioned in chapter two, faculty perceptions of their effectiveness within online and face to face courses rank high on the list of achieving a professional environment in both venues. Within the context of those valued interpersonal relationships (teacher-to-student and student-to-student), the virtual “instructor's role has become more of a facilitator than a traditional lecturer" (Yang, Cornelious, \& Association for Educational Communications, and Technology, 2004, p. 849). 
STEM Interviewees Observed Importance of Emotional Intelligence Online and

Face to face. Participants discussed the need to have a healthy balance in their

professional interactions with students. Some believed that they needed to be accurately

aware of how much latitude to grant students, especially on discussion board postings.

Instead of ignoring inappropriate discussion posting from online or online student,

Participant 6 decided that a more direct approach was needed to address students with

passive aggression and inappropriate behavior:

I actually had at one point in one of my online classes a forum where they could post anonymously about their frustrations and things like that. I found that they got too personal when they could be anonymous and very unprofessional at times. After that, I discontinued allowing them to do anonymous posts. (Participant 6)

Furthermore, several participants determined that their PUEI was adequate and that they often paid attention to and were aware of cultural climate in classrooms. Participant 6 reflected on the idea that fear does not produce good learning and that knowledge of cultural differences should be considered. Literature from The Mayer and Salovey (1997) study proposed that mental abilities requires two elements, "intelligence and emotion” (p.4). Fear, for example, “...is a feeling state that corresponds to a relationship -- the urge to flee others" (p. 267). Participant 3 believed that it is the responsibility of the instructor to structure comfortable learning environments for students:

I think it is rather important because if they are feeling fear, for example, there is no learning where there is fear. There are some key emotions that I need to be very aware of or we're not going anywhere. (Participant 3)

Several participants described themselves as introverts. They believed their own PUEI personal experiences and personalities helped sensitize them to be more aware and accurate of the needs of students online and face to face. Somehow participants felt 
inclined them to other people's opinions and their feelings. In this way, introverted instructors felt akin and familiar with introverted students. As such, some participants recognized accurate perception of emotions as an important element in their own pedagogy, and that fostering a healthy and protective learning environment for faculty and students can produce more than better students, but better educators said one participant:

I do some of this in my methods class. I try to get future teachers to understand where they are at so they can handle different types of people. I do some of those surveys with them so they can know what they are and interact with other people. Not everyone is the same. They have to interact with those people in their classes. (Participant 5)

Participants' awareness of their own PUEI and emotional content responses were deliberate and thoughtful as they gaged their acumen. One participant with professional expertise in facilitating learning processes, carefully described how emotional awareness contributes in determining the best ways to deliver course material and objectives to student. In most college settings, the private lives and issues of students are not the primary concern. However, smaller colleges and smaller class sizes may make a difference:

To me, it is very important because if I don't understand at least some of what they are going through and I just focus on what I am trying to teach and whether they are performing the work that I am assigning to them, I may not know if they are underperforming because of external pressures, family issues, perhaps even learning disabilities. Those kinds of things all impact whether or not students acquire knowledge when they come to your class. To me, especially when I am online, partially because of the type of student that I attract when I teach online, but in general because I don't have the in class, face to face interaction where I can watch for nonverbal cues or signs of disengagement, it is important for me to be aware of emotional issues that may be impacting my students. (Participant 17) Although participants agreed that facial expressions and common visual effects are less complicated to ascertain in face to face settings, most participants agreed that 
regardless of the setting, accurate interpretation is the goal for both online and traditional settings (e.g. face to face classrooms). Although challenging, participants informed the investigator that a motivating goal was to provide students with quality instruction regardless of the platform. One faculty explained that their PUEI online becomes more challenging in the absence of emotions. Therefore, Participant 12 attempts to pay closer attention to student emotions that are missing (e.g. facial expression, tone, and meaning):

If there is a personal issue that a student is dealing with, it is not apparent to me that they have this issue, but they may not be absorbing whatever it is that I am trying to convey to them. That said, facial expression and the obvious things that are available in face to face environments are much better cues for that than online where you rely much more on students voluntarily disclosing whatever issues they have. It is not readily apparent in an online environment. (Participant 12)

In general, most participants expressed that they experienced positive outcomes when they had the ability to stop, rethink, and pause, thus using their PUEI. These expressions suggest that in order to maintain flow and continuity, good communication is believed to be paramount online and in face to face formats. Additional examples from participants indicated that instructors and students needed to maintain adequate levels of emotions and awareness in both settings, a necessary and challenging goal to achieve at times, especially online:

I think it is probably critical in both environments. I can tell you from my experience, it is easier to do that face to face. (Participant 14)

STEM instructors were careful to avoid judging students that may appear harsh during email exchanges. Participants indicated that their PUEI informed them that it can be easy to misconstrue exactly what student intentions are in an email. In general, when an online situation with a student is perceived as problematic, several respondents indicated that their immediate response was to use an alternative method of 
communication. For example, one particular instructor decided to invite the online student to their physical office, since the student was local. Another participant reported that Skyping was used as their option and PUEI. This allowed the instructor and student to have a visual of one another. Finally, if Skype was not feasible, this instructor stated that they simply scheduled a telephone conference with the student. According to the interviewee, the benefit can be two - fold, both instructor and student have an opportunity to get a better feel for the emotions they are experiencing in real time. Next, human accuracy of emotions were felt as instructor/student discussed the matter. The same participant shared a phenomenon from their PUEI experience in a face to face class in prison:

Yes. Working in a prison, I had students who came in and were very upset. They were upset over a grade, but maybe the grade wasn't really what upset them. It just set them off. You really need to get to the bottom of what the problem is and keep them calm and bring them back down and find out what is truly the problem. Is it truly the grade or is there something else going on in their life? They don't have to tell you exactly what is going on in their life, but if you can see that there is an issue, maybe a family issue or a spouse or a boyfriend/girlfriend issue that is overlaying into the classroom, then you can work with them and be a little more accommodating maybe to the situation. (Participant 19)

In an online setting, Participant 19 reported that when issues occur, it has been their PUEI practice to take time, be accurate, and aware of the message content from the student. What was the student intending to state? In this example, Participant 19 chose to discover the student's intent. Eventually as the situation unfolded, Participant 19 reported that they felt comfortable scheduling a personal meeting with the student. They described how their PUEI assisted them in three ways: (a) seek understanding, (b) evaluate, and if necessary (c) nudge the student toward a greater emotional awareness by modeling good emotional awareness and intelligence. In Participant 19's perception: 
I think it is critical that you know and be accurate and not jump to a conclusion that a student may be overreacting when really they are just an excited student or maybe they have had a rough day and that is coming across in their email to you. (Participant 19)

From the perspective of Participant 19, accurate awareness of the student's emotional issue or need was the first challenge. However, Participant 19 had to identify when such intervention is needed, which can be more difficult online than in a face to face course:

I think it is very important to be accurate especially online because things can be perceived wrongly very easily. You can have a student who may come across as being very strong or opinionated in that they are right, but really, maybe they are just upset and they are just trying to get their point across. (Participant 19)

Social sciences interviewees observed emotional states online and face to face.

The equally Social Science scholarly participants and educators reflected on the significance of accurate awareness of emotional intelligence and their PUEI competencies skills during pedagogy use. The shared perceptions and individual experiences provided a deeper insight into this scientific study of STEM, Social Science, face to face, and online teaching. The earlier mentioned study of Humphrey, Curran, Morris, Farrell, and Woods (2007) study claimed that the use of emotional intelligence in schools has proven to be as controversial as the lack of agreement among emotional intelligence theorists in the social science area, (p.235).

According to Kremenitzer (2005), "a current interest in education is the growing awareness that the development of social and emotional skills in [students] is critical for the foundation of academic knowledge achievement in the classroom” (p. 3). Of great importance among educators is building foundations for instructors to interact and 
develop socially and emotionally in academic learning arenas. An example of accurate awareness, was reported by several respondents. One Social Science participant stated the following regarding their PUEI skills to assess emotional issues and needs of students during pedagogy:

It is of vital importance. Many of the classes that I teach are very controversial...We are talking about poverty, or work and the economy, or we are looking at race or sex or gender or sexuality. So one of the things I do is I can read a room. I have learned how to. Maybe it is from my training in communication studies. I have learned how to read non verbals and I know when people are not comfortable. A lot of times I will try to lighten the moods. I will say something to the effect that I realize not all of you agree and I realize this is the first time some of you have ever heard this. That is OK. You shouldn't feel guilty because of something you are thinking right now. You shouldn't feel that you are being attacked. (Participant 1)

From the above example, this educator looked for ways to connect through course content and on an emotional level with students. This participant appeared eager to inform this investigator how their PUEI worked for them during instruction. The participant provided an analogy from an online and face to face instruction. The face to face class discussion related to cognitive behavioral therapy and focused on how thoughts influence feelings and behaviors. This participant indicated that their PUEI is through verbal reinforcement during class lectures (e.g. asking students how they are doing and/or whether the information is clear is helpful?):

You've got to. In classes I look at faces and body language. I check in with my students because I think it's always important to know where students are emotionally. In my line of work and the training that I have had in sport and exercise psychology, you have to be cognizant and aware of how students are feeling. Because how they're feeling is going to influence how they present in class, how they interact in class, and how they respond to responses and things like that. I think I always try to check in with my students to make sure I know how they're feeling. (Participant 2)

The same participant provided a second example from an online format: 
Sometimes online it's more difficult. I have to read in between lines and look at some of the postings and emails. I will send an email and say hey how are you doing, you haven't said much this week and those types of things. I try to always be cognizant of my students' emotions as much as possible. (Participant 2)

In this section of the study, we continue to learn more about whether faculties believe it is important to accurately acknowledge and be aware of the student emotional issues and needs during online and face to face venues. A few participants' responded by empathizing with introvert students. As such, they used a comparison of their PUEI in face to face and their awareness of with the introvert (less vocal students). In their opinion, when some students appear to be disinterested, it may not be that the student is not prepared for class, but the instructor may need to draw them out. In that way, this respondent identified with the seemingly more introvert (distant) student in the class, explaining that some students may be shyer than others. By this, the participant explained that one way of attempting to encourage the introvert student was to invite them into the conversation. The respondent indicated that this experiment worked. Ultimately, the student began to feel more comfortable. The goal of this participant was to encourage the student through their PUEI by informing the introvert student that their opinions were valued. The participant was not only accurately aware of the class but of individual behaviors of introvert students:

I can attempt to. Because I am an introvert - I will begin with face to face. I had a greater encounter with other introverts in that face to face environment. Because I am an introvert, I recognize that some students seem to be aloof or not participating... It is just that person is not comfortable. (Participant 4)

Also, a second participant identified themselves as an introvert. This introverted instructor expressed that extroverts tend to have a larger presence in classroom sceneries. As a matter of practice this introverted faculty member $P U E I$ supports their facilitation of 
the classroom (e.g. evaluating the room to determine the needs of each student when

feasible):

I think I am an introvert and I think I am sensitive to people's opinions and their feelings toward me. I think I have a pretty good sensitivity and it is important to me to understand how people are feeling especially when they are engaging with me in a teaching situation. I can remember scanning the class in face to face classes and looking at the students and assessing whether or not they were engaged or trying to get them to pay attention. (Participant 7)

The next participant described awareness of student emotions in both settings.

This participant's PUEI informs them that instructors have a vital role in being accurately aware of their class, whether online or in face to face setting. Moreover, students should be given the benefit of the doubt, if they do not appear to be engaged. The burden, is on the instructor to determine why:

It is extremely important. Let me give you an example. If somebody is not speaking a lot either online or face to face, it is up to the professor to assess why. Is it because they are an introvert? Generally speaking, introverts need more time to process information. Or is it because they feel threatened because maybe their boss is in the same class or maybe people of a higher rank are in the same class and they are intimidated or don't feel comfortable? On the other hand, if someone is talking a lot and we have all had the students who are the first to answer every time a question is asked, do they want security or a pat on the back? Those kinds of emotional needs have to be addressed by the professor. If it is addressed in class, it is done tactfully so students or other students are not embarrassed. Or you take it offline. Addressing those emotional needs is paramount for building a safe environment where everyone can learn. (Participant 18)

Sometimes the difference between online and face to face and this respondent's PUEI meant you did not have to tell a student (in person) that they failed your class. This instructor observed that face to face, emotional situations with students were more difficult when delivering unpleasant news. Moreover, this respondent expressed that finding ways to maintain fairness, validate a student, and tell them that they received a 
failing grade was often uncomfortable. Essentially, one is saying there is nothing more that you can do for them except. It is uncomfortable, says one participant:

Well even thinking about face to face communication, you know, when a student emails you a concern kind of validating their emotional experience while still being OK, well I understand that you might be upset about this, or you might not understand how this is happening, but here is how I see it. (Participant 10)

In many ways Participant 10 preferred to deal with a tough situation online rather than face to face. Participant 10 detailed the steps regarding the energy and emotions required to invest in an emotional laden conversation with a student that had failed the class. Participant 10 explained that online made the process much easier. Whereas, face to face required more self-control. Participant 10 was concerned that the student would misread or incorrectly judge their temperament or body language:

It is almost easier to do it online because you don't have to face the person. Telling a student face to face, I'm sorry, there is nothing I can do, you are going to get an $\mathrm{F}$ in the class. Face to face is a little bit more difficult. I have your grades. There is nothing I can do. Whereas telling them in an email seems easier. I don't have to invest as much emotional - what is the word I am looking for? Packaging. If I talk to them face to face, I have to manage myself. I can't make it let it seem like I am happy about giving them an F. I can't seem like I am too upset. You have to manage that middle road emotion for something like that. (Participant 10)

As we move to the next few participants' responses, it is evident that all

participants believed that awareness is important, but many indicated the responsibility should be mutually shared.

I think it is very important to identify and acknowledge those needs and to avoid our first gut reaction to where a student is coming from. I think sometimes we tend to be judgmental and assume a student is slacking off or something and not really get in touch with their needs. I don't think we can truly help them learn if we can't help them overcome some of the barriers created by their emotional needs. (Participant 20)

Responses were varied among interviewee's regarding their PUEI (e.g. (a) emotional awareness and (b) degree of interaction). Participant 11 suggested that 
instructors must be (1) in tune, (2) available to assist, and (3) responsible for the student's success. Participant 11 further stated that emotions and academic success can be correlated. Participant 11 claimed that instructors are not (a) full-filling their roles, (b) doing all they are capable of, and (c) holding themselves accountable.

It is very important. The reason is that their emotional needs really relate to how they are going to, whether or not they are going to successfully complete the expectations of the course both online and face to face. If you are not in tune to what their emotional needs are, you are not going to be doing your job as an instructor. (Participant 11)

Another participant believed that taking time in the first few days of the semester to assist and make sure that everyone is acclimated was a normal part of their PUEI routine in online courses. This participant described their PUEI goal was to (1) ease their students' anxiety, (2) assist with navigation, and (3) ease the emotional tension. In the opinion of this respondent, supporting and correctly introducing students to technology is their PUEI. Also, another key objective of online engagement, is to decrease student fears in the initial days of the class. Therefore, this instructor indicated that all students are not prepared to take an online course:

I find a lot of that is emotional, if I can use the word stability--for my students in their initial first couple of days especially when we talk about online... When you are able to kind of walk them through everything, the tension, the apprehension is kind of diminished...I spend the first two days not even looking at content, but really getting them familiar so that it becomes user friendly for them. (Participant 13)

Participant 13 discussed their PUEI in face to face settings and their ability to read body language and cues:

Then when it comes to face to face, I am a behaviorist by trade so I look at their body language, their unspoken, the cringes in their forehead to gauge how comfortable they are with the information that I am sharing. It is not only the syllabus, but how I want assignments done or the requirements and stuff like that. 
It is very critical that I read body language. I think I do a good job at it. [Laughing.] (Participant 13)

The investigator observed the diligence of respondents attempting to be "meaning makers" (p. 83) of their work. The precocious examples of their PUEI and how they maintained positive feedback to students appeared impressive. Instead of highlighting what is incorrect, the next participant described using both (a) congratulations and (b) accentuated correct and positive items. Then, a student is able to receive both positive and negative feedback on their assignment:

It is very important to me. Not only in teaching, but also in personal human interaction, I make sure that I am able to gage the individuals who I am communicating with to ensure that I am communicating as clear as possible and being a positive influence and not being negative to anyone. In teaching, I try to make sure of my tone when I speak to students on the phone or when I send email correspondence or discussion board statements, and grade their papers, and also address my comments. (Participant 16)

Respondents' PUEI advised how to go about addressing emotional issues and needs of their student and questions. Participant 20 suggested, it is easy to be impatient and allow the business of the semester to overwhelm our positive image toward students:

I think it is very important to identify and acknowledge those needs and to avoid our first gut reaction to where a student is coming from. I think sometimes we tend to be judgmental and assume a student is slacking off or something and not really get in touch with their needs. I don't think we can truly help them learn if we can't help them overcome some of the barriers created by their emotional needs. (Participant 20)

As previously documented in the literature review of Chapter 2, the Han and Johnson (2012) study suggested that the use of emotional intelligence in pedagogical settings may help to narrow "transactional" online distance between teachers, students, and peers. The above study also warned about the variances in emotional intelligence styles. For example, face to face and online professional learning environment interactions may not always be duplicated between settings. A second example of this 
variance is the inconsistency between synchronous and asynchronous online venues. Therefore, the argument has been made that classroom results in face to face settings should not or "cannot be applied to online environments without evidence of empirical studies in online" (p. 86). Fabio and Palazzeschi (2008) used the Bar-On (2004) design to posit that "emotional intelligence and self-efficacy have a positive relationship in traditional school settings" (p. 86). This is an indication from the theoretical debaters in the field, that varying emotional intelligence constructs "may give different results in understanding the relationship between emotional intelligence... and learning environments" (p. 87). The outcome of the Han and Johnson (2012) study verified that fostering "an emotional-oriented perspective" may tend to improve online interaction between instructors and students. Two final indicators from the Han and Johnson (2012) examination reported that the lack of environmental clues may have a direct impact on whether or not teachers and students can communicate gracefully (p. 87).

\section{Branch II: Capacity to use emotions to facilitate thought (Emotional} facilitation of thinking).

Ebb and flow: projecting, creating, and establishing engagement. As mentioned earlier in chapter two, the opinion of the anti-technologist seemed to be that face to face instruction is more trustworthy. Essentially, face to face instruction automatically endorses students as "eye witnesses" to more accurate communication than do on-line courses. In other words, the anti-technologists argued that instructors who present in face to face venues deliver more guaranteed emotionally reliable messages. Also, there may be some perception that greater teaching liabilities and pressures are attached to developing into an excellent online instructor. 
All of the above can impact the emotional environment of virtual classrooms. Because of the historical relationship between the physical and practical nature of teaching, virtual instruction remains confusing for some (Hallström \& Gyberg, 2011). Also, face to face classroom communication is not easily replicated in online formats. For example, "live" instructional moments are not easily transposed from traditional face to face settings to online settings. Therefore, "technology teachers, teacher educators, curriculum developers and researchers can be provided with good analytical tools for this purpose" (Hallström \& Gyberg, 2011, p. 3).

The literature review also identified disadvantages which included the supplementary groundwork required to teach efficiently on-line, seclusion due to a lack of face to face interaction, technical complications, a drain on registration in seated classes, issues related to dial-up Internet access, and under-prepared students in on line classes (Hurt, 2008, p. 10).

Advantages of digital learning previously mentioned in chapter two include “digital technologies afford enormous potential for individual or group breakthroughs--provided that the existing apps are treated as approaches to be built upon (allowing us to be app-enabled), rather than ones that constrict or constrain one's means and one's goals (causing us to become app-dependent)" (Gardner \& Davis, 2013, p. 161). Although, online is viewed by some as a competitor to face to face instruction and has been referenced by many names (e.g., progressive or unconventional). Bejus (2013) promulgated that the move to online is not due to its vast superiority. Online offers fiscal advantages in educational programs. Accordingly, online courses may be viewed as a 
resourceful alternative to face to face (a) long standing, (b) highly esteemed, or (c) well regarded teaching method.

Participants described the advantages and disadvantages of applying emotional intelligence principles and $P U E I$ online and in face to face settings. STEM responders varied in their responses regarding whether to apply emotional intelligence principles in the class room, for educational purposes in online or face to face settings.

STEM participants PUEI: Advantages and disadvantages of emotional Intelligence online and face to face. One participant indicated that they were much more at ease in implementing emotional strategies and tactics in face to face environment. The main advantage reported in face to face for several respondents were their ability to immediately respond to technical difficulties. However, online during synchronous instruction it would be more of a disadvantage to attempt to address an emotional situation. One participant pointed out that online was not only demanding, but was not feasible to always practice $P U E I$ consistently.

That is a lot of work. It is a lot of typing. I have to be a quick typist. Sometimes I have multiple conversations going on. I think I have 58 students in my one online course. (Participant 6)

Participant 14 reported that based upon their PUEI they observe which students are emotionally present and connect with them. According to the above participant, this strategy allows them to monitor an audience during a presentation and connect with students in a similar manner. Smaller classrooms were described as more emotionally focused with more interaction. In fact participants noted that management of emotion became much more important in smaller settings. For example, one participant pointed out how their PUEI protected a student from failing in front of the entire class: 
The last round of presentations ...there was a student who was struggling for a whole variety of reasons. And I mean really struggling. She had trouble really performing even at the level for the class. It was so drastic that other students in the class noticed. Now we have a real emotional problem... if I don't handle this correctly, is going to melt down in a very public and unpleasant way. Because this student was struggling to get through her presentation, I basically said OK, sometimes things go wrong with presentations. I am going to walk you through some questions based on what I know your presentation is. You are just going to answer some questions. We are going to get through it. (Participant 14)

Participant 14 identified the following situation as a moment when their PUEI helped to facilitate a process for not only the benefit of one student, but for all students. Because of the instructor's PUEI actions, other students began to perceive what was happening; they began to model the instructor's PUEI, and showed support to their struggling peer. In the words of Participant 14:

It turned into this nice, supportive thing with no tears. Everybody got through the presentation. In that context, being aware of the student's emotional state and my own emotional state and the emotional state of others was absolutely critical. If I weren't aware of all of those things, it could have been a real disaster and it could have been very damaging to that student and maybe the other students in the room. (Participant 14)

The above participant indicated that their goal was to resolve the issue with the least amount of emotional embarrassment and stress to the struggling student. As far as an example online, Participant 14 specified that they preferred to handle emotional issues in a tangible setting (e.g. face to face):

You know, I am much more comfortable with the tactical things that you can do in a face to face class. Online, I would have to really think through about my tactic if a student is giving an online presentation and it blows up. (Participant 14)

A respondent with professional training skills in emotional intelligence noted that emotional intelligence's dark side. Gatekeepers and instructors were cautioned that all must be aware of individuals desiring to inappropriately use emotional intelligence principles to do harm: 
There are advantages and disadvantages for everything. I believe there is documented research that people can use it to manipulate especially in the areas of empathy. Getting someone to admit to something and then use it against them later. I have not seen examples of that. (Participant 18)

A second interviewee believed that emotional intelligence is an extremely delicate philosophy. From previous experience, this participant warned that unethical behavior could result from the random use of emotional intelligence, thus, should be carefully considered prior to mandating its use in classroom settings:

Disadvantage I think at times they are trying to work on play on the emotions of the faculty member if they think they can get whatever they are trying to get whether more time or a better grade or whatever it may be. You have to trust, but verify and check it out. (Participant 7)

Several participants indicated that they attempted to deliver meaningful messages to students on a variety of topics as a way of displaying their PUEI. For example, one respondent believed that it was their responsibility to attempt to inspire students and encourage them to do more than just complete assignments. Instead, this respondent spoke about their attempt to stimulate students on an emotional level. In turn, hoping that student's would see the value and do the same for their students in the future:

I think I try to come across that whatever I am teaching is important. It is giving them a reason to do the assignment they are to do. I am trying to motivate them because this is more than just about them. It is something that is going to go with them for the rest of their lives or some kind of emotion that they might want to pass on to their students when they are a teacher in the class. (Participant 5)

Social science participants PUEI: Advantages and disadvantages of emotional intelligence online and face to face. Social Science participants reported their PUEI by describing several past events. Participants described the advantages and disadvantages of their online PUEI that were beneficial to students, in some way. Most comments reflected the views of several other participants, however, those with distinguishing 
remarks, are noted. Apparently, many participants indicated that they enjoyed the mobility and flexibility that online offered (e.g. able to be in different locations). Participants spoke about the additional work that instructors and students occur during online instruction. Well the student has to do more because online learning is more active. When discussing students input, face to face was viewed as a way for students to sit back and hit cruise control. Although, online was viewed by many participants as more challenging the benefits to online were appreciated.

In the perception of several participants, online favored self-directed students, that are willing to read the class material, hence, they are more successful: Online advantages of using emotional intelligence indicated that:

I think one of the very first things I put out on my very first email is that the way to success in the online class was to read. You have to read. Read everything. You have to. There is no other way to get the information in a manner timely enough anyway. (Participant 15)

However, Participant 13 felt their PUEI meant that introverted students should not use their personality as a reason to hide behind technology. Participant 13 cautioned that, although, most students viewed online as a way to experience anonymity, instead, they felt that online courses should not provide a camouflage of protection for students to avoid engaging. Furthermore, this respondent explained that their PUEI through the Socratic Method was a way of engaging all students to make an effort to participate:

It is hard for them to hide behind the anonymity of online because I do the random calling. I randomly choose students. It is very hard for them to hide. You are going to get called on during a class session at least once. (Participant 13)

Although, most participants reported that they were satisfied with the advantages online offered. However, there were several critiques from respondents regarding the nature of online issues due to delayed human interaction. Some felt that disadvantages 
included instructors burdened with daily email (communication), reading assignments, and too much time spent on technology issues:

Most definitely. I think there are advantages and disadvantages in both types... Online does take a little more emotional work and it is more work for the students as well. (Participant 10)

In general, respondents appreciated the advantages and disadvantages in face to face settings. Most participants reported that online lacked a crucial piece that face to face environments offered. Their PUEI assessed that the physical ability and advantage to see the learning process, engage with students, and have emotional interactions was limited online.

Another participant spoke about their enjoyment of seeing the authentic academic process unfold:

I am able to bring reality. I like to bring physical, tangible evidence and displays. I am able to gauge their perception, their viewpoint, and see how they are doing physically. (Participant 16)

According to a veteran instructor, no disadvantages existed in using emotional intelligence in either setting. Instead of focusing on faculty PUEI, this participant proposed, along with three others participants agreed that instructors and students should be trained on PUEI principles:

I don't see any disadvantage. As a matter of fact, I am thinking maybe we should introduce students to the concept so they can think about it as they engage online and face to face. (Participant 20)

Four participants believed that there were advantages and disadvantages for students and instructors. Some of the biggest differences illustrated by several participants were the illusive behavior of students in online setting. Some found it harder to foster relationships because students $\log$ in at different times, if at all. In contrast to face to face settings, students were described as parroting what others stated. Quite the reverse of 
other reports, some participants expressed that it was much more difficult to draw a student out online. Another participant mentioned that they missed the ability to have ongoing discussions, similar to face to face settings:

I think in a classroom, you want discussion about the material. (Participant 10) Most participants were seasoned faculty with a range of $5-35$ years of experience. Many were considered digital immigrants, but had taught online for several years. It was interesting to note, despite the extreme flexibility that online offered and additional work involved in maintaining connections with students; most reported that they favored face to face over online courses. Participant's responded to this question by stating that they missed the personal engagement, human connection, and immediate feedback and response between instructor and student that online did not offer. Perhaps, this indicates the importance of PUEI, for some interviewees. However, none of the participants planned to shy away from future online instruction, but planned to continue improving course content in both online and face to face.

Face to face, I can sort of see them. The eye contact, the body language, the slouching in a chair, or where you choose to sit in there. Are you engaged by writing? I do see that stuff. As a public school teacher, I was known to pull out the introvert and make them feel a part of the class. I take that same philosophy in my platforms of online or face to face. I tell students that they cannot be an introvert in the class because I will engage you by calling on you and encouraging you. I think a part of that is encouraging them to take part in some aspects of the class. (Participant 13)

Throughout the study, participants appeared to think and care deeply about how PUEI can further impact their courses and interactions with students. To reiterate, this investigator noted that participants talk about the significance of ongoing discussions on several occasions. As one participant indicated:

I think in a classroom, you want discussion about the material. (Participant 10) 
The principal claim made by Mayer, Salovey, and Caruso (2008) was that emotional intelligence is deeper than just feelings and emotions. The principle claim made by Mayer, Salovey, and Caruso (2008) was that emotional intelligence is deeper than just feelings and emotions. Participants recognized that future teachers and students need to first "know themselves." The skill to assess an academic classroom or situation was noted as important, whether online or in face to face.

Caring and being aware of changes and cultural climates inside of classrooms were equally important. Reportedly, over half of the participants admitted that the use of emotional intelligence was a conscious and general practice in their daily pedagogical routine. After interviews were completed, another group of participants articulated their desire to learn more regarding general application of emotional intelligence principles. The remaining participants expressed a general interest in learning more about the concept and how their PUEI might assist them and thought that subconsciously PUEI were used in their daily their professional and personal lives. The remaining few participants articulated that they were vaguely familiar and had not consciously used emotional intelligence principles.

\section{Branch III: Capacity to understand emotional meaning (Understanding and}

\section{analyzing emotions).}

\section{A discussion and deliberation of participants' PUEI: Whether mutually} responsive communication was necessary or socially important for faculty and students online and in face to face. The literature from Chapter 2 addressed what it means for faculty to inspire students. It may mean that emotions, personality, and getting to know the individual on a private and/or personal platform should be a decisive decision 
(Radford 2003, p. 256). Theorists, (Radford, 2003; Zeidner, Roberts, \& Matthews, 2002; Zeidner, Matthews, \& Roberts, 2004) appeared to join voices in denouncing those individuals or institutions that would misuse emotional intelligence theory. Finally, Radford (2003) envisioned emotions as essential to the "quality of our lives" (p.256) but cautioned that emotional intelligence constructs should be used carefully and responsibly. Seemingly, one view that all theorists at least agree with is that individuals using emotional intelligence theory should make the effort to conduct ethical research and protect vulnerable people. Radford (2003) assumes that "as teachers we are continuously aware of the emotional environment of the classroom..." and that part of instruction should include teaching students "about the appropriateness of feeling in particular contexts" (p. 266). The contexts referred to should promote a sense of stability that allows students to thrive and encourages a well-adapted emotional life (p. 266). Moreover, Radford (2003) believes that this can be achieved if "contemporary trends" of dualist are implemented from two angles of "individual emotional identity" (pp. 266-267) and through the well-defined emotional "culture and climate" of institutions.

\section{STEM: Learning is about engagement and all involved must do their part to} participate. Participants' discussed their PUEI and deliberated whether mutually responsive communication was necessary or socially important for faculty and students when interacting with one another online and in face to face? Some participants reflected on their teaching contracts in classes of over 100 students. The thought of emotional engagement for such a large student population seemed daunting for this respondent teaching such a larger section. The science and biology instructor described their PUEI while attempting to manage and communicate with their large enrollment classroom. In 
this scenario, the interviewee expressed disappointment and concern for students because it was difficult to make a true connection for two reasons (1) student expectations probably were not met and (2) students were probably reticent to participate. This respondent believed that there is a real lack of engagement between faculty and students in the course and no one truly wins:

I think that I lose out when that happens and I think that they lose out when that happens. (Participant 9)

Participant 9 went on to discuss some of the issues related to connecting with students and attempting to grasp their attention during class. It was apparent that the interviewee had been attempting to connect with students, but to no avail. In fact the respondent described this situation as "large problem" because students were not responding to questions in this face to face course besides the same three students in the front of the class. In the opinion of Participant 9, seemingly, for now, their best effort of their PUEI is still unfolding:

It is frustrating for me in that if I try to get across to them, if they will just answer, the information will stay with them more and they will retain that information better, and that they will gain from that engagement in class whether they are one of five or one of 250. (Participant 9)

The participant indicated that they agreed with this study's theme that Learning is about engagement and all involved must do their part to participate. Furthermore, from the participant's perspective students were not mutually responsive or appeared willing to communicate in this necessary face to face forum. The situation was problematic for this faculty member and students although they did not seem to notice:

I think that I agree with the statement about engagement. They really should understand that if they participate, I will do a better job and they will get more out of that class time they are spending. (Participant 9) 
However, the participant reported the opposite in another course online. Students are (1) communicating, (2) participating, and (3) interacting as expected. Perhaps, it is due to the format of this specific online course system:

...The way that we have set up the online classes that I teach is that there are many more things that are expected of the students to turn in and to show what they are thinking, express how they have processed that information on their own. (Participant 9)

This important detail indicates how this participant $P U E I$ was used to tackle a problem viewed by some as loss. However, in this scenario it is apparent that the interviewee is aware of the students, yet it is not known if the students are aware. This participant will continue their PUEI by attempting to problem solve, foresee causes, and consider the impact of how to manage a face to face emotional connection quandary. After additional discussion this participant indicated that they idea of incentives has been considered.

One participant did not agree nor disagree. Instead, their PUEI in online course interactions and mutual responses, between faculty and student were contingent:

... I think it depends on the subject matter. Participant 3

However, online environment was viewed as the primary communicator with two main features (a) textbook and (b) power point, etc. In reflection, Participant 3 recalled a personal online experience as a student:

That is the one thing I didn't like about taking an online class myself. It was all reading. It was all me. There was no lecture. It is different. (Participant 3 )

Participant 3 identified their PUEI in face to face was concretely different compared to the online experience and expectations. The onus, in this respondent's explanation was primarily on the instructor not the student to mutually respond and communicate: 
It is definitely different. Face to face, I have a lot more delivery responsibility. It is much more easier for them to ask for clarification. There is much more clarification going on. (Participant 3)

Other participants reported that mutual responsive was important in the classroom.

The respondents' reasons varied, based upon their PUEI in online or face to face settings.

Denoting a few additional comments from interviewees indicated that their PUEI must be through interaction and inquiry:

Participant 12 was firm regarding honoring response time with students. This respondent deferred to following the university's policy that they were associated with requiring instructors to reply within 24 hours, etc. Although, this respondent believed in responding within 24 hours, they did not expect the student to respond right then. However, this participant was clear that mutual timeliness was critical for both faculty and student, although, students are not always timely with their online response:

Because I believe it is important and because I meet my requirements for responding in a timely manner, I expect the students to the same. That doesn't always happen in the other direction. It is more important for me to respond in a timely manner because they are the customers, so to speak. They are taking the course and they are looking to me for guidance. Sending a response to them in a timely manner has a potential to impact their performance. (Participant 12)

Also, Participant 12 regarded face to face venue in the same manner. This participant took pride in their responsibility. They described their PUEI conforming to meet the needs of the student. Office hours were usually flexible, in the afternoon, or early the following day to address issues. Participant 12 indicated that dependability and timely responses in face to face were manageable.

Other participants agreed that the conversation was one-sided between instructor and students, so they practiced asking open ended questions. Participant 6 believed that students would miss the point of pedagogical learning in face to face, if they did not learn 
to form their own opinion as learners and teachers. This participant believes in utilizing the Socratic Method and pointed out:

Yes. In face to face... They are trying to take over my persona and my experiences are different especially because I am a female and most of my students are male. They don't have the same experiences that I do so they really need to have that interaction. They are like, no, that doesn't work for me. That is fine. They are supposed to have that disagreement, that cognitive discord. It makes them think, OK, this is the kind of teacher she is, but it is not the kind of teacher I would be. I want to have that discussion. (Participant 6)

Participant 6 also believed that students should debate and discuss relevant and controversial topics, whether online or in face to face settings. Participant 5 described mutually responsiveness as the responsibility of the instructor to (1) You definitely have to be involved, (2) demonstrate why the information is crucial, and (3) model expectations say another participant:

If there is no buy-in from the student, they won't participate. You have to motivate them and show them why it is important to learn that particular topic. (Participant 5)

In another undergraduate class Participants 5 and Participant 6 noted that motivating their students to learn was easy. The participant shared that they are honest and upfront with the students. For example:

In my undergrad face to face, it is pretty easy. I tell them when they go for an interview with a supervisor or principal, they will ask about this subject matter. If they don't know, they won't get the job. I don't put fluff in my class. What I put in there is stuff that is important for them to know. (Participant 5)

Social sciences: Learning is about engagement and "all involved must do their part to participate"

The emerging theme in this section related to responsibility and responsiveness. Supporting students in their growth, but at the same time teaching them to ascend seemed to be the guarded message. What does it mean to be a good educator? What does it mean if a student fails? This phenomenon seemed to be ever present. Were the participant 
responses silently indicating that there are no losers?

In face to face milieus, most Social Science participants acknowledged that mutual responsiveness was necessary accompanied by numerous examples and explanations. Moreover, participants' voices clearly indicated that instructors are responsible to impart knowledge to students. For some participants, the process was enlightening as an instructor observed students attempting to gather knowledge and understanding:

When I'm looking at students and lecturing and I see the eyes light up and the heads nodding, I know they're hearing me, they're understanding, and they're integrating it into what they already know. That is totally fantastic, and I really like to see that. (Participant 2)

Systematically, other participants designated the instructor responsible for providing students with points of contact, office hours, and/or alternative methods of communication. To this point, the student must keep the instructor informed, if there is confusion related to an assignment or a life event. Participant 4 indicated:

I like for students to know that they can reach me. (Participant 4)

Again Participant 4 indicated that their PUEI in communicating with students meant more than simply saying I am available and here are my office hours. Instead, Participant 4 believed that student needed to feel comfortable and able to know that the process was trustworthy. Therefore, Participant 4 expressed that instructors needed to do more than post a sign that their door is open for business. Instead, Participant 4 indicated that their PUEI meant that the cyber or physical door was not only open to students, but the message should convey. I am approachable. "Hello, how may I help you?" Therefore, Participant 4 PUEI meant:

I have to establish that foundation first though so I can build on loyalty so the student knows that they can contact me. (Participant 4) 
Participant 7 evaluated other instructor skill levels more broadly. But firmly contested that their PUEI in teaching should be more about engagement and less about lecturing. In their opinion, teaching may be a performance, yet, it must be engaging:

...Y You have faculty especially at the university who just lecture and they don't have any engagement. Students just sit and take notes or fall asleep or whatever they do. I don't think those are your best teachers. They see themselves as the sage on the stage and they spout off the content that they think is important. That is not the best teaching situation. (Participant 7)

However, Participant 1 debunked the notion that instructors are solely responsible for instructor-student engagement. Attempting to recognize what the student is going through, what is communicated, and how to professionally handle academic situation with PUEI can be challenging as indicated. Participant 1 indicated that students needed to participate and engage:

It is also necessary for them [students] to see the other side of it as well. Participant 1

An example provided related to a student considering a question on an exam unfair. In the opinion of this above participant, some students were passive aggressive. Instead students would:

They write it on my evaluation at the end of the semester and it is something that I never even knew was a problem. (Participant 1)

Participants continued to explore their PUEI and its relationship to mutual responsiveness. This specific participant appeared concerned that students need to engage in mutual communication when there are issues because instructors will never know there is a problem. Another participant seemed to agree:

Yes. I mean both parties have a responsibility to create a successful learning environment. Both parties must share equally in that responsibility. (Participant 11)

Reiteration was considered a helpful technique says another participant. Participant 
11 implemented their PUEI through reminder to the class that they were not communicating:

Oftentimes, I tell my class if you are not communicating back to me on what I am teaching you, ... I can't tell that you are learning. I only know that I am teaching. (Participant 11)

Participant 13 challenges their class to embrace learning in such a way that it is uncomfortable, not only by inquiring why, but by probing beyond the answers given, and indulging at a higher capacity and understanding. Emphatically, Participant 13 underscored:

I think it is important, this mutual responsiveness. It has to be reciprocal. (Participant 13)

Therefore, making sense of who was responsible to mutually respond to Participant 15 meant that their PUEI encouraged students to share because it may help others. Thus, their mantra to students was about sharing knowledge, share what you know, or share what you think you know:

I have worked really hard to really know the tip of this finger. Now you don't know what is on the tip of my finger, but that doesn't mean that what you do know can't help me learn even more. I am going to share with you what is on the tip of my finger and hopefully throughout the semester, we will learn together. I am trying to include them in the learning process, vest them in it. (Participant 15)

Many participants communicated that online presented its own unique concerns, although some courses were viewed more or less problematic than others. Participant 4 indicated that feedbacks on assignment are always provided. Comment reminded students that:

I am here. (Participant 4)

Comments can also mean that a student may be late on an assignment. Overall, mutually responsiveness seemed to ignite energetic responses from all participants. Another point 
mentioned related to mutual responsiveness was:

There is research that shows that one of the top five things is the responsiveness of the faculty in the online environment for students. If faculty don't respond in a timely manner, if they are not promptly posting results from graded activities that is an issue for the student. (Participant 4)

An emotional factor that was not mentioned often through the different conversations is the impact that online teaching and learning has on education. In some ways, conversations are diminished from the disconnectedness that can accompany online teaching and learning. Participant 7 expressed the impact of online seclusion in the following statement:

I think there is a feeling of being isolated in the online environment if they don't get responsiveness. I think there is a requirement on the faculty's part and on the student's part. I think one of the best practices in instructional pedagogy or andragogy is to have a lot of engagement discussions. Chatrooms or something to make sure all of the participants are being engaged. (Participant 7)

Overall, respondents believed that instructors needed to be more responsive. Their rationales included and ranged between (1) highly important for communication purposes, (2) responsibility is on the instructor, and (3) it is everyone's responsibility. Mutual responsiveness is highly important and communication can be active or one way. However:

Effective communication is a personal, individual responsibility. In my teaching style, if you don't communicate with me, especially online, I have no way of knowing if you are physically present. Face to face, being responsive shows that you are processing the information. Not necessarily agreeing, but processing the information and understanding the different perspectives. (Participant 18)

Participants in this study did not complain about the additional demands that accompany online experiences, but simply enlightened the investigator about the happenings in their worlds (e.g. online and face to face). Clearly, participants enjoyed the challenge of technology, learning a new skill, and an opportunity to be a pioneer and a 
face in the new world of learning. Often participants described the nature of online as a place where individuals are expected to be extremely independent and technologically savvy. As previously mentioned, the differences noted between online and face to face instruction can appear to be isolative for faculty and students.

As mentioned earlier in chapter two, the opinion of the anti-technologist seemed to be that face to face instruction is more trustworthy. Essentially, face to face instruction automatically endorses students as "eye witnesses" to more accurate communication than do on-line courses. In other words, the anti-technologists argued that instructors who present in face to face venues deliver more guaranteed emotionally reliable messages. Also, there may be some perception that greater teaching liabilities and pressures are attached to developing into an excellent online instructor.

All of the above can impact the emotional environment of virtual classrooms. Because of the historical relationship between the physical and practical nature of teaching, virtual instruction remains confusing for some (Hallström \& Gyberg, 2011). Also, face to face classroom communication is not easily replicated in online formats. For example, "live" instructional moments are not easily transposed from traditional face to face settings to online settings. Therefore, "technology teachers, teacher educators, curriculum developers and researchers can be provided with good analytical tools for this purpose" (Hallström \& Gyberg, 2011, p. 3).

Branch IV: Capacity to manage emotions (Reflective regulation of emotions) Additional strategies or PUEI principles utilized to manage emotional engagement and/or language practices with students online and face to face. Throughout this qualitative study, it was evident that participants deeply cared and wanted to make 
meaning of their work by examining old educational philosophies for new educational stratagems. Remarks from participants indicated that work was not simply work. Participants were courageous and unabashed in their discovery to explore their ability and look for ways to support their current roles and explore their PUEI.

Participants appeared to be a caring group of faculty devoted to making an impact in their current role as they struggled with ways to influence or remain the same. Throughout the study, participants engaged in an in depth process of exploring their PUEI with the investigator. Most appeared to welcome the challenge of adopting additional tools to help assess their PUEI and have the chance to be a part of the advent of new technology online and in face to face formats and to help advance education. Yet, there were times of struggle, where some participants were comfortable with their current PUEI skill level and emotional intelligence abilities. Other moments included painful memories for some participants as they recalled tragedy and painful moments in their professional and personal lives that interconnected with some responses.

Many universities and colleges have changed how instructors teach and how students learn, by incorporating distance education. However, some universities and colleges have opted to abstain from offering full degrees or specific courses online. It was evident that participants teaching online, face to face, and hybrid courses believed that they are a part of an innovative educational designed process that is yet to be completed. Participants openly shared their views, values, and academic philosophies, while opening themselves up for criticism.

Participants are complemented on their determination to pursue teaching excellence, in light of the heavy expectations and changes that accompany their teaching 
roles. For example, educational settings modify technological tools frequently which require participants to adapt to changes online and in face to face. Participants did not agree on all aspects of emotional intelligence principles and believed that students needed more support in this area. But all participant believed that education is in a season and time of uncertainty, in a time of challenge and opportunities.

Participants did not shy away from being an intricate part of determining how the online and face to face process might continue and/or evolve. Branch IV continued to challenge participants to observe their emotional awareness strategies in online and face to face venues. Many participants indicated that PUEI is transferable and can use professional and personal. Throughout this study some participants expressed that increased awareness of their PUEI can assist educators to think more profoundly in their roles.

Participants shared examples of frustrating moments and times with students. They perceived that some of their previous strategies may have unintentionally included emotional intelligence principles. Not all participant responses were the same. Many reactions varied and examples are provided to compare how participants struggled to handle tough interactions online and in face to face. Participants were honest in sharing their experiences. In their opinion, sometimes they struggled through difficult situation and viewed the past conflicts as opportunities to reflect on past online and face to face situation.

STEM: Strategies to managing engagement and language development of emotional intelligence. It was obvious that some strategies worked better during emotional engagements with students in their face to face and online classes. In retrospect and 
stepping back, one participant was able to say:

Online is much easier. I can step back and react however I will act in private and formulate a response that really minimizes the emotion the response. (Participant 3 )

The question whether emotional intelligence has a place in education varied in responses. Some participants believed that it may have a place, but should be carefully implemented. For example, one participant expressed that a balance must be maintained, since one can have too much or too little emotional intelligence. To better explain the "too much or too little rationale" the participant used an example about student sharing their complaints about another colleague. The STEM participant believed in their ability and PUEI, but worried about another colleague by stating:

I have a colleague. Brilliant. Brilliant. The feedback that I get from students are I want to put sharp objects in my eyes. She talks like a drone. I am about to slip into a coma. These are the comments that I get. She doesn't have enough emotional intelligence. The students can be doing anything. I have sat in her classes. The students can be doing anything in the world and she just continues on with her lecture as if she were doing it for a camera. I don't think she has enough. I think I have too much. She is sort of like my idol. Not that I want to be like that, but she feels a lot less pain. Her students don't cause her pain at all. I envy that. (Participant 3)

In this particular circumstance, Participant 3 explained what was meant by envy. For example the feedback that student provided can be viewed as the opposite of the above scenario. Their styles are completely different, in their individual classroom including how events are handled within the classroom. Whereas, Participant 3 stated that student described her course as markedly challenging, but did not view the comments negatively. In comparison to the above instructor, where students indicated that they felt like they wanted to "put sharp objects in their eyes," students seemed to care about how this participant viewed them as students. For example, students complained that course assignments were unreasonably difficult, yet they did not want to disappoint their 
instructor. In the opinion of Participant 3, instructor must pay attention to their students

(e.g. know what they are doing when feasible), as this may implicate that students appreciate a level of animation, reaction, and emotional connection:

Absolutely. Yep. One of the things I have gotten feedback about is you make me feel like I am working for my mother. Your class is difficult, excessively difficult, but you give me an added pressure that I don't want to disappoint you. He said not that that is bad, but there is just a pressure there that is not there when I have - and then he talked about this other teacher that I was describing, the one with no emotional intelligence. (Participant 3)

Another STEM participant provided an example of how PUEI principles are implemented in Branch IV and when explaining assignments to online students. In this participant's opinion, the use of humor is part of their teaching scheme. This was mentioned throughout the interview as an additional coping strategy to manage some of the emotional engagement and language practices with students. For example, students have the option to complete assignments using their own style.

I think for the online students, when I give them assignments, I try to show them it is not about them. It is about what they are going to do for their students, their program, and their school district. I try to use that to get away from what I am doing to what they need to do to be professionals. We do in the undergrad courses. Even my technical undergrad courses are teachers. I say what I think is important and give some ways that they can teach it to their students. You will all have your own teaching style. You may want to do it differently. I give examples. I think that is what you are asking. (Participant 5)

One STEM participant used direct and interactive communication as an additional strategy or emotional intelligence principle to manage emotional engagement and language practices to address issues with students online or face to face? The use of reiteration and restatement was helpful, says this instructor. Whenever one student does not understand a particular assignment others may have a similar issue. According to this participant misinterpretation can occur online or in face to face. To avoid some of the 
issues, the instructor responds to the student and ask if they responded to the question correctly with expectations that the student would reply. In other instances, this respondent rationalized that sometimes students just want to vent. In this instructor's experience, student's often do not really have issues with and instructor or the assignment. Instead, the student may want to moan about the assignment, then tackle it:

For example, I had a student who was not a good writer and was concerned about the length of a paper I had assigned. They wanted to vent for a few minutes and once they had, they could do the work. It is almost like they have to go through a process of letting go of negative emotion and fear in order to get through the assignment. (Participant 6)

Participant 6 shared an online experience regarding additional strategies that are used:

I have seen that in online classes, too. Sometimes students challenge the assignment, the word count, or the number of sources they are to use just to see if I tell them they can use less. I don't. I stick to it. I have established this for a reason. There is a reason to look at these sources or to have this number of pages because you are building on a program or research. Once you defend your choices, they have a tendency to say OK. They just needed to vent. (Participant 6)

In many respects, the Participant 6 managed not only their emotions, but also the emotions of the student. The above case in point did not appear to get out of hand and was a win-win for the instructor and the student. Thus, by allowing student(s) to have a "temper tantrum" and when they are done, they are ready to move on?

Yes. They are. We all are. And I realize that more at the lower levels of my courses or with my freshmen and sophomore, my face to face undergrad, and more with introductory courses. They are trying to set boundaries and see how far they can push the person. I don't give in. I have learned as a parent not to. [Laughing.] (Participant 6)

Another STEM participant provided examples and strategies as evidence of their PUEI classroom practices during online and face to face instruction. This point was reiterated by the participant in previous responses and emphasized here. They indicated 
that the use of appropriate use of emotional language is a way to manage emotions.

No. That is what I was trying to get to with that. Staying away from the monotone, letting them see when there is something that they may not understand or to stress. A lot of it in the classroom is trying to get them excited. I am lucky because it is biology and so many cool things go on with that. Emotionally in the classroom, I don't try to be too distant. I don't try to be unapproachable. In that way, I want them to know they can ask any questions that come up and are in their minds. I try to encourage that whether they do it or not. I try to encourage them that it won't be like why are you wasting our time about this or an attitude that they shouldn't interrupt me or those things. (Participant 9)

Also, the same interviewee illustrated their activity level and practice strategy in another setting:

When online, there is much less of that that you get to do. It is more through the feedback for their work of encouraging them when they have done a good job or showing them with the assignments the kind of excitement and the coolness by showing them news articles that are current and that these things are relevant that they need to have a position on. I encourage them to express their opinion if they have it or discover it if they haven't already. It is about asking them where they stand on things or what is their understanding. (Participant 9)

One distinctive reflection from a STEM participant seemed to capture the essence of PUEI innovative practices in face to face classroom. As a strategy, this participant required students to work in small groups. In this case, the participant accomplished two emotional intelligence goals. First, the respondents used strategy by carefully and thoughtfully pairing students within groups to complete assignments. Next, to manage emotional engagement for students the goal was to cautiously group introvert and extrovert students together. In order to successfully group students in the two categories, one would need to know and identify each student by personality. The size of this class is not known, but it is interesting to note the participant's comments regarding (a) knowing a student very well, (b) knowing which students struggle with specific concepts, (c) knowing student personalities, (d) knowing student work ethic, (e) knowing students 
learning styles and patterns was a demanding process:

This also relates to the introvert/extrovert discussion. Picking the groups themselves becomes incredibly important. You get to know the students very, very well. You know the students who struggle with certain concepts, the students who are extroverts, the students who are introverts, the students who work hard, and the students who maybe don't work as hard. You try to compose groups that force the students to interact in ways that make them build on their skills or assess the way they are approaching an assignment. It is difficult, but I find that that can very often be critical. Just getting the two or three people together in that group can do everything from help an introvert participate a little more to help a weaker student understand how stronger students do things. (Participant 14)

An example of this would be that this year we had many students from Brazil in our classes. They have different study habits. One of the students from the US came to me and said my partner does all the classroom exercises before he comes to class. I said does that surprise you? She said I think so because nobody else does that. I said do you see where that might add to the value? She said yeah. It is not me telling her she should do this. It is a peer saying I want to come and be prepared for class so I do the classroom exercises and then I do them again if I can't solve them. So I find that group composition, if you get to know those students well enough and you spend enough time trying to think through who are two people I want to bring together because they each have something that the other one needs, that is a tool that I need. (Participant 14)

A follow-up to the above example is that student groupings are chosen if they are viewed as emotionally compatible. What is more, is that in this critical example the instructor must have enough knowledge about each student, in order to group them. Participant 14's PUEI in the midst of a classroom group work situation appeared successful. Again, placing two students together that did not get along or students that have the capacity to be disruptive was not the objective.

A simple example is if I know two students who don't get along. If I know they are going to be disruptive, I don't put them together. But I need to know them well enough. (Participant 14)

The use of instructors' strategies to improve online and face to face sensitivities was important to remain calm. Participant 19 elaborated on how asking questions for clarity helps to manage emotional exchanges to diminish a potential conflict. This example 
exemplifies an instructor choosing to calmly engage, displaying an emotional connection

to the student's concern, despite the student's emotional state:

Most certainly there were strategies that I used to diffuse the situation. Talking in a very calm tone. Not raising your voice. Of course online, you would have to convert that to your verbiage or some of those exclamation points. Keep it very calm and ask them. One of my biggest things was always you tell me what has you so upset. Tell me what has you so upset. Where did this all start? Where did it come from? Is there something that I did? Maybe I did something that I didn't realize I was doing. We can all do something that comes across the wrong way. And just letting them know that you are listening, that helps to calm them down. (Participant 19)

\section{Social science: Strategies to managing engagement and language development of}

emotional intelligence. Participant 1 reflected on several past incidents, but one particular event seemed troubling to the interviewee. Participant 1 contemplated how to manage current and future challenging engagements and language with students in face to face setting when they became insolent. During the interview, Participant 1 dialogued and pondered with this investigator in a thought provoking and critiquing manner. Which is best, constructively walking away or remaining with a disenchanted students? Sometimes the answer was not easy:

I don't know that I always have the most effective means. Sometimes I just cease communication. A student will have a problem and I will give them my stance, my response. Sometimes if they argue with me, I just walk away. I will literally just be like, we have covered this and there is nothing we can say. (Participant 1)

A lot of times online, I will send a final response and cc the chair of my department. There was a student I talked about previously who was upset about the quizzes and stuff. I wrote it out again and said this is a final reason why we won't do this. I carbon copied the email to the chair of the department if you want to engage the dialogue at a higher level administratively. (Participant 1)

Another participant, with more experience in emotional intelligence principles, used personal strategies to manage emotional engagement or practices in online or face to face venues. This participant pointed out that utilizing a personal responsibility approach helps 
to manage all the emotions that emerge at once. According to Mayer and Salovey (1997)

it is important that we learn to supervise, distinguish, and tag our emotions. This does not mean that we discount or ignore useful information, but resist making bad decisions that often are irreversible:

I manage them by training myself not to overreact to occurrences. Many times, you could make an intelligence decision if you would step back and not react so quickly. Allowing yourself to absorb the event and take that conceptual view of what occurred so that you can be able to respond in a way where you don't lose the students, you don't break that student's trust, or you don't offend the student. (Participant 4)

The ongoing theme to note is that all participants are engaging in a dialogue of what is considered healthy in each of the above-mentioned and forthcoming occurrences. Another participant identified a time when their PUEI was tested. Additional strategy and intervention were required in a face to face classroom to diffuse emotionally charged students engaged in political discussion. The respondent began by sharing the origin of the discussion, the nature of the content and how the class erupted into an emotional charged verbal bantering scene. In reflection, this instructor was completely surprised by the confusion and student's unexpected responses, the use of managing emotions was evident by utilizing a big picture approach to assist in reigning in some of the high emotions of the entire class. One faculty provided an example of their attempt to manage and facilitate their students' emotions, when a sensitive conversation occurred in the traditional classroom:

One pops out to me. I was teaching at UNLV. It was an intro sociology class. There was a non-traditional student and they said something really bad about women. I thought the class was going to lynch him. It caught me off guard and the rest of the class was like, you did not just say that. I can't remember what he said specifically. It was something about that women shouldn't become politicians. It was something specifically about gender. Without shutting him down like the rest of the students were trying, I tried to calm everyone down and talk about why he thought that way. 
The rest of the people didn't understand why he felt that way. You are white male. Is it your privilege? Others didn't necessarily buy into the idea of privilege. We had a larger conversation going off topic of what we were talking about that day to kind of bring it back down to a place where he could leave the school without people throwing things at him. It was something pretty nasty. (Participant 10)

Participant 10 provided an online example of how additional strategies were used to manage emotions in an online discussion. Ultimately, the second example featured an online discussion between students on the topic of immigration. Again, the same instructor indicated that intervention was required when the dialogue exploded into more adversarial conversation. According to the Participant 10 the difficulty between the two learning formats appears to be the ability to immediately respond to tough situations versus the delayed response after 24 hours or longer in online. As such the use of interjections for both courses appeared to sort out and strategically manage those emotions from students:

Online, I had a student in a Rights and Ethnicity class. They wrote some really defaming things about immigration. That was when the anti-immigration movement was really big around 2008 to 2009 . I got on him and said remember, this is a space where opinions don't belong. We want to get it into an academic discussion and coach it toward the sociological terms we have been using. You could see the conversation devolving as more people chimed in attacking the student on a more personal level. They were interjecting. I asked why he thought that way. It is more difficult online definitely because there is a delayed response whereas face to face, you can deal with it right away. Bang. You can stop what we you are doing and address a problem to figure it out. Something is obviously going on there. Online, I know the original post wasn't because he was angry, but the responses were all anger related. (Participant 10)

Participant 11 believed that their ability level and Capacity to manage emotions was fairly sharp. Their discussion addressed the belief that prior to taking an online course, some level of educational training should be required. Furthermore, Participant 11 viewed face to face as more significant than online. But the future of online is still unfolding and students are not receiving the best from their online experiences, because 
they need training on how to engage when enrolled online. To this end, Participant 11

advocated that students need to receive emotional intelligence training in order to thrive from online experiences:

I think that there is probably some kind of training or workshop that could be provided to students to prepare them for the online learning environment I think for us to just have students enroll in school and assume that they know how to be engaged in an online course is really not a good way to go. We need to be training them as to how they can get the most from their online learning experience. It is different. There are some different things that they need to be focused on to do that. I think we need to train them on that in regard to a workshop or something when they first enter school with the understanding that they will be taking online courses. (Participant 11)

A not so pleasant experience was provided by another participant. It was apparent that this had been a difficult situation and had a lingering impact. Before the interviewee responded they exhaled and stated the following "this is a heavy question." The participant continued and described a conflict that occurred while teaching a course, when an uninvited guest attended the face to face class. Participant 15 described how they implemented their PUEI strategies, during the problematic exchange with a student. The story is rather lengthy and details how Participant 15 attempted to manage emotional content and engage in appropriate language, but nothing seemed to work:

I had a student in my classroom and he wasn't even actually my student or a student at WVU. He came into my classroom though and he was very disruptive and stood up and blah, blah, blah. He needed to leave. What he was doing scared me because I thought he was on drugs or crazy or something. But he was very aggressive. That is a big word. You just didn't know what he was going to do. I have never had that kind of situation in my classroom before. I have had two students get in a fight before. I have had two students get in a fight before. I have had some drunk guy over in the corner snoring his head off before. But never have I had a person in my room that made me fearful for myself as well as my other students.

With that right there, I am lecturing and at the same time I am thinking about how I can diffuse it. I was trying to figure out a strategy in my mind. The first thing I did was try to tell him that I would address all of his questions and issues after lecture. Let's get through this and then we will talk about it. I wasn't discounting what he 
was saying, but that would take longer so let's take care of it after class. That worked for about ten minutes and then something else I was lecturing about made him stand up and do it over again. He had an outburst first and I told him we would talk about it after class. He came down the aisle at me and said he was going to the restroom and that he would be right back. He came back. First I said let's talk about it later. Then I used authority and said if there are more outbursts and disturbances, I would have to call security.

He sat down. Ten minutes later, there was another outburst. At that time, I said come down to the front of the class, and we will talk about it. Before you do that, pack up your stuff and bring that with you. While you pack up, I will continue to lecture to the rest of class. He did. It was authority. I told him to do something. I am the figure of authority. When he came down front, I said I am sorry, you need to leave, and you need to leave right now. I walked him out the door and I shut the door.

Basically, I first tried to diffuse it by pushing it off. I can't ignore that with a class of more than 200 people. I will tell you how bad it was. Once I pushed him - I didn't push him, I walked him to the door. When I walked back to the podium, the entire class erupted in applause. I was justified in what I was doing. I am nice and sweet and great and I love everybody all the way up until you are hindering my ability to do my job or you are hindering or being obnoxious or out of line. When there are things like that, now I get aggressive. I guess I was aggressive if you think about it that way. His aggression, after I couldn't diffuse it, then my aggression kicked in. It wasn't that nasty. That is the only thing I can think of to answer that question. (Participant 15)

Strategies can often be tricky as the next participant recalls how management is not always easy, but remaining positive is a choice. The following participant discussed their deliberate efforts to assess maintain a positive disposition (e.g. managing their emotional engagement). Also, this instructor strategy included responding positively, if a student's comment was negative:

I make sure that if there is anything negative presented, I make sure that my response is positive. That is a way in which I always manage. Always being congratulatory to students no matter how bad or incorrect their assignments may be. I always find something positive to say and give them a sense of hope. I let them know that I am looking for their best interest. (Participant 16)

As I have tried to show in describing participant responses and highlighting the themes that were meaningful to participants in STEM, Social Sciences, online, and face 
to face environments. The interviews have provided an opportunity for respondents to have actual active involvement in this particular phenomenon that they have more than enough experience and knowledge with their responses. As the investigator, it was easy to listen to what the respondents had to say and connect to the online and face to face experiences with them. However, some questions were not always supportive for the respondents. There were some occurrences where the questions were not applicable and experiences or strong feelings were viewed from different perspectives.

As shown in Branch I, II, III, and IV, through various dialogic interactions with the respondents in this study, participant seemed to be able to discourse as a beginning for some and at advanced levels for others on constructively describing and explaining the phenomenon of interest from their individual and collective experiences. While responding to the interviews, participants intimately engaged in attempting to making sense and meaning of their professional, personal, and perspectives views presented in this study. Participants eagerly embark upon the issues presented in the interviews, their understanding of each issue was stretched to cover more complicated questions than before.

The discussants information did not seem to come just from their exposure to new perspectives. Rather, it was likely from a process of building their identity and understanding as dual instructors, one from developing as an instructor online and the other in other in face to face, as respondents experimented with their PUEI, currently, and for the future. While responding to the interview questions, their several selves were weaved in what was being presented, further to build their future visions of a better and improved online and face to face PUEI. Some discussants expressed skepticism related 
to necessitating emotional intelligence principles in academia, while others were positively enthusiastic. This investigator deliberated with respondents and encouraged them to reflect and reach back as instructors.

Content analysis triangulation. The goal of collecting syllabi was to attempt to support, compare, and strengthen this study by combining methods known as triangulation (Patton, 2002, p. 247). Therefore, $(N=20)$ participants submitted $(N=40)$ electronic syllabi from their online and face to courses. Some participants submitted one copy indicating syllabi were used for both courses. These artifacts were intended to reinforce the survey and interview data.

Most syllabi suggested evidence of faculty PUEI by the content, assignments, and invitations for students to connect with their individual instructor. Some participants attempted to engage students during the semester with certain phrases. For example, several participants' syllabi for online utilized more personalized language than in their face to face course, unless the same syllabi were used. Of the $(\mathrm{N}=40)$ syllabi, $(\mathrm{N}=34)$ syllabi included the instructor's name and $(\mathrm{N}=6)$ did not reference or list the name of the instructor.

Three substantive questions with subcategories were compared and weighed in a limited way (1) Whether participants' PUEI principles were evident in their syllabi for online and face to face courses? (2) Whether the syllabi reveal, demonstrate, engagement, or offer opportunities for students to connect with instructors? (3) Whether the syllabi are representative of faculties' responses from their PUEI surveys, and interviews? The responses to the three questions are evident in some cases in the information below. 
Of the syllabi collected, each was viewed for content, language, semantic, assignments, opportunities and invitations to connect, instructor/student relationship building, and invitation for office hours or by appointment. All syllabi collected included evidence of a contact number for students to connect with their instructor. The following are illustrations and instances of syllabi employing both indifferent language and personalized language from faculty. Some statements appear to indicate that faculty are attempting to use their PUEI to engage students as evidenced by language, content, phrases, and/or expressions:

- I am sorry to have to address such an uncomfortable and negative subject... (Participant 4)

- Please note:...

- Our progress depends on the overall understanding of the class as a whole

- Referred to themselves as instructor

- Classes may also include group activities...

- Please meet with the instructor if you have...

- I concur with that commitment and expect to maintain a positive learning environment...

- I assume that you check your email daily...

- Comfortable learning environment...

- DO NOT address me as Mr. or Mrs. My mother is not teaching this course so please...

- $\quad Y o u$ will be responsible...

- I will drop your 2 lowest quiz... 
- Communicating with me...

- Please use...

- ...committed to helping you succeed and encourage you to...

- A note on free speech...

- When differences occur, all members of the class are expected to conduct themselves in a civil manner and refrain from personal attacks or such slurs and innuendoes...

- As a courtesy to the instructor and to others, please turn off cell phones during class...

- Instructor expectations of students...

- Students' expectations of instructor...

- Only for individual...

Content analysis triangulation attempted to capture a more comprehensive, allinclusive, and contextual portrayal in a limited manner from the syllabi collection in conjunction with survey reports and interview responses. One example of triangulation and overlap that occurred originated from Participant 4 interview comments in Branch IV (e.g. "I want my students to know I am here"). Also, the first item in the above content analysis triangulation list illustrated Participant 4 PUEI in the syllabi comment.

Several other respondents' syllabi included custom-made comments for students to meet with instructor (e.g. online and in face to face - office visit, chatroom, discussion board, etc.). In this instance the qualitative study used (a) Semi-structured open ended interviews, (b) Document analysis of course material, and (c) Triangulation across participant perspective. 


\section{Chapter 5}

\section{Discussion}

The purpose of this research study was to evaluate faculty perceptions of their use of Emotional Intelligence PUEI in STEM, Social Science, online and face to face Pedagogy and Andragogy. The key findings from the survey indicated that participants scored highest in Branch I Perceiving emotions and Branch IV Managing emotions. The second highest PUEI measure was Branch II Capacity to use emotions. Branch III Capacity to understand emotional meaning reported the lowest mean score. Perhaps this is due to the participants' awareness.

This study draws particular attention to the notable rise of emotional issues in online and face to face. Academic concerns slightly differed between educational contexts (online and face to face). Although, most faculty reported experiencing similar issues with students online and in face to face settings. Emotional intelligence, a complexity often viewed skeptically is a recurring theme for this study and can greatly benefit higher educational institutions, professional learning environments, and businesses particularly.

The participants (faculty) were within a complex field that involved particular personal preferences, hopes, and expectations. Their interviews and surveys helped to identify themes and patterns. This research may begin to illustrate how emotional intelligence and various individual face to face or online experiences can converge over time resulting in positioning the ways faculty interact (students with faculty, faculty with students, and faculty with faculty). To transition into new learning patterns (online and 
face to face) in STEM and Social Science, instructors shared experiences can assist in understanding experiences in higher education environments.

Another point that is interesting from this area is that STEM and Social Science disciplines were not vastly different in their responses. General stereotyping indicate that STEM individual are believed to be lower in social skill. Perhaps, this image notion may be reconsidered at least within professional learning venues. Some educators from this study viewed face to face and online instruction equally effective, while other educators favored/preferred face to face, but were unwilling to give up teaching online. The nearly similar scores indicated from STEM and Social Science disciplines may be a reason to challenge out-of-date stigmatization and labeling of individuals pursuing STEM professions. Perhaps, this study begins the conversation which asks which group has higher interpersonal skills, STEM or Social Sciences. STEM and Social Sciences participants appeared to embrace the opportunity to grapple with interconnected issues in their present work. For example, participants responded to whether teaching should be entertaining, engaging, and informational. More significantly, are their PUEI principles needed to balance the academic classrooms.

Perhaps, faculty believed that face to face instruction endorsed more accurate communication than on-line courses. In referencing interviewee's comments from this study, online is distinguished from face to face. Some participants agreed that, online did not offer the immediacy of real time responses and often was unable to deliver more guaranteed emotionally reliable correct messages.

Based on the nature of online educational settings, the commitment required to interact and maintain recognition with students may have limitations. Respondents in this 
study indicated some challenges, due to limited interaction and lack of incentives for online learning versus traditional settings. One participant indicated that accurate perceptions were probably critical in both environments. Other participants stated that their PUEI to identify cues was easier to utilize in face to face. Generally, face to face interactions allowed faculty to better assess their students, observe, and identify nonverbal cues or signs of disengagement, and emotional issues that may be impacting their students.

It is also interesting to state that females scored higher even though the number of males was greater. It is not known whether the lower scores indicate social and culture norms. As Participant 10 commented about manners and customs:

Everyone has traditions. Everyone has all of those things that they grew up with in their family. Race or sex or gender or sexuality. (Participant 10)

In many ways, the two groups, STEM and Social Sciences were analogous. There were no statistically significant differences between the two groups. But, that is not to say the differences between the STEM and Social Sciences group do not differ, but it means that differences are likely due to chance and not likely due to the manipulation. The nearly similar scores indicated from STEM and Social Science disciplines may be a reason to challenge out-of-date stigmatization and labeling of individuals pursuing STEM professions. Perhaps, this study begins the conversation which asks which group has higher interpersonal skills, STEM or Social Sciences.

Clearly, the participants believe that there is a higher emotional intelligence in traditional classroom delivery than online and that faculty and students alike fare better because of the immediate feedback and available physical connections. Participants reported an increased sense of effectiveness in face to face courses (evident by their 
physical ability/presence to interact and quickly identify/analyze behaviors) reflective in student evaluations. Some participants reported that in face to face situations, students were much more guarded in their comments and more careful about what they said and how they said it. Another advantage identified in this study was that more introverted online students have an opportunity on-line to "come out of their shell" and participate without feeling uncomfortable. Academic struggles for on-line students, however, may go undetected far longer than for students in traditional setting.

Understanding how instructors incorporate Emotional Intelligence online and in face to face instruction can include the practice of emotional strategies and tactics in both teaching environmentsa, and is significant in understanding faculty aptitudes. Table 4 Descriptive Statistics: Branch I The Capacity to Accurately Perceive Emotions illustrates faculty ability to connect with students. Question 7 and Question 8 are (7) "I am able to make emotional connections with my students regardless of my instructional venue" and (8) "Most people I know consider me to be perceptive regarding my emotional state and theirs. " Considering the existing differences and experiences reported by participants online and in face to face, it is critical to support faculty through both instructional environments (e.g., pedagogies and andragogys).

This multiple-case study contributes to the body of knowledge by investigating and informing present practice on emotional intelligence. Additional recommendations include training and assisting students to develop positive and professional practices, while interacting online and in face to face with instructors. The final recommendation emphasizes modifying faculty-student emotional intelligence and interpersonal 
relationships to the changing practice of instructing online, face to face, STEM, Social Sciences in pedagogy and andragogy.

\section{Interview}

Faculty perceptions of face to face and on-line effectiveness suggested that teachers perceived face to face to be more effective, but that online had benefits for both students and faculty that face to face did not offer. Participants agreed that responsibly observing and understanding emotional states belonged to both faculty and students. Both were responsible for mutually relaying information in appropriate tones regardless of whether the interface occurs online or face to face.

Faculty members believed in their competence to manage and understand students' emotional content in both venues but appreciated the advantage they felt in face to face environments. Respondents expressed an openness to embrace students' emotional issues but noted that not all of their colleagues felt the same way. In both venues tone and awareness of emotions were two areas identified as difficult to accomplish at competent levels for both teachers and students. Teachers played an important role in diffusing anger between peers or anger toward instructor.

The Mayer and Salovey (1997) four basic domain concepts tended to easily overlap in data collection for survey and semi-structured interviews. Specific interview questions effectively and adequately fit in more than one branch or category. Questions (e.g., six, twelve, and thirteen) demonstrate the capacity of some interview questions capability to overlap and coincide with more than one branch. The following are three original interview questions (e.g., six, twelve, and thirteen) from this research study that arguably matched survey and syllabi content. 
(1) Interview question number six was analyzed under Branch II, but could readily be matched and analyzed under Branches I and/or Branch III.

a. Example of Question Six:

i. Please provide an example of deliberate efforts you use to strategically assess the mood of students (online and face to face)?

(2) Interview question twelve was analyzed under Branch IV, but has the capacity to be analyzed under Branches II and/or Branch III.

a. Example of Question Twelve:

i. Discuss and describe how you responded/handled and managed the "perceived" hostile tone? What was your process?

(3) Interview question thirteen was analyzed under Branch IV, but has the capacity to be analyzed under Branches I, II, III, or IV:

a. Example of Question Thirteen:

i. Introducing the Definition of Cyber Keyboard Muscles - where inhibitions are lower, and some level of anonymity can be maintained. The act of typing, forwarding, or sending from any electronic device a message which the individual (sender) would most likely not personally verbally state or convey such strong emotional message to the receiver (face to face) otherwise. From the above, provide an example of a cyber keyboard muscles event occurring in your face to face and online venues (e.g. where a student forwarded a c.k.m. via emessage). Think about how you responded and the outcome. Be prepared to describe your memory/reflection of this event.

The above illustration represents three semi-structured interview questions (e.g., six, twelve, and thirteen). These three questions demonstrate potential cross-sectional placement and analyzation between Mayer and Salovey (1997) four branches and semi-structured interview questions created from this study. This investigator attempted to develop a formula to define this study's importance by systematically replicating the iterative process reliably. The process was not always duplicated exactly, since all data could not be considered.

Qualitative data collection include playing with metaphors, concepts, and analogies. One example is the creation of the term cyber keyboard muscles, a concept 
developed during the pilot study phase representing respondents concerns and challenges. Therefore, the creation of the term $(\mathrm{ckm})$ by this investigator is an example of comparisons, analogies, and/or playing with metaphors.

\section{Emotional Intelligence and Online Challenges}

For some instructors maintaining emotional equilibrium and emotional intelligence in on-line instruction was difficult. The lack of a physical presence can make it much easier to disregard students and to avoid an emotional connection with them. The most frequent miscommunication was identified by participants as a lack of respect in virtual written communications. Several participants articulated concerns over the content and nature of email, stating that some on-line students' email responses lack civility and seemed to reflect limited emotional awareness. Not all participants are convinced that PUEI of Emotional Intelligence concepts may be used to improve communication in online and face to face instruction.

During extreme emotional circumstances both faculty and students may require special considerations. Some respondents contended that face to face students are likely to communicate or process their emotions more appropriately than on-line students. According to many participants some passive (introvert) students have the option to hide behind the virtual screen. Some participants noted that often visual imagery and face to face interactions available in face-to-face settings can assist in processing issues in learning environment relationships. It is not founded whether face to face students were seen as better able to engage in healthy emotional behaviors. 


\section{Advantages of Online Instruction}

Participants identified several major advantages that online offered for faculty and students including: a less intimidating environment, limited public speaking assignments, and social interactions for introverted students. Online was viewed as an opportunity for introverted students to be relaxed, and willing to engage, and they pursued more engagement opportunities with their instructor.

\section{Strategies to Managing Emotional Engagement and Language}

Each participant agreed that strategically managing engagement, language, and emotion can be complicated. Overall, for various reasons, faculty favored face to face instruction over online. Respondents reported that face to face offered smoother transitions in communication, immediate ability to assess body language recognition, and the ability to address misinterpretations.

The pedagogical features of online and face to face instruction were reported as distinctly different. Participants elaborated on their PUEI ability to better meet student needs within face to face environments, as online hampered their ability to observe student needs emotionally or physically. The results of this qualitative study indicated that faculty perceptions of Emotional Intelligence on effective instruction favored interactions with students in face to face environments.

\section{Triangulation}

In the previous chapter, Patton (2002) reminded researchers that artifacts do not reveal all (p. 247). The study considered whether the syllabi, survey, and interviewee's perception were substantiated among the three data collection methods. In this instance, although triangulation was used to accompany the qualitative data. Faculty 
(participants) PUEI in this study was studied by combining surveys questionnaires, interpreting semi-structured interviews, and evaluating syllabi content. This investigator searched for the meaning of this triangulation method, in order to interpret the syllabi data. The triangulation method was measured by observing whether faculty PUEI were evident in their syllabi via language, semantic, content, assignments, communication style, were inviting and/or supportive. The scope of triangulation was limited in this study, since the content analysis data (e.g., syllabi) were collected but did not include a detailed discussion with respondents, to explain how content analysis is implemented with their PUEI. But, participants' responses were representative of many of those interviewed, and it is implicit that a larger sample may have found a further range of perceptions of emotional intelligence within various settings (e.g., STEM, Social Science, online, and face to face).

\section{Future Research}

Other considerations for future studies include removing Mayer and Salovey (1997) emotional intelligence branch concepts for respondents to openly react to questions, without intervening theory. The intent of open questions invites participants to describe their PUEI online, face to face, STEM, and Social Science without constraints or the need to fit within the limitations of emotional intelligence branches. One example will include re-interviewing participants to thoroughly discuss syllabi, what participants thought about syllabi, and more probing questions related to syllabi and their PUEI.

As demands increase for accessing online, face to face, hybrid courses, preparing instructors and students to be dynamic users of Emotional Intelligence within both venues would support the evolution of distance learning. Using Emotional Intelligence to 
determine students' perception of effectiveness could be considered for future research. Studies of effectiveness and best use of Emotional Intelligence constructs in face to face and online venues could include collaborations between instructors and students perceptions. Simultaneously, this study should evaluate which face to face, online, and/or hybrid learning environment provides optimal achievable outcomes for higher educational: a) degrees, b) certificates, and c) courses. Thus, the debate among higher education institutions is to determine which pedagogical or andragogical format is suited for specific occupations (e.g., Social Science/client services professions). Given these findings, the role and impact of Emotional Intelligence and effective instruction should be explored online and in face to face instruction as technology usage increases and face to face interaction decreases.

Other questions that emerged from this study that may also be considered a limitation include investigating (a) how to serve a diverse group of students with varying learning needs, (b) from different disciplines, and (c) whether gender differences matter online and/or in face to face, (d) exploring the differences between faculty instructing in asynchronous and/or synchronous learning environments.

While the results of this study are bound to the contextual responsibilities in academe, conclusions gathered from respondents can be applied and implemented in different settings. Building on the results of this study and regardless of the learning milieu, faculty ambition is to witness student learning processes, engage/draw shyer students out online, and into dialogue and discussion. 


\section{Limitations}

The study was limited to 20 full-time voluntary faculty participants instructing at higher education institutions. However, the inclusion of a larger data base (e.g., sample of faculty members) would provide additional value. Next, the survey, semi-structured interview questions, and content analysis did not incorporate more descriptive online questions (e.g., asynchronous and/or synchronous) and did not include the type of learning environments faculty instructed. Additionally, this study was limited in resources and time to conduct and recruit additional participants.

This researcher's interest in Emotional Intelligence models prompted this study. Therefore, an investigation of faculty Perceptions of Using Emotional Intelligence PUEI in academia (online and face to face) was conducted to examine technology instruction in emotional intelligence, and a variety of disciplines including the following related issues: (e.g., emotional tone, emotional content, interpersonal relationships, and interpersonal skills). The above limitations are not uncommon issues. Shortages of resources or difficulties gaining access to research participants are cited as common motivations for choosing a multiple case study approach as a primary method of investigation. 


\section{References}

Allix, N. M. (2000). The theory of multiple intelligences: A case of missing cognitive matter. Australian Journal of Education, 44, 272-288.

Appleton, K. (1997). Analysis and description of students' learning during science classes using a constructivist-based model. Advances in Law \& Child Development, 34(3), 303-318.

Altheide, D.L., (1987). Ethnographic content analysis. Qualitative Sociology, 10(1), 6577.

Bandura, A. (1977). Self-efficacy: Toward a unifying theory of behavioral change. Psychological Review, 84, 191-215.

Baran, E. (2011). The transformation of online teaching practice: Tracing successful online teaching in higher education. (Ph.D., Iowa State University). ProQuest Dissertations and Theses.

Barchard, K. A. (2003). Does emotional intelligence assist in the prediction of academic success? Educational \& Psychological Measurement, 63(5), 840-858.

Bar-On, R. (1988). The development of a concept of psychological well-being. Unpublished doctoral dissertation. Rhodes University, South Africa.

Bar-On, R. (1997). Emotional quotient inventory (EQ-i): A measure of emotional intelligence. Toronto, Canada: Multi-Health Systems.

Bar-On, R. (2000). Emotional and social intelligence: Insights from the emotional quotient inventory (EQ-i) In R. Bar-on and J. D. A. Parker (eds.), Handbook of Emotional Intelligence. San Francisco: CA Jossey-Bass. 
Bar-On, R. (2003). How important is it to educate people to be emotionally and socially intelligent, and can it be done? Perspectives in Education, 21(4), 3-13.

Bar-On, R. (2004). The bar-on emotional quotient inventory (EQ-i): Rationale, description and summary of psychometric properties. Hauppage, NY: Nova Science Publishers.

Bar-On, R., \& Parker, J. D. A. (2000). The handbook of emotional intelligence: Theory, development, assessment, and application at home, school, and in the workplace. San Francisco, CA: Jossey-Bass.

Bar-On, R., Tranel, D., Denburg, N. L., \& Bechara, A. (2003). Exploring the neurological substrate of emotional and social intelligence. Brain: A Journal of Neurology, 126(8), 1790-1800. Retrieved from doi:10.1093/brain/awg177

Becher, T., \& P. Trowler. 2001. Academic tribes and territories: Intellectual enquiry and the cultures of disciplines. 2nd ed. Buckingham, UK: SRHE and Open University Press.

Bejus, J. (2013) “Online learning” Progressive Economists listserv(pen$1 @$ lists.csuchico.edu). May 9.

Brooks, D. C. (2011). Space matters: The impact of formal learning environments on student learning. British Journal of Educational Technology, 42(5), 719-726.

Blake, N. (2000). Tutors and students without faces or places. Journal of Philosophy of Education, 34(1) 183-198.

Bower, B. L., \& Hardy, K. P. (2004). From correspondence to cyberspace: Changes and challenges in distance education. New Directions for Community Colleges, 2004(128), 5-12. 
Boyatzis, R., \& McKee, A. (2006). Intentional change. Journal of Organizational Excellence, 25(3), 49-60.

Cherniss, C., Extein, M., Goleman, D., \& Weissberg, R. P. (2006). Emotional intelligence: What does the research really indicate? Educational Psychologist, 41(4), 239-245.

Chronology of teaching (Anonymous, 2015). Retrieved from https://www.google.com/search?q=picture + of $+440+$ Xenophon + of + Athens \&biw $=12$ 70\&bih $=784 \&$ tbm $=i$ sch $\&$ tbo $=u \&$ source $=$ univ\&sa $=X \&$ ei $=v V M-$ VYfGA42byQSXh4CgBQ\&ved=0CDgQ7Ak

Ciarrochi, J., \& Blackledge, J. T. (2006). Mindfulness-based emotional intelligence training: A new approach to reducing human suffering and promoting effectiveness. In J. Ciarrochi, J. R. Forgas, \& J. D. Mayer (Eds.), 206-228. Hove England: Psychology Press/Erlbaum (UK) Taylor \& Francis.

Clegg, S. (2008). Academic identities under threat? British Educational Research Journal. 34(3), 329-345.

Cole, M., \& Bruner, J.S. (1971). Culture differences and inferences about psychological process. American Psychologist, 26, 867-876.

Comas-Quinn, A. (2011). Learning to teach online or learning to become an online teacher: An exploration of teachers' experiences in a blended learning course. Recall, 23(3), 218-232.

Conlin, M. (2004). I'm a bad boss? Blame my dad. Business Week, (3882), 60-61. 
Davies, M. Stankov, L., Roberts, R. D. (1998). Emotional intelligence: In search of an elusive construct. Journal of Personality and Social Psychology, 75(4), 989-1015. Retrieved from doi:10.1037/0022-3514.75.4.989

Delanty, G. 2008. Academic identities and institutional change. In Changing identities in higher education: Voicing perspectives, eds. R. Barnett and R. Di Napoli, 124-133. London: Routledge.

Denham, S. A. (1998). Emotional development in young children. 1-260. New York: Guilford.

Desroches, B. (1995). Your boss is not your mother (1st edition). New York: William Morrow \& Co.

Desroches, B. (2006). Your boss is not your mother: Creating autonomy, respect, and success at work (2nd ed.). Evanston, Illinois: Agate.

Díaz, L. A., \& Entonado, F. B. (2009). Are the functions of teachers in e-learning and face-to-face learning environments really different? Journal of Educational Technology \& Society, 12(4), 331-343.

Dickson, W. P. (1985). Thought-provoking software: Juxtaposing symbol systems. Educational Researcher, 14(5), 30-38.

Driscoll, M. (2001). Psychology of learning for assessment. (2nd ed.). Boston: Allyn and Bacon.

Elias, M. J., Zins, J. E., Weissberg, R. P., Frey, K. S., Greenberg, M. T., Haynes, N. M., Kessler, R., Schwab-Stone, M. E., \& Shriver, T. P. (1997). Promoting social and emotional learning: Guidelines for educators. Virginia: Association for Supervision and Curriculum Development. 
Ellis, R., Goodyear, P., O’Hara, A., \& Prosser, M. (2007). The university student experience of face-to-face and online discussions: Coherence, reflection and meaning. ALT-J. Research in Learning Technology, 15(1), 83 - 97.

Fabio, A. D., \& Palazzeschi, L. (2008). Emotional intelligence and self-efficacy in a sample of Italian high school teachers. Social Behavior and Personality, 36(3), 315326.

Fleming, D. (2004). Leadership wisdom from unlikely voices. California: Zondervan Press.

Freud, S. (1930). Civilization and its discontents. Austria: Internationaler Psychoanalytischer Verlag Wien.

Gardner, H. (1983). Frames of mind: The theory of multiple intelligences. New York: Basic Books.

Gardner, H. (1991). The unschooled mind: How children think and how schools should teach. New York: Basic Books.

Gardner, H. (1993). Frames of mind: Theory of multiple intelligences. Waukegan, IL: Fontana Press.

Gardner, H. (1999). Intelligence reframed. New York: Basic Books.

Gardner, H. (2011). Frames of mind. The theory of multiple intelligences ( $3^{\text {rd }}$ ed.). New York: Basic Books.

Gardner, H. \& Davis, K. (2013). The app generation: How today's youth navigate identity, intimacy, and imagination in a digital world. New Haven: Yale University Press. 
Gardner, H., \& Hatch, T. (1989). Multiple intelligences go to school: Educational implications of the theory of multiple intelligences. Educational Researcher, 18(18), 4-9.

Georgouli, K., Skalkidis, I., \& Guerreiro, P. (2008). A framework for adopting LMS to introduce e-learning in a traditional course. Journal of Educational Technology \& Society, 11(2), 227-240.

Giddens, A. (1991). Modernity and self-identity. Cambridge, MA: Polity Press.

Goldstein, B. (2013). As MOOCs move mainstream, universities must pay to play. Education's Digital Future Stanford Graduate School of Education University Entrepreneur in Residence. Retrieved from http://edf.stanford.edu/readings/moocsmove-mainstream-universities-must-pay-play

Goldsworthy, R. (1999). Lenses on learning and technology: Roles and opportunities for design and development. Educational Technology, 39(4), 59-62.

Goldsworthy, R. (2002). Supporting the development of emotional intelligence through technology. Computers in the Schools, 19(1), 119-148.

Goleman, D. (1998). Working with emotional intelligence. New York: Bantam.

Goleman, D. P. (1995). Emotional intelligence: Why it can matter more than IQ for character, health and lifelong achievement. Bantam Books, New York.

Goleman, D. (1999). Emotional intelligence. New York: Bloomsbury.

Gubrium, J. J., \& Holstein, J. A. (2001). Handbook of Interview Research (1st ed.). Thousand Oaks, CA : Sage 
Hallström, J., \& Gyberg, P. (2011). Technology in the rear-view mirror: How to better incorporate the history of technology into technology education. International Journal of Technology \& Design Education, 21(1), 3-17.

Han, H., \& Johnson, S. D. (2012). Relationship between students' emotional intelligence, social bond, and interactions in online learning. Journal of Educational Technology \& Society, 15(1), 78-89.

Hanson, J. (2009). Displaced but not replaced: The impact of e-learning on academic identities in higher education. Teaching In Higher Education, 14(5), 553-564.

Harris, S. 2005. Rethinking academic identity in neo-liberal times. Teaching in Higher Education, 10(4), 421- 433.

Hardy, K. P., \& Bower, B. L. (2004). Instructional and work life issues for distance learning faculty. New Directions for Community Colleges, 128, 47-54.

Hein, S. (2003). Emotional intelligence, emotional abuse, emotional support. The dark side of emotional intelligence. Retrieved from http://stevehein.com

Hein, S. (2005). Introduction and history of emotional intelligence. Innate emotional intelligence vs "EQ". Retrieved from http://www.core.eqi.org/history.htm\#Innate\%20Emotional\%20Intelligence $\% 20 \mathrm{vs} \% 2$ $0 \% 22 \mathrm{EQ} \% 22$

Hein, S. (2006, December 13). Emotional intelligence, emotional abuse, emotional support. The dark side of emotional intelligence. Retrieved from http://stevehein.com Hein, S. (2012). Emotional intelligence, emotional abuse, emotional support. The dark side of emotional intelligence. Retrieved from http://stevehein.com 
Henkel, M. (2000). Academic identities and policy change in higher education. London: Jessica Kingsley.

Herrnstein, R. J. \& Murray, C. (1994). The bell curve. New York: Free Press.

Hosie, P., Forster, N., \& Sevastos, P. (2004). The impact of global pressures on the affective well-being of Australian managers' performance. Research and Practice in Human Resource Management, 12(1), 134-171.

Humphrey, N., Curran, A., Morris, E., Farrell, P., \& Woods, K. (2007). Emotional intelligence and education: A critical review. Educational Psychology, 27(2), 235254.

Hurt, J. (2008). The advantages and disadvantages of teaching and learning on-line. Delta Kappa Gamma Bulletin, 74(4), 5-11.

Institute for the Future (IFTF). (2014). Mapping educational institutions to learning flows: Our work. Retrieved from http://www.iftf.org/our-work/globallandscape/learning/from-educational-institutions-to-learning-flows/

Jeffcoat B. S., \& Golek, J. H. (2004). Evaluating the cost effectiveness of online and face-to-face instruction. Educational Technology \& Society, 7(4), 167-175.

Jorgenson, O. (2003). Brain scam? Why educators should be careful about embracing brain research. The Educational Forum, 67, 364-369.

Kettner-Polley, R. (2000). Social interaction systems: Theory and measurement. Society, 37(5), 92-93.

King, M. L. K., Jr. (January-February 1947). "The purpose of education." The Papers of Martin Luther King, Jr., King's Papers Project. 
Kinman, G., Jones, F., \& R. Kinman. (2006). The well being of the UK academy 19982004. Quality in Higher Education, 12(1), 15-27.

Kremenitzer, J. (2005). The emotionally intelligent early childhood educator: Selfreflective journaling. Early Childhood Education Journal, 33(1), 3-9.

Kolowich, S., (2013). Why some colleges are saying no to MOOC deals, at least for now. The Chronicle of Higher Education-Technology. Retrieved from http://chronicle.com/article/Why-Some-Colleges-Are-Saying/138863/

Kolowich, S., (2013). Why professors at San Jose State won't use a Harvard professor's MOOC. The Chronicle of Higher Education-Technology. Retrieved from http://chronicle.com/article/Professors-at-San-Jose-State/138941/.

Kremenitzer, J. P. (2005). The emotionally intelligent early childhood educator: Selfreflective journaling. Early Childhood Education Journal, 33(1), 3-9.

Lafair, S. (2009). Don't bring it to work: Breaking the family patterns that limit success. San Francisco: Jossey-Bass.

Landy, F. J. (2005). Some historical and scientific issues related to research on emotional intelligence. Journal of Organizational Behavior, 26, 411-454.

Lane, C. (1994). The tainted sources of 'The Bell Curve'. New York Review of Books, 41(20), 14-18.

Leon, A. C., Davis, L. L., \& Kraemer, H. C. (2011). The Role and Interpretation of Pilot Studies in Clinical Research. Journal of Psychiatric Research, 45(5), 626-629. doi:10.1016/j.jpsychires.2010.10.008 
Lerner, J. S., Small, D. A., \& Loewenstein, G. (2004). Heart strings and purse strings: Carry-over effects of emotions on economic transactions. Psychological Science, 15(5), 337-341.

Lincoln, Y. S., \& Guba, E. G. (1985). Naturalistic inquiry. Thousand Oaks, CA: Sage.

Locke, E. A. (2005). Why emotional intelligence is an invalid concept. Journal of Organizational Behavior, 26, 425-432.

Mandel, J. (2006). Your boss is not your mother: Eight steps to eliminating office drama and creating positive relationships at work (1st ed.). Evanston, Illinois: Agate.

Mayer, J. D. (2001a). A field guide for emotional intelligence. In J. Ciarrochi, J. P. Forgas, \& J. D. Mayer (eds.). Emotional intelligence and everyday life, 3-24, New York: Psychology Press.

Mayer, J. D. (2001b). Primary divisions of personality and their scientific contributions: From the trilogy-of-mind to the systems set. Journal for the Theory of Social Behaviour, 31(4), 449-477. doi:10.1111/1468-5914.00169

Mayer, J. D. (2008). Personal intelligence. Imagination, cognition, and personality. 27(3), 209-232. New York: Baywood. doi: 10.2190/IC.27.3.b. Retrieved from http://thecfce.com/wp-content/sitefiles/dev/strengths/soci003.pdf

Mayer, J. D. (2013). Personality described. Psychology Today. Retrieved from http://www.psychologytoday.com/blog/the-personality-analyst/201312/personalitydescribed

Mayer, J. D. (2014). Know thy self. Psychology Today. Retrieved from http://www.psychologytoday.com/articles/201402/know-thyself 
Mayer, J. D., \& Caruso, D. R. (1999). Emotional intelligence meets traditional standards for an intelligence. Intelligence, 27(4), 267.

Mayer, J. D., Caruso, D., \& Salovey, P. (1999). Emotional intelligence meets traditional standards for an intelligence. Intelligence, 27, 267-298.

Mayer, J. D., Caruso, D., \& Salovey, P. (2000). Selecting a measure of emotional intelligence: The case for ability scales, In R. Bar-on, \& J. D. A. Parker (Eds.). The Handbook of Emotional Intelligence, 320 - 342, San Francisco: Wiley \& Sons

Mayer, J. D., DiPaolo, M. T., \& Salovey, P. (1990). Perceiving affective content in ambiguous visual stimuli: A component of emotional intelligence. Journal of Personality Assessment, 54, 772-781.

Mayer, J. D. \& Gaschke, Y. (1988). The experience and meta-experience of mood. Journal of Personality and Social Psychology, 55, 102-111.

Mayer, J. D., \& Geher, G. (1996). Emotional intelligence and the identification of emotion. Intelligence, 17, 89-113.

Mayer, J. D., Panter, A.T., \& Caruso, D. R. (2012). Does personal intelligence exist? Journal of Personality Assessment, 94, 124-140.

Mayer, J. D., \& Salovey, P. (1993). The intelligence of emotional intelligence. Intelligence, 17(4), 433-442.

Mayer, J. D., \& Salovey, P. (1997). What is emotional intelligence? In P. Salovey \& D.J. Sluyter (eds.), Emotional development and emotional intelligence: Educational implications. 3-31.

Mayer, J. D., Salovey, P., \& Caruso, D. (2000). Models of emotional intelligence. In R. J. Sternberg (ed.), 396-420. New York, NY: Cambridge University Press. 
Mayer, J. D., Salovey, P., \& Caruso, D. R. (2002). Mayer-Salovey-Caruso emotional intelligence test (MSCEIT) item booklet.

Mayer, J. D., Salovey, P., \& Caruso, D. R. (2004). Emotional intelligence: Theory, findings, and implications. Psychological Inquiry, 15(3), 197-215.

Mayer, J. D., Salovey, P., \& Caruso, D. R. (2008). Emotional intelligence new ability or eclectic traits? American Psychologist, 63(6), 503-517. doi:10.1037/0003066X.63.6.503

Mayer, J. D., Salovey, P., Caruso, D. R., \& Sitarenios, G. (2001). Emotional intelligence as a standard intelligence. Emotion, 1(3), 232-242. doi:10.1037/1528-3542.1.3.232

McKenna, B. (2013). Predatory pedagogy. Society for Applied Anthropology. 24(2), 2127. Retrieved from http://192.163.234.187/ sfaanet/news/index.php/archive/volumes-20-24/.

Merriam, S. B. (2001). Qualitative Research. Jossey-Bass. San Francisco, CA.

Merriam, S. B. (2009). Qualitative Research. Jossey-Bass. San Francisco, CA. Morgan, S. E., Reichert, T., Harrison, T. R. (2002). From numbers to words: reporting statistical results for the social sciences. Allyn and Bacon. Boston, MA.

Murphy, A. P. (1999). Promotional intelligence. A Digital Salon. Retrieved from http://www.salon.com/1999/06/28/emotional/

Nixon, J. (1996). Professional identity and the restructuring of higher education. Studies in Higher Education, 21(1), 5-16.

Patton, M. Q. (2002). Qualitative research and evaluation methods (3rd ed.). Sage Thousand Oaks, CA. 
Payne, W. L. (1986). A study of emotion: Developing emotional intelligence; selfintegration; relating to fear, pain and desire. Retrieved from (Unpublished Dissertation Abstracts International). University Microfilms, (No. AAD9-5947), 47, (1-A) 203A)

Perry, C. W. (2012). Constructing professional identity in an online graduate clinical training program: Possibilities for online supervision. Journal of Systemic Therapies, 31(3), 53-67. doi:10.1521/jsyt.2012.31.3.53

Prenksy, M. (2001). Digital natives, digital immigrants. On the Horizon, 9(5), 1-6.

Powell, S. R., \& Ross, M. R. (2003). Building capacity from within: Changing the adult working environment in our schools. In Elias, M. J., Arnold, H., \& Hussey, C. (eds.). $E Q+I Q=$ Best leadership practices for caring and successful schools. 89-99, Thousand Oaks, CA: Corwin Press.

Quillen, I. (2012). When technology tools trump teachers. Education Week, 31(37), 1-21.

Radford, M. (2003). Emotional intelligence and education. International Journal of Children's Spirituality, 8(3), 255-268. doi:10.1080/1364436032000146520

Roberts, R. D., Zeidner, M., \& Matthews, G. (2001). Does emotional intelligence meet traditional standards for an intelligence? Some new data and conclusions. Emotion, 1(3), 196-231. Retrieved from doi:10.1037/1528-3542.1.3.196

Rosa, M. \& Lerman, S. (2011). Researching online mathematics education: Opening a space for virtual learner identities. Educational Studies in Mathematics, 78(1), 6990. doi:10.1007/s10649-011-9310-9

Rubin, M. M. (1999). Emotional intelligence and its role in mitigating aggression: A correlational study of the relationship between emotional intelligence and 
aggression in urban adolescents. (Unpublished Dissertation). Immaculata College, Immaculata, Pennsylvania.

Saarni, C. (2000). Emotional competence: A developmental perspective. In R. Bar-On \& J. D. A. Parker (eds.), The handbook of emotional intelligence, 68-91. San Francisco: Jossey-Bass.

Salovey, P., \& Grewal, D. (2005). The science of emotional intelligence. Current Directions in Psychological Science (Wiley-Blackwell), 14(6), 281-285. doi:10.1111/j.0963-7214.2005.00381.x

Salovey, P., \& Mayer, J. D. (1990). Emotional intelligence. Imagination, cognition \& personality, 9(3), 185-211.

Salovey, P., \& Sluyter, D. J. (eds.). (1997). Emotional development and emotional intelligence: Educational implications. New York: Basic Books.

Senior, C., Howard, C., Reddy, P., Clark, R., \& Lim, M. (2012). The relationship between student-centred lectures, emotional intelligence, and study teams: A social telemetry study with mobile telephony. Studies in Higher Education, 37(8), 957-970. Retrieved from doi:10.1080/03075079.2011.556719

Seok, S., DaCosta, B., Kinsell, C., \& Tung, C. K. (2010). Comparison of instructors' and students' perceptions of the effectiveness of online courses. Quarterly Review of Distance Education, 11(1), 25-36.

Singh, P., \& Pan, W. (2004). Online education: Lessons for administrators and instructors. College Student Journal, 38(2), 302-308.

Skinner, B. F. (1978). Reflections on behaviorism and society. Upper Saddle River, New Jersey: Prentice Hall. 
Smith, L. G., \& Smith, J. K. (1994). A narrative of people and ideas. Lives in Education.

Stake, R. E. “Case Studies.” In N. K. Denzin and Y. S. Lincoln (eds.), Handbook of Qualitative Research. Thousand Oaks, Calif.: Sage, 1994.

Stern, E. (2005). Pedagogy meets neuroscience. Science, 310, 745.

Talbert's (2014). Blending and flipping modern architecture. The Chronicle of Higher Education. A Digital Salon. Retrieved from http://chronicle.com/blognetwork/castingoutnines/2014/06/23/guest-post-blendingand-flipping-modern-architecture/

Talbert, R., (2014). Grand Challenges for Mathematics Education. The Chronicle of Higher Education. A Digital Salon. Retrieved from http://chronicle.com/blognetwork/castingoutnines/2014/06/28/grand-challenges-formathematics-education/

Tatli, Z., \& Ayas, A. (2012). Virtual chemistry laboratory: Effect of constructivist learning environment. Turkish Online Journal of Distance Education, 13(1), 183199.

Teijlingen, E., \& Hundley, V. (2004). Pilot Study. In Michael S. Lewis-Beck, A. Bryman, \& Tim Futing Liao (Eds.), The SAGE Encyclopedia of Social Science Research Methods. (pp. 824-825). Thousand Oaks, CA: Sage Publications, Inc. doi: http://dx.doi.org/10.4135/9781412950589.n715

U.S. Department of Education, National Center for Education Statistics. (2003). Distance Education at Degree-Granting Postsecondary Institutions: 2000 - 2001 (NCES No. 2003 - 017). Washington, D.C.: U.S. Department of Education. Retrieved from http://nces.ed.gov/pubs2003/2003017.pdf. 
United States Distance Learning Association. Distance Learning Glossary, n. d. http://www.usdla.org/html/resources/dictionary.htm.

Urtel, M. G. (2008). Assessing academic performance between traditional and distance education course formats. Journal of Educational Technology \& Society, 11(1), 322330.

Vesely, A. K., Saklofske, D. H., \& Leschied, A. D. W. (2013). Teachers-The vital resource: The contribution of emotional intelligence to teacher efficacy and wellbeing. Canadian Journal of School Psychology, 28(1), 71-89. doi:10.1177/0829573512468855

Vygotsky, L. S. (1987). The collected works of L.S. Vygotsky. R. W. Rieber, \& A. Carton (eds). New York: Plenum Press.

Waterhouse, L. (2006a). Multiple intelligences, the mozart effect, and emotional intelligence: A critical review. Educational Psychologist, 41(4), 207-225. doi:10.1207/s15326985ep4104_1

Waterhouse, L. (2006b). Inadequate evidence for multiple intelligences, mozart effect, and emotional intelligence theories. Educational Psychologist, 41(4), 247-255.

Willis, J. W. (2007). Foundations of qualitative research: Interpretive and critical approaches. Thousand Oaks, CA: Sage.

Yang, Y., Cornelious, L., \& Association for Educational Communications, and Technology. (2004). Ensuring quality in online education instruction: What instructors should know? (pp. 847-860). Association for Educational Communications and Technology. 
Zeidner, M., Matthews, G. M., \& Roberts, R. D. (2001). Slow down, you move too fast: Emotional intelligence remains an "elusive" intelligence. Emotions, 1, 265-275.

Zeidner, M., Matthews, G., \& Roberts, R. D. (2004). Emotional intelligence in the workplace: A critical review. Applied Psychology: An International Review, 53(3), 371-399. doi:10.1111/j.1464-0597.2004.00176.x

Zeidner, M., Roberts, R. D., \& Matthews, G. (2002). Can emotional intelligence be schooled? A critical review. Educational Psychologist, 37(4), 215-231.

Zheng, L., \& Smaldino, S. (2003). Key instructional design elements for distance education. Quarterly Review of Distance Education, 4(2), 153-165.

Zheng, L., \& Smaldino, S. E. (2006). Teachers' perceptions of the application of design elements. Quarterly Review of Distance Education, 7(1), 35-47. 
Appendix A

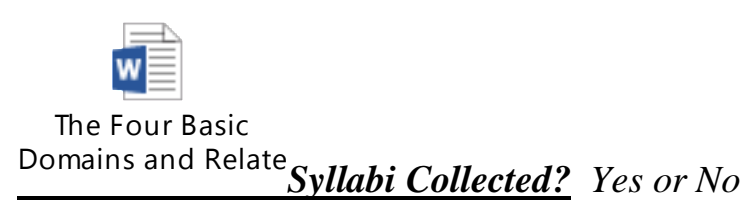

Be sure to collect two syllabi which are typical examples of your online and face to face courses. Please forward a digital copy prior to the interview. Thank you.

Consent Form Collected? Yes or No

If consent form was forwarded prior to the scheduled interview (request permission to modify consent form interview date).

\section{Survey Questions:}

Allow participants to briefly discuss the survey: (e.g. length, meaning, and support to faculty and students, thoughts, concerns, or comments)?

\section{Special Note to Participants:}

The survey contained two sections: Part 1 and Part 2. Part 2 was optional, but all were encouraged to complete both sections. Meanwhile, if you proceeded to (Part 2) of the survey, a scale discrepancy was identified on a few questions at the end of the questionnaire. You may either disregard and/or send me an email response to the ambiguous questions, if you prefer. As such, the decision was made to keep the survey understanding as is, to avoid invalidating previous participant responses. Thus, all participants will encounter the same information. Thank you for.

Interview: Are you ready to begin the interview?

Please respond to the each question based on your experiences in both (online and face to face) courses, unless it is not applicable.

\section{INFORM PARTICIPANT----WHEN RECORDING BEGINS}

\section{Review: Mayer and Salovey four basic domains and related skills: (Mayer et al., 1997, p.} 108):

The capacity to accurately perceive emotions:

The capacity to use emotions to facilitate thought:

The capacity to understand emotional meaning:

The capacity to manage emotions

Thank you for joining me, today is and my name is Eveldora Wheeler. I am a doctoral candidate in Educational Psychology at West Virginia University in the College of Education and Human Services and Department of Learning Sciences and Human Development. My dissertation topic is:

“What are Faculty Perceptions of Using Emotional Intelligence in Pedagogy and Andragogy?" 
I am interviewing: who has volunteered to participate in this study. During the interview, please feel free to let me know if we need to pause for any reason. You may skip questions that you do not feel comfortable answering. Again, thank you for joining me.

\section{Opening Questions:}

Please describe your current vicinity, room, where you are seated/standing, why you chose this locality, and your thoughts/feelings? Life's pace seems to be faster and faster; how do you attempt to maintain a balance between work, school, family/kids, social, etc.?

\section{Introduction:}

- Participant's name, degree(s) earned (which Institution)?

- Please describe and explain your teaching experiences:

- Institution's name/location where participant instructed online/face to face?

- Title of teaching position, what program and/or college(s)?

- How many years of online and face to face instruction? Are or were the courses in STEM or Social Science disciplines? What is the name/level of courses you are currently teaching/taught in face to face and online?

- Describe your unique teaching style in face to face and online? Please provide examples? Which environment do you prefer and/or which is most suitable for your teaching style?

- How do you describe yourself (e.g. introvert, extrovert, or other), please explain?

- What are your perceptions of your own: (a) comfort level and $(b)$ effectiveness?

- What is your experience level(s) with technology and what formal training have you received in face to face and online course? How would you describe yourself: Digital native (extremely familiar/accustomed) or digital immigrant (new to technology-last five years)?

\section{Interview Questions categorized by Branches I, II, III, and IV:}

Branch I - The capacity to accurately perceive emotions (Perception, appraisal, and expression of emotion)

The next few question request that you react to statements:

(1) How important is it to accurately acknowledge and be aware of the emotional issues/needs of your students in your online/face to face courses? Please explain your response?

(2) How do you accomplish Compare your awareness of your emotions in face in your face to face vs online courses, please explain?

(3) Explain how you maintain emotional awareness and/or emotional connections--- in face to face or online venue? Is one more challenging than the other, please explain? 
Branch II - The capacity to use emotions (Emotional facilitation of thinking)

Reflection on practice and usage-Think of a time:

(4) How do you Project, Create, Establish, or Accomplish the right tone online and in face to face?

For educational purposes, the following questions ask you to think about which learning environment you believe is more significant (e.g. online or face to face):

(5) If you were to provide a description to someone learning/hearing about face to face and online courses for the first time, explain the concrete differences between the two milieus?

(6) Please provide an example of deliberate efforts you use to strategically assess the mood of students (online and face to face)?

(7) What are some advantages and disadvantages for you when using E.I. online and face to face? What are advantages and disadvantages for students?

Branch III The capacity to understand emotions (Understanding and Analyzing Emotions)

The next few question require you to react to a few statements. Learning is about engagement and "all involved must do their part to participate":

(8) Discuss whether it is necessary or socially important for faculty and students to be mutually responsive when communicating with one another in face to face or online?

(9) Explain how you maintain emotional awareness and/or emotional connections--- in face to face or online venue? Is one more difficult than the other, if so, please explain?

(10) In your experience, generally what has been the impact of online and face to face professional learning environments on introverted/extroverted/other students (e.g. social contributions in class discussions)?

Branch IV The capacity to manage emotions (Reflective Regulation of Emotions)

Emotional Intelligence Principles Examined - more or less significant when teaching online or face to face courses:

(11) What additional strategies or Emotional Intelligence principles have you utilized to manage your emotional engagement and/or language practices with students online and face to face venues?

Introduce the Definition of Cyber Keyboard Muscles - where inhibitions are lower, and some level of anonymity can be maintained. The act of typing, forwarding, or sending from any electronic device a message which the individual (sender) would most likely not 
personally verbally state or convey such strong emotional message to the receiver (face to face) otherwise. From the above, provide an example of a cyber keyboard muscles event occurring in your face to face and online venues (e.g. where a student forwarded a c.k.m. via e-message). Think about how you responded and the outcome. Be prepared to describe your memory/reflection of this event:

(12) Discuss and describe how you responded/handled and managed the "perceived" hostile tone? What was your process?

Aggression:

Identify and describe a time when you dealt with student aggression (online and face to face) (e.g. a time when a student ignored your email or electronic communication, please explain):

(13) Describe your reaction to an emotional event during class? How do you feel you managed the impact with students?

Next, describe a personal/emotional event that may have spilled over into the classroom. In general, how much did your emotions effect your level of engagement during instruction (online and face to face) Think of a time when you experienced or viewed a student's tone during communication as aggressive (e.g. face to face, online, or other):

(14) What comes to mind when I state tone vs. words (clarity) in face to face and online?

(15) For educational purposes, which learning environment is more significant (e.g. online or face to face)?

Communication Tools and Identity Construction:

(16) What other communication tools should be considered when teaching online or face to face?

(17) How do you construct a professional identity/presence in your face to face/online courses?

Allow participant to include additional information, as needed?

Thank you for your participation.

Offer five dollar gift card and/or letter of participation (request address to forward letter, for hardcopy). 


\section{Appendix B}

Participants, please review the Verbal Script form providing me with permission to use your words for the purpose of the study and providing details of the study.

\section{Dear Professor,}

Thank you for taking time to receive my email. I hope your semester is going well. My name is Eveldora Wheeler and I am collecting data in pursuit of my Ed.D. Educational Psychology degree from West Virginia University. I am conducting a voluntary qualitative and quantitative study with higher education faculty that have taught both face to face and online courses. If you have taught both, face to face and online courses: "Will you provide me with your feedback, in a 25-30 minutes interview?" I will need to collect two syllabi prior to the interview via email: one from an online and one from a face to face course you have taught.

The selection level of participants include: (a) faculty that have taught in post-secondary milieus and (b) both face to face and online environments during one's teaching career. The research question is: "What are Faculty Perceptions of Using Emotional Intelligence in Pedagogy and Andragogy?" The dissertation study goal is to specifically measure and explore faculty's view and description of Emotional Intelligence use in face to face and online professional learning environments.

The goals are simple but important. This study will document faculty's voice and description of the potential impact of computer-generated and traditional instruction (face to face and online). Faculty and higher education institutions can gain knowledge to support best practices for learning and teaching as instructor's transition between face to face and online venues. Faculty perceptions are critical in digital and traditional classrooms of higher learning. Thus, your feedback as an instructor is invaluable. Participants are required to: sign one consent form, forward two electronic syllabi (e.g. online and face to face), complete one survey, and one recorded interview. Participants completing the above will receive a one-time \$5.00 dollar Star Bucks gift card. I hope you will take time to participate.

Please note, participates must be 18 years of age or older. This study presents minimal risk, besides the inconvenience of time. Participants will not be subject to coercion or undue influence. Again, it is voluntary and your refusal or withdrawal from the study will not affect your class, grade, or job status. For an opportunity to participate in this survey, please email me at ERWheeler@ mail.wvu.edu, call my office at 304.293.7535, or text me at 724.816.9553. Thank you.

Sincerely,

Eveldora Wheeler, Senior Lecturer, LMSW, MBA, ABD

Doctoral Candidate in Educational Psychology

College of Education and Human Services and Department of Learning Sciences and Human Development 


\section{Appendix C}

My name is Eveldora Wheeler and I am collecting data for my dissertation. As the Principal Investigator for this study, I am requesting an opportunity to interview you as a faculty member. Currently, I have a dual status at West Virginia University: (a) Part-time faculty in the School of Social Work and (2) Ed.D. Candidate in Educational Psychology from West Virginia University College of Education and Human Services. The chair of my dissertation committee is Dr. Ugur Kale at West Virginia University College of Education and Human Services and Department of Learning Sciences and Human Development. Dr. Kale may be reached at 304.293.2156 or Ugur.Kale @ mail.wvu.edu and respectfully Professor Emeritus Richard T. Walls at 304.293.3335 or RichardWalls@ mail.wvu.edu. I may be reached at 304.293.7535 or ERWheeler@mail.wvu.edu. This data collection represents the final two chapters (four and five) of my dissertation and are being conducted in fulfillment of the requirements and final completion of the Ed.D. Degree.

Please allow me to introduce my Dissertation topic: What are Faculty Perceptions of Using Emotional Intelligence in Pedagogy and Andragogy? Below is a description of my research. Specifically, the study will measure and explore how faculty use Emotional Intelligence in Face to Face and Online Professional Learning Environments. Additionally, the study will discuss the role of Emotional Intelligence from faculty teaching in face to face and online environments including: (a) comfort levels, (b) perceived differences, and (c) perceived effectiveness between the two mediums. The selection level of participants include faculty/instructors teaching in post-secondary environments.

West Virginia University Institutional Review Board (IRB) approved and reviewed this study on November 29, 2012 for a term of three years. This study is voluntary and refusal or withdrawal from the study will not affect your class, grade, or job status. Participants will not be subject to coercion or undue influence. This study presents no more than minimal risk, besides the inconvenience of time. Participants may choose to: (1) answer all questions, (2) respond only to those that apply, and/or (3) quit the study at any designated time. The privacy interests including interview and accompanying data will be kept anonymous and confidential, as is appropriate to the study. All participates must be 18 years of age or older.

Additional research objectives may present the opportunity to: (a) enrich institutions and instructor's knowledge, awareness, and potential training needs, (2) assess positive and negative outcomes/contributions to academic institutions, and (3) discover plausible values and types of adjustments/transitions necessary when teaching between the two settings. Participants are required to: sign one consent form, forward two electronic syllabi (e.g. online and face to face), complete one survey, and one recorded interview. Participants completing the above will receive a one-time \$5.00 dollar Star Bucks gift card. Please read and review the attached form(s) and contact me if you have questions or concerns. Thank you for agreeing to tell me about your experiences and reflections from your instruction with online and face to face courses. 


\section{Appendix D}

Participants, please sign release form providing me with permission to use your words for the purpose of the study.

\section{Consent/Release Agreement}

I, (participant), hereby give to Eveldora R.

Wheeler (principal investigator) as a donation this interview recorded on (date). With this, I hereby transfer to the Eveldora R. Wheeler (principal investigator) legal title and all literary property rights to the interview, including copyright.

I understand the interview may be made available for research and such publication as Eveldora R. Wheeler, (principal investigator) may determine. This may include use of electronic publishing that is not for profit. The interviews may not be broadcast, cablecast, or electronically published for commercial purposes without my written consent.

ture of Interviewee

Type or Print Name

Address

Date 


\section{Appendix E}

RE: Letter of Participation for Dissertation Study

Dear Dr.

Thank you for taking time from your demanding schedule to participate in my Dissertation study on February 9, 2015. Often the middle of a semester, is not the most conducive time to take on additional responsibilities, yet you did. Besides meeting the criteria of this study your interaction was valued as professional and amicable.

The research topic is: What are Faculty Perceptions of Using Emotional Intelligence in Pedagogy and Andragogy? This study presents no more than minimal risk, besides the inconvenience of time. During the survey and interview, participants could choose to: (1) answer all questions, (2) respond only to those that apply, and/or (3) quit the study at any designated time. This data collection represents the final two chapters (four and five) of my dissertation and are being conducted in fulfillment of the requirements and final completion of the Ed.D. Degree. The chair of my dissertation committee is Dr. Ugur Kale at West Virginia University College of Education and Human Services and Department of Learning Sciences and Human Development. Dr. Kale may be reached at 304.293.2156 or Ugur.Kale@ mail.wvu.edu and respectfully Professor Emeritus Richard T. Walls at 304.293.3335 or RichardWalls@mail.wvu.edu.

This study has been approved by West Virginia University Internal Review Board (IRB). The researcher preliminarily screened each participant via telephone communication and/or email correspondence. The research protocol included:

(1) Researcher identified participants (e.g. faculty) teaching or had taught in Social Sciences and/or STEM courses

(2) Researcher elected participants (e.g. faculty) instructing at post-secondary professional learning environments

(3) Participants were required to submit and/or complete:

a. Consent form

b. Two sample electronic syllabi from both (e.g. (a) face to face and (b) online) courses

c. Online survey

d. Recorded interview

(4) All Participants received a $\$ 5.00$ Starbucks gift card and/or letter of participation Again, Dr___, thank you for sharing your perceptions, experiences, and reflections regarding your cyber and traditional professional learning environments. Additionally, it was a pleasure getting to know you. If you have additional questions, please contact me via email at erwheeler@mail.wvu.edu or telephone 304.293.7535. Have a great semester.

Sincerely, 


\section{Appendix G}

Survey fill - in text Comments for Participants

\section{6. * Regarding the abilities found I am satisfied with student comments and participation in completing course evaluations at the end of the semester...}

\section{Tell us Why?}

Overall, student evaluations are neither satisfactory or unsatisfactory.

Even comments that are not what I want to hear I can learn from them.

It is based on students' subjective opinions.

This is a hard question to answer because I am satisfied with some comments, but not with others. There are fair comments and unfair comments. There are instances where course evaluations are used as a form of retaliation by disgruntled students, and there are instances when the feedback is sincere. Teaching evaluations need to be taken with a grain of salt. If I have 1 out of 50 negative comments, I will obsess over the one negative.

It lets me know what I am doing well, and what I can improve on. Often my students who take the survey offer wonderful and useful feedback. I just wish I could get more of them to participate.

Normally good feedback and close to $100 \%$ participation.

The participation rate of generally very low.

Most are good but I do not know how constructive they are. 


\section{Appendix H}

Survey fill - in text: Write down at least one appraisal of yourself and what you think you might do to increase your abilities here.

I take things too personally. I can separate the private (social) from professional.

I would like to be better at recognizing students' boredom. Perhaps I could take a course in learning to recognize facial expressions and their link to emotions.

Taking more time for self-reflection would help me improve in these areas.

I am very aware of others emotions as it is something I continue to always work on

2. Ability to counsel myself to delaying important decisions if I am in a negative state? This is something I have been working on as I can be impulsive. I have been working on this - when I have a situation such as this I have been making myself wait a day to respond to let my emotions settle.

I am very intuitive.

Continuing to be cognizant when teaching will further increase my perception of students and my emotions.

I am naturally an emotional person. Sometimes I let my emotions get out of check, but I rarely lose control of my behavior because of it. Instead, I usually let things that bother me eat away at me, and this is something I need to improve. I can sometimes take things too personally. For example, I have caught many students cheating over the years. Dishonesty makes me angry, but I usually do not lose control of my emotions while working with the students. I tend to internalize it which I know is not good for me.

I am too emotionally connected to students in face-to-face courses, to the point of it detracting from covering intended material. It would do me well to put some space between myself and my students.

Sometimes make decisions when in negative state of mind, will try and be more observant of my emotional state when important decisions are required

Respectful of where students are in their academic journey. I can increase this ability by maintaining a caring relationship with my students.

I would like to do more training for myself and my students in order to better facilitate the educational processes while understanding and applying emotional facilitation of instruction. I realize how important it is for me to be at my best when doing challenging work and would like to learn how to better counsel my students to remember the importance of their emotional as well as physical health when working through challenging content, processes, and tasks.

I am good at keeping my "cool". To increase my abilities, I can change the pace or topic, or give the class a break.

I need to focus on maintaining a positive attitude when overwhelmed with multiple tasks. Learn to prioritize. 
Delaying making important decisions when in a negative state. I should take evaluation of my emotional state before decisions and try to adjust any negativity before reaching a final decision. Sometimes it's the stress of the decision itself that is creating the negative emotion and, therefore, it might be hard to control.

I am very passionate in my teaching. One way to increase my ability in my passion is to recognize that not all people share my passion and accept that as being okay.

Determining the appropriateness of reaching out to students who might be going through some sort of emotional issue. 


\section{Appendix I}

The Four Basic Domains and Related Skills are:

1. The capacity to accurately perceive emotions:

Perceived emotions are a rudimentary Emotional Intelligence skill which requires one to have awareness of ones' own and the feelings of others' in order to accurately assess and synthesize the world around you.

2. The capacity to use emotions to facilitate thought:

Mayer explains this skill as the ability to "employ your feelings to enhance the cognitive system (thinking) and, as such, can be harnessed for more effective problem-solving." One may view the world in two or more completely different modes, happy or sad. These two events allow you to interpret, express, and experience moods differently.

3. The capacity to understand emotional meaning:

According to Mayer this is a predictive skill which requires one to be capable of foreseeing causes and the impact of situations. In essence, one must ascertain "how people will feel and react under various circumstances. For example: The answers within this skill set should respond to the following question: Why are we dismayed? What if a hostess refuses to take a patron's order at a restaurant, what will happen? How would the individual feel?

4. The capacity to manage emotions (Mayer et al., 1997, p. 108):

Sometimes managing our emotions means that one must juggle several emotions at once. Emotions need supervising, distinguishing, and tagging. Mayer, et al stated that our emotions provide us with useful information, but if useful information is discounted we may end up making poor choices. For example: Mayer, et al suggests remaining open to one's emotional presence, grow in wisdom from them, and use feelings to take proper action. "Anger, along with other emotions, is often misinterpreted, but it can "help us to overcome adversity, bias, and injustice." But if anger is left ignored, it can lead to inappropriate conduct. 
Appendix J

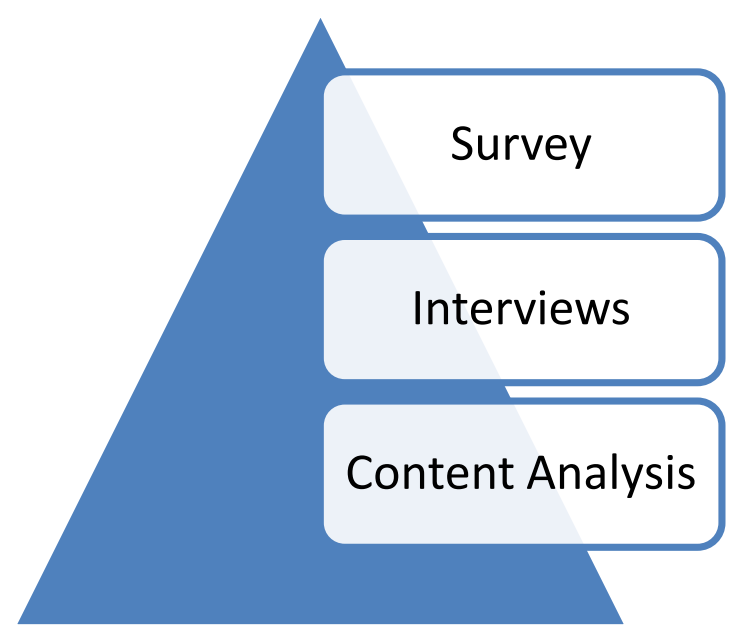

